\title{
Morphological aspects of the loss of phospholipid asymmetry of the cell membrane
}

Citation for published version (APA):

Stuart, M. C. A. (1998). Morphological aspects of the loss of phospholipid asymmetry of the cell membrane. [Doctoral Thesis, Maastricht University]. Universiteit Maastricht. https://doi.org/10.26481/dis.19981030ms

Document status and date:

Published: 01/01/1998

DOI:

10.26481/dis.19981030ms

Document Version:

Publisher's PDF, also known as Version of record

\section{Please check the document version of this publication:}

- A submitted manuscript is the version of the article upon submission and before peer-review. There can be important differences between the submitted version and the official published version of record. People interested in the research are advised to contact the author for the final version of the publication, or visit the DOI to the publisher's website.

- The final author version and the galley proof are versions of the publication after peer review.

- The final published version features the final layout of the paper including the volume, issue and page numbers.

Link to publication

\footnotetext{
General rights rights.

- You may freely distribute the URL identifying the publication in the public portal. please follow below link for the End User Agreement:

www.umlib.nl/taverne-license

Take down policy

If you believe that this document breaches copyright please contact us at:

repository@maastrichtuniversity.nl

providing details and we will investigate your claim.
}

Copyright and moral rights for the publications made accessible in the public portal are retained by the authors and/or other copyright owners and it is a condition of accessing publications that users recognise and abide by the legal requirements associated with these

- Users may download and print one copy of any publication from the public portal for the purpose of private study or research.

- You may not further distribute the material or use it for any profit-making activity or commercial gain

If the publication is distributed under the terms of Article $25 \mathrm{fa}$ of the Dutch Copyright Act, indicated by the "Taverne" license above, 
Morphological aspects of the loss of phospholipid asymmetry of the cell membrane 
1998. M.C.A. Stuart, Marstricht, The Netherlands

ISBN 90-9012093-9

Druk: Dalawyse / Universitaire Pers Maastricht 


\title{
Morphological aspects of the loss of phospholipid asymmetry of the cell membrane
}

\author{
Proefschrift
}

ter verkrijging van de graad van doctor aan de Universiteit Maastricht op gezag van de Rector Magnificus, Prof. dr. A.C. Nieuwenhuijzen Kruseman, volgens het besluit van het College van Decanen in het openbaar te verdedigen op vrijdag 30 oktober 1998 om 12.00 uur door 
Promotores

Prof. dr. J. W. Arends

Prof dr. R. F. A. Zwaal

Co-promotor

Dr. P. M. Frederik

Beoordelingscommissie

Prof. dr. G. J. van der Vusse (voorzitter)

Prof. dr. P. J. C. Van Breda-Vriesman

Prof. dr. A. D. R. Brisson (Rijksuniversiteit Groningen)

Prof. dr. F. C. S. Ramaekers

Prof. dr. A. J. Verkleij (Universiteit Utrecht) 
Aan mijn ouders

Voor Maike, Tijmen, Merijn, ....... 



\section{Contents}

\section{Chapter 1}

General introduction

1.1 Preface

1.2 Cell membrane architecture

$\begin{array}{ll}1.3 \text { Loss of membrane phospholipid asymmetry } & 14\end{array}$

1.4 Morphological aspects of the loss of membrane phospholipid asymmetry $\quad 16$

1.5 Experimental approach

1.6 References

\section{Chapter 2}

Perspective and limitations of cryo-electron microscopy.

\section{Chapter 3}

Binding of annexin $V$ to bilayers with various phospholipid compositions using glass beads in a flow cytometer.

\section{Chapter 4}

Ultrastructural detection of surface exposed phosphatidylserine on activated blood platelets.

\section{Chapter 5}

Surface exposure of phosphatidylserine during apoptosis of rat thymocytes precedes nuclear changes.

\section{Chapter 6}

Sarcolemmal phosphatidylserine asymmetry in cardiomyocytes subjected to simulated ischemia.

\section{Chapter 7}

General discussion

Summary

Samenvatting

Curriculum vitae

List of publications 

Chapter 1

General introduction 


\subsection{Preface}

The studies presented in this thesis describe the cellular morphological changes in association with topological membrane phospholipid reorganisations. In order to understand the background of membrane phospholipid asymmetry and the loss of this phospholipid asymmetry the subject is introduced below. The basic concept of membrane architecture and the mechanisms involved in the generation and regulation of phospholipid distributions across the membrane bilayer are reviewed in relation to the studies presented here.

\subsection{Cell membrane architecture}

The cell membranes of all eukaryotic cells have a common architecture. The inside of the cell is separated from the outside by two apposed monolayers of lipids each of a different composition. These monolayers are joined by hydrophobic interactions to form a bilayer. Proteins are attached to or embedded in the bilayer (fluid mosaic model, as proposed by Singer and Nicolson 1972) and together they form the cell membrane. The membrane serves as a selective barrier between the inside and the outside of the cell. Valuable building blocks and nutrients are admitted to the cell whereas waste products are expelled through the plasma membrane. The lipid part of the membrane is mainly composed of phospholipids and cholesterol. Phospholipids are molecules based on a glycerol phosphate or a ceramide phosphate with a hydrophilic head group and two hydrophobic hydrocarbon tails. When brought in water the phospholipids spontaneously form bilayers, because the hydrophobic tails tend towards each other (hydrophobic interaction), whereas the hydrophilic head groups are exposed to water. There are several different classes of phospholipids based on different head groups. The choline phospholipids phosphatidylcholine (PC) and sphingomyelin both have a choline head group, whereas the aminophospholipids phosphatidylethanolamine (PE) and phosphatidylserine (PS) have a head group containing a free amine. The polar head groups of these phospholipids are charged but neutral, with the exception of PS which carries a net negative charge (Fig 1.1). Apart from these major phospholipid classes there are other lipids (e.g. inositol phospholipids, glycolipids) which are of functional importance but are present in relatively small quantities. The hydrophobic tails of the phospholipids are between 14-24 carbon atoms long and one of the tails usually contains one or more double bounds (= unsaturated lipids). In addition to the phospholipids, cholesterol is an important constituent of the bilayer membrane and can be present in variable amounts up to one molecule for every phospholipid molecule. Cholesterol is oriented in the bilayer membrane with its hydroxyl group close to the polar head of the phospholipids and its steroid ring interacting with the hydrocarbon tails of the phospholipids.

The different phospholipid classes are not randomly distributed over the plasma membrane but are asymmetrically allocated in the two apposed monolayers. This 

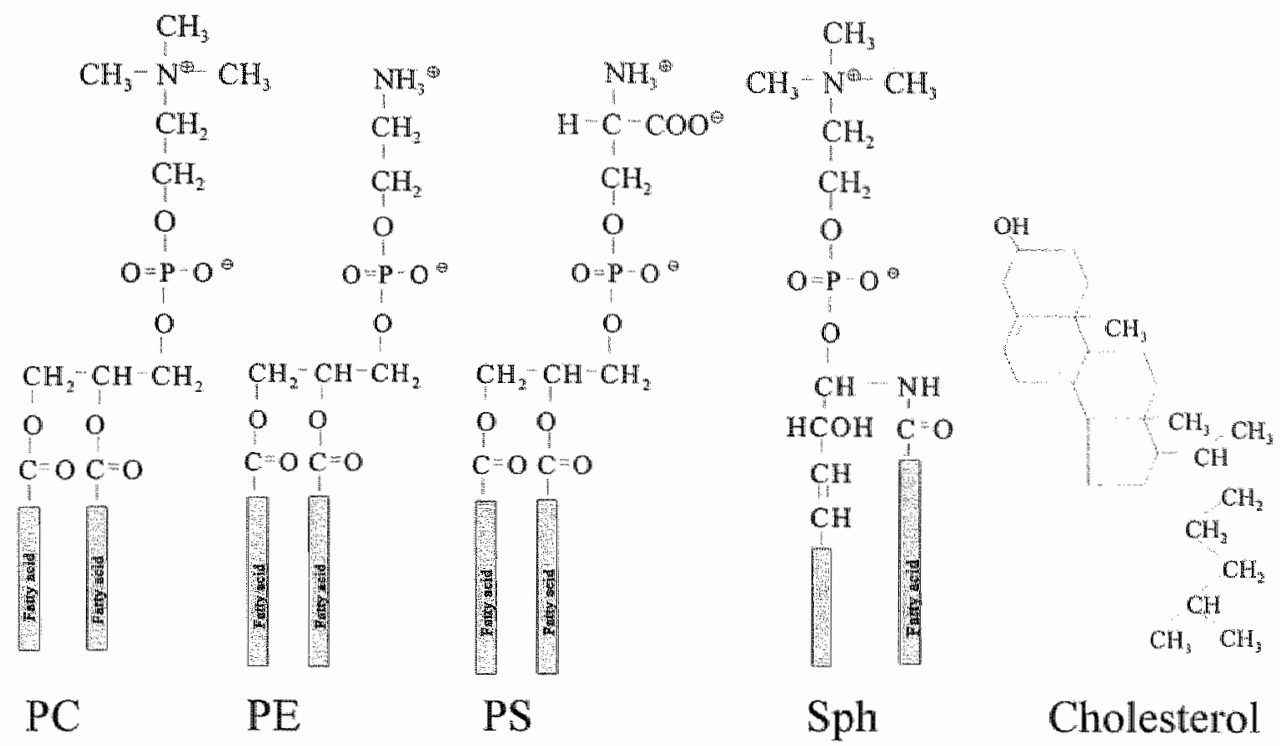

Figure 1.1 The structure of the main phospholipid classes and cholesterol. Phosphatidylcholine (PC), phosphatidylserine (PS) and phosphatidylethanolamine (PE) are based on a glycerol backbone with two fatty acid chains and a phosphate with different head groups esterified to the glycerol. Sphingomyelin. (Sph) is based on ceramide phosphate.

asymmetry was first suggested to exist in erythrocytes by Bretscher (1972), and confirmed and extended by others (Verkleij et al. 1973, Gordesky and Marinetti 1973, Gordesky et al. 1975). The choline phospholipids are predominantly located in the outer membrane leaflet, whereas phosphatidylethanolamine is essentially and phosphatidylserine exclusively located in the leaflet facing the cytosol (Op den Kamp 1979). A wide variety of cell types, from various species, has been investigated since, using several techniques. The traditional techniques used are chemical labelling of phospholipids in the outer membrane leaflet with non penetrating agents (Gordesky el al. 1975) and selective degradation of phospholipids present in the outer- or inner mono layer with exogenous phospholipases (Verkleij et al. 1973, Zwaal et al. 1975). Other techniques measuring accessibility of phospholipids for phospholipid transfer proteins (van Meer et al. 1980), or detecting the membrane lipid distribution of spinlabelled (Seigneuret and Devaux 1984) or fluorescently labelled lipid probes (Connor and Schroit 1987), have yielded virtually identical results. It is now fairly well established that plasma membranes of all eukaryotic cells exhibit this asymmetrical distribution of the major phospholipid classes (table 1.1), (for a review see Devaux 1992, Zachowski 1993).

The possibility that phospholipids move between the two bilayer halves has been investigated even before the asymmetric distribution of the lipids in the cell membrane was discovered. Using spin-labelled PC, Komberg and McConnell (1971) 
demonstrated that in artificial vesicles the exchange of phospholipids from one monolayer to the other (transverse diffusion or flip-flop) is a very slow process with a typical half time of several hours, which is in contrast to the very rapid phospholipid movement in the plane of the membrane (lateral diffusion)(Devaux and McConell 1972). The synthesis of the various phospholipid species and their transport to the plasma membrane leads to an asymmetrical distribution over the plasma membrane (for a review see Hjelmstad and Bell 1991). Together with the slow flip-flop, this asymmetric synthesis could only partly explain the distinct difference in phospholipid composition of the two monolayers as found for many cell types.

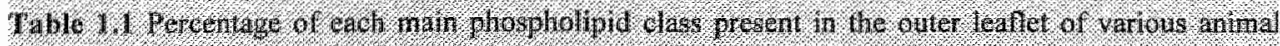

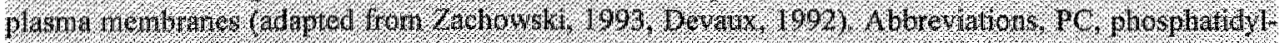

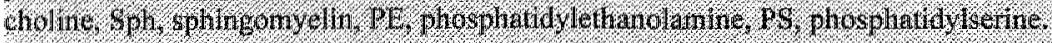

\begin{tabular}{|c|c|c|c|c|c|}
\hline Cell type & $\mathrm{PC}$ & Sph & $\mathrm{PE}$ & PS & Reference \\
\hline erythrocyte (human) & 77 & 80 & 20 & $<4$ & $\begin{array}{l}\text { Butikofer et al. } 1990 \text {, Gascard et al. } \\
1991 \text {, Gordesky et al. 1972, } 1975 \text {, van } \\
\text { Meer et al. 1981, Verkleij et all. } 1973\end{array}$ \\
\hline erythrocyte (mouse) & 50 & 85 & 20 & 0 & Rawyler et al. 1.985 \\
\hline \multirow[t]{2}{*}{ erythrocyte (rat) } & 62 & 100 & 20 & 6 & Renooij et al. 1976 \\
\hline & 63 & 100 & 0 & & Crain and Zilwersmit, 1980 \\
\hline erythrocyte (monkey) & 67 & 82 & 13 & 0 & van der Schaft et all. 1987 \\
\hline platelet (human) & 45 & 93 & 20 & 9 & Perret et al. 1979 \\
\hline platelet (pig) & 40 & 91 & 34 & 6 & Chap et al. 1977 \\
\hline cardiac sarcolemma (rat) & 43 & 93 & 25 & 0 & Post et al. 1988 \\
\hline erythroleukaemic cell (mouse) & 45 & 80 & 50 & 15 & Rawyler et al. 1985 \\
\hline LM cell & 48 & & 24 & & \\
\hline synaptosonne (mouse) & & & $10-15$ & 20 & Fontaine et al. 1980 \\
\hline intestinal brush border (rabbit) & 32 & 63 & 34 & 44 & Lipka et al. 1991 \\
\hline \multicolumn{6}{|l|}{ intestinal brush border (trout) } \\
\hline middle & & & 46 & 32 & Pelletier et al. 1987 \\
\hline posterior & & & 36 & 31 & \\
\hline kidney brush border (rabbit) & 35 & 80 & 23 & 15 & Venien and Grimellec, 1988 \\
\hline $\begin{array}{l}\text { hepatocyte (rat) bile canalicular } \\
\text { surface }\end{array}$ & 85 & 65 & 50 & 0 & Higgins and Evans, 1978 \\
\hline hepatocyte (rat) contiguous surface & 80 & & 0 & 20 & Higgins and Evans, 1978 \\
\hline hepatocyte (rat) sinusoidal surface & 85 & 65 & 55 & 0 & Higgins and Evans, 1978 \\
\hline fibroblast (chick embryo) & & & 35 & 20 & Session and Horwitz, 1983 \\
\hline myoblast (chick embryo) & & & 65 & 45 & Session and Horwitz, 1983 \\
\hline myoblast (Quail embryo) & & & 73 & 44 & Session and Horwitz, 1983 \\
\hline
\end{tabular}

A mechanism which translocates amino phospholipids (by active transport) from the outer to the inner membrane leaflet seems to be a plausible explanation for the generation of asymmetric membranes. This so called aminophospholipid translocase was first identified in erythrocytes by Seigneuret and Devaux (1984) and found to be 
present in many other cell types. To establish the presence of this translocase in several cell systems various PS analogues were used (see table 1.2 for an overview). This translocase was described as a Mg-ATP dependent protein of $110 \mathrm{kDa}$ that accumulates amino-phospholipids on the cytosolic side of the membrane (Morrot et al. 1990, Zimmerman and Daleke 1993). The transport rate of translocase is higher for PS than for $\mathrm{PE}$, whereas there is hardly any affinity for $\mathrm{PC}$ and sphingomyelin (Zachowski et al. 1986). Translocation activity could only be observed in the presence of hydrolysable Mg-ATP indicating that translocation requires energy. Translocase activity can be blocked by high cytosolic $\mathrm{Ca}^{2+}$ levels, vanadate and $\mathrm{N}$-ethyl-maleimide (Seigneuret and Devaux, 1984, Zachowski et al. 1986), indicative for the protein nature of the translocase. Active translocation of phospholipids, from the inner to the outer monolayer, has been demonstrated, but occurs at much slower rates (Bitbol and Devaux 1988, Tilly et al. 1990, Connor et al. 1992). An imbalance between the inside and outside may result from non equal rates of transport. Cholesterol has a fast lateral diffusion over the two monolayers like other small uncharged hydrophobic molecules. The cholesterol distribution over the membrane is therefore difficult to measure. The near absence of PS and PE in the outer membrane leaflet is maintained during normal cell function, including membrane fusion processes such as involved in vesicular transport (endocytosis, exocytosis). Nevertheless the plasma membrane of cells is a highly dynamic bilayer subjected to numerous processes and a constant turn over of lipids (and proteins).

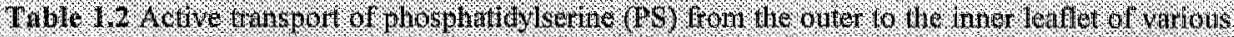

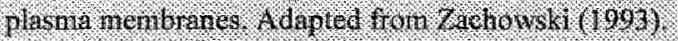

\begin{tabular}{|c|c|c|c|}
\hline Cell & PS analogue & $t_{1 / 2}$ & Reference \\
\hline \multirow[t]{4}{*}{$\begin{array}{l}\text { erythrocyte } \\
\text { (human) }\end{array}$} & spin-label & $<5 \mathrm{~min}$ & $\begin{array}{l}\text { Bitbol \& Devaux, 1988, Calvez et al. } \\
\text { 1988, Morrot et al. } 1989\end{array}$ \\
\hline & long-chain, diacyl & $8-10$ min & Daleke \& Huestis, 1985 , Tilley et al. 1986 \\
\hline & fluorescent (NBD) & $10-30 \mathrm{~min}$ & $\begin{array}{l}\text { Colleau et al. } 1991, \text { Connor \& Schroit, } \\
1987,1989\end{array}$ \\
\hline & lyso-derivates & $3 \mathrm{~h}$ & Bergmann et al. 1984 \\
\hline K 562 erythroblast & spin-label & $<\min$ & Cribbier et al. 1993 \\
\hline $\begin{array}{l}\text { erythroleuknemic } \\
\text { cells. }\end{array}$ & long-chain, diacyl & $<15$ min & Middelkoop et al. 1989 \\
\hline \multirow[t]{3}{*}{ platelets } & endogenous PS & $3-5 \mathrm{~min}$ & Comfurius et al. 1990 \\
\hline & spin-label & $7 \mathrm{~min}$ & Sune et al. 1987 \\
\hline & fluorescent (NBD) & $4-8 \mathrm{~min}$ & Tilly et al. 1990 \\
\hline lymphocytes & spin-label & $7 \min$ & Sune et al. 1988, Zachowski et al. 1987 \\
\hline macrophage & spin-label & $<3 \min$ & \\
\hline spermatozoa & spin-label & $10 \min$ & \\
\hline nerve endings & spin-label & $30-40 \mathrm{~min}$ & Zachowski \& Gaudry Talarmin, 1990 \\
\hline $\begin{array}{l}\text { fibroblast } \\
\text { (hamster) }\end{array}$ & fluorescent (NBD) & $5-15 \min$ & $\begin{array}{l}\text { El-Hage Chahine et al. 1993, Martin \& } \\
\text { Pagano } 1987\end{array}$ \\
\hline
\end{tabular}




\subsection{Loss of membrane phospholipid asymmetry}

The asymmetric distribution of the phospholipids over the plasma membrane can be partially or completely abolished when cells are stimulated. This stimulation leads to a state in which phosphatidylserine and phosphatidylethanolamine are exposed at the outer membrane leaflet. Such an exposure may give rise to cell recognition (e. g. by scavenger cells, of neighbouring cells), and the area with exposed PS/PE may provide a catalytic surface for certain enzymatic reactions. The development of a catalytic surface is reflected by the generation of procoagulant activity during activation of blood platelets. The rapid collapse of phospholipid asymmetry in the platelet cell membrane has been reviewed by Schroit and Zwaal (1991). Since lipid bilayer membranes that expose anionic phospholipids are procoagulant, interaction of various coagulation factors with the activated platelet surface leads to a dramatic enhancement in thrombin formation. Other examples of loss of membrane asymmetry are:

- aging of erythrocytes (Diaz and Schroit 1996)

- stimulation of erythrocytes (Comfurius et al. 1990)

- sickle cell anaemia (Frank et al. 1985, Tait and Gibson 1994)

- cells executing the apoptotic program (Fadok et al. 1992a,b; Martin et al. 1995)

- cardiomyocytes which lose their membrane asymmetry upon ischemic or

metabolic stress (Musters et al. 1993, Post et al. 1993)

- sperm cells which lose their membrane asymmetry to favour fusion (Nolan et al. 1995).

In the apoptotic process PS exposition leads to recognition and removal of the apoptotic cell by macrophages. Figure 1.2 depicts the PS-dependent reactions which take place at both sides of the membrane surface.

Over the years several hypotheses about the mechanism of PS translocation from the inner to the outer membrane leaflet have been postulated. As first demonstrated for erythrocytes, simple inhibition of amino-phospholipid translocase does not cause collapse of phospholipid asymmetry (Comfurius et al. 1990). Initially the binding of aminophospholipids to the cytoskeleton was proposed as a mechanism to preserve the asymmetric distribution of phospholipids because of the interaction between phosphatidylserine and the cytoskeletal proteins spectrin and band 4.1. Furthermore, cytoskeleton degradation by calpain frequently accompanies loss of membrane asymmetry (Verhallen et al. 1987, Fox et al. 1991, Squier et al. 1994). However, an important role for a compromised interaction between PS and cytoskeletall proteins in the loss of membrane lipid asymmetry was rejected, because asymmetry is maintained in cytoskeleton free vesicles derived from cells (Calvez et al. 1988, Kuypers et al. 1993, for a review see Schroit and Zwaal 1991).

Loss of membrane phospholipid asymmetry seems to be mediated by high cytosolic calcium levels (Bevers et al. 1990, Williamson et al. 1992) and is usually accompanied by membrane blebbing and shedding of vesicles (Sims et al. 1989). Redistribution of phospholipids during this process ("scrambling") is irrespective of the different phospholipid classes as was demonstrated using various fluorescent lipid analogues (Williamson et al. 1995, Smeets et al. 1994, Verhoven et al. 1995). The mechanism by 
which the asymmetric distribution is lost is not fully understood and several possibilities have been proposed. In addition to high intra-cellular calcium and membrane blebbing, the loss of lipid asymmetry is usually accompanied by increased calpain activity (Fox et al. 1991) and the formation of phosphatidylinositol 4,5bisphosphate (PIP2)-callcium complexes (Sulpice et al. 1994). However, neither cytoskeleton degradation (Basse et al. 1993), nor aminophospholipid translocase inhibition (Bevers et al.1989, Bitbol et al. 1987) or formation of Ca-PIP2 complexes (Bevers et al.1995) can account for the randomization of membrane phospholipids observed during different cellular activations. Therefore, other mechanisms must be involved in the loss of membrane phospholipid asymmetry.

\section{Extracellular side}

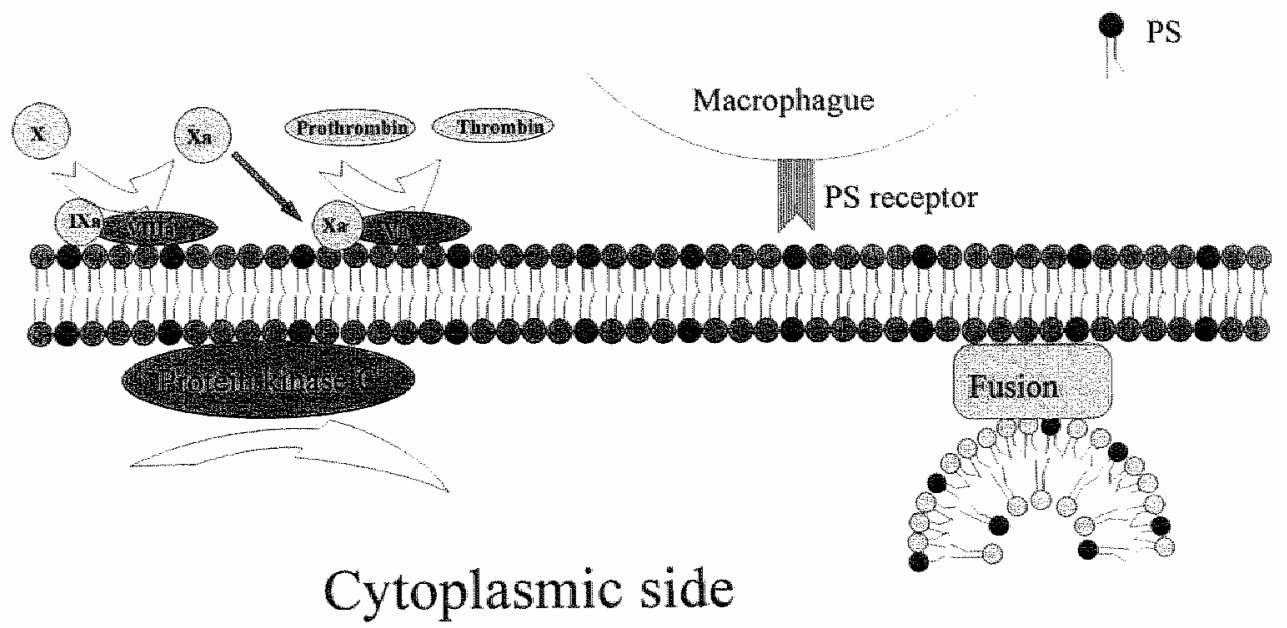

Figure 1.2 schematic representation of some aminophospholipid-dependent reactions occuring at the extracellular and cytoplasmic surface of the plasna membrane (redrawn after Zachowski, 1993).

Strong evidence was produced by several groups that a membrane protein might be responsible for phospholipid scrambling (and membrane blebbing) upon an increase of intra-cellular calcium concentration (Zwaal et al. 1993, for a review see Diaz and Schroit 1996), in which membrane blebbing is likely the consequence of phospholipid scrambling. There are, however, a few reports of phospholipid scrambling without (or reduced) membrane vesicle formation (Dachary-Prigent et al. 1995, Williamson et al. 1992, Pasquet et al. 1996) under specific conditions. Reconstitution experiments with partially purified membrane protein fractions suggest that indeed a specific protein or proteins are responsible for the phospholipid reorganisation (Comfurius et al. 1996). Recently, Bassé et al. (1996) purified a $37 \mathrm{kDa}$ membrane protein from erythrocytes, which upon reconstitution into phospholipid vesicles, is capable of scrambling phospholipids in the presence of calcium as monitored with NBD labelled 
phospholipids.

The protein was inactivated by trypsin and showed half maximal activity at $20-60 \mu \mathrm{M}$ calcium. Based on a partial amino-acid sequence, cDNA encoding for this protein was cloned (Zhou et al. 1997). The scramblase is a proline rich membrane protein with a single transmembrane segment. Northern blotting with scramblase cDNA revealed transcripts in various cell types suggesting that this protein functions in all cells. Scrambling of phospholipids does not lead to irreversible damage in the form of a leaky bilayer membrane. During various types of cell activation leading to loss of membrane asymmetry neither release of intra-cellular enzymes (such as LDH) nor the uptake of wital dyes (e.g. propidium iodide) could be detected. This indicates furthermore that the loss of membrane asymmetry is under careful control and not the result of an uncontrolled breakdown of the plasma membrane.

\subsection{Morphological aspects of the loss of membrane phospholipid asymmetry}

As summarized in paragraph 1.2 , much biochemical work has been done in relation to the asymmetric distribution of phospholipids over the two bilayer halves of the plasma membrane and the loss of this lipid asymmetry. However, little is known about the ultra-structural changes related to disturbances in membrane phospholipid asymmetry. It was also not clear at the beginning of our study where loss of lipid asymmetry is localised, i.e. is it an overall loss or is it restricted to certain areas? In our studies we have tried to supplement biochemical data with relevant morphological information. With this approach a more precise and therefore a better understanding of the loss of membrane phospholipid asymmetry can be achieved on a (sub)cellular level. Cell stimulation followed by a massive (lipid) reorganisation of the membrane is likely to have implications for the (ultra)structure. A bilayer membrane is presently conceived as a dynamic steady state of an active amino-phospholipid influx and a slow transfer diffusion of choline-lipids over the bilayer. In this steady state the amount of phospholipids in each mono-layer must be in a balance. When this balance is disturbed the membrane can accommodate slight differences by bending. For example in small vesicles with high curvature the difference between the amount of phospholipid in each separate monolayer becomes significant. A vesicle with a diameter of $500 \mathrm{~nm}$ has a $1 \%$ difference between inner and outer surface, whereas in a sonicated vesicle of $30 \mathrm{~nm}$ the outer monolayer contains nearly twice as much lipid molecules as the inner

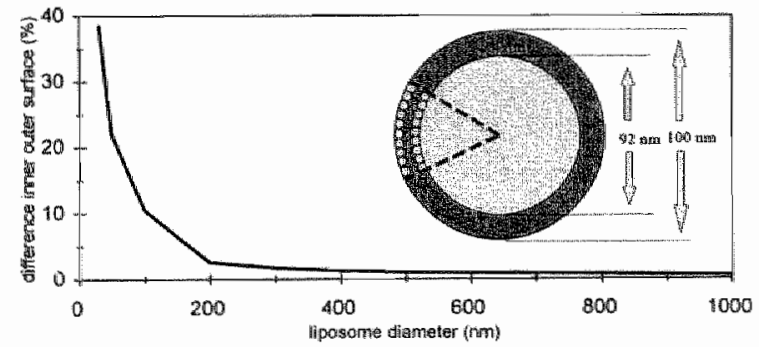

Figure.. 1.3 Difference between phospholipid surface from the inner and outer layer of the bilayer membrane as a function of the vesicle diameter. 
monolayer (see fig 1.3). With small unillamellar vesicles $(20-100 \mathrm{~nm}$ ) of dipalmitoylphosphatidyl-choline a size dependent shift in transition temperature $\left(T_{\mathrm{n}}\right)$ was demonstrated. This indicates that strongly curved bilayers of phospholipids behave different from none or hardly curved bilayers (Lichtenberg et al. 1981). It has been demonstrated in very large unilamellar vesicles that a $1 \%$ difference in the amount of phospholipids between the two monolayers already leads to blebbing of the membrane in order to compensate this imbalance (Farge and Devaux 1992).

When medium chain choline phospholipids (e. g. DMPC, Daleke and Huestis 1985) are added to erythrocytes, they spontaneously incorporate into the outer membrane leaflet. This area surplus is compensated by bulging of the membrane (echinocyte). When the added lipid is an aminophospholipid it will be transported to the inner leaflet resulting in a surplus of lipid at the inside of the membrane which will be accommodated by invaginations (stomatocyte) (Daleke and Huestis 1985, Seigneuret and Devaux 1984). Thus, not only the cytoskeleton determines the shape of a cell, but the distribution and surface ratio of phospholipids over the two membrane halves is a (local) shape determining factor as well.

In this thesis we investigated three different models of cell stimulation, in order to correlate morphological changes (e.g. blebbing) to the loss of membrane phospholipid asymmetry.

These models are: - the activation of blood platelets (chapter 4)

- induction of apoptosis in thymocytes (chapter 5)

- simulated ischemia of neonatal cardiomyocytes (chapter 6 ).

For all three models loss of membrane phospholipid asymmetry has been described (Schroit and Zwaal 1991, Fadok et al 1992 a,b, Post et al. 1993), accompanied by an increase in intracellular calcium levels and a relatively low energy state of the cell. In all model systems studied, the cell membranes were (largely) intact (non leaky for intracellullar enzymes and or vital dyes) under the experimental conditions. The aim of these studies was to investigate early (ultra)structural membrane alterations and to localize (with an immunocytochemical and structural approach) where and when the loss of membrane phospholipid asymmetry takes place. The hypothesis is that blebbing of the cell membrane is a local and early event in the loss of membrane phospholipid asymmetry. A similar association between blebbing and the loss of the membrane asymmetry is expected in the biological models investigated: platelet activation, apoptosis of thymocytes and ischemia of neonatal cardiomyocytes.

\subsection{Experimental approach}

For the fixation and detection of ultrastructural changes in the plasma membrane upon cell stimulation and the subsequent localisation of PS exposition on the membrane, the use of cryo-techniques is essential. Small ultrastructural changes, especially membrane blebs, are very difficult to preserve with classical electron microscopical techniques, which dissolve rather than conserve these structures. Furthermore, these classic techniques preclude the subsequent localisation of PS on the plasma membrane. We 
therefore used cryo-electron microscopy (Frederik et al. 1989) (chapter 2) and freezesubstitution techniques (Humbel et al. 1991)(chapter 4-6) to overcome these problems. The ultrastructural localisation of lipids in the cell is still an unexplored field, whereas the ultrastructural localisations of proteins made a great progress with the development of antibodies and suitable cryo-techniques (Tokayasu 1973, Slot and Geuze 1981, Geuze et al. 1981). Several different approaches have been used to detect lipids at an uitrastructural level (see table 1.3 for an overview). Radio-labelled phospholipids, cholesterol and steroids have been used for autoradiographic localisation at an ultrastructural level (for a review see Stein and Stein 1971). Localisation studies using autoradiography at the ultrastructural level are, however, not always as reliable as one would hope for because fixation of lipids can be a problem. This, combined with a rather limited spatial resolution $(150-200 \mathrm{~nm})$ of the autoradiographic process, makes it inappropriate for the detection of asymmetry loss. Gold-conjugated phospholipases have been used to localize phospholipids at an ultra-structural level (introduced by Coulombe et al. 1988) but this technique did not receive much attention. "Antiphospholipid antibodies" have also been used to localize phospholipids although the real nature of these antibodies remains unclear. The anti-phospholipid antibodies probably bind via a protein cofactor (Galli, 1993). Phospholipid-binding proteins can serve as suitable probes for the detection of phospholipids on the outer mono-layer of the cell membrane. They can either be used directly labelled or secondary labelled with a specific antibody. In chapter two we directly labelled the procoagulant surface of stimulated blood platelets with coagulation factor Va coupled to gold particles followed by cryo-electron microscopy. Factor $\mathrm{Va}$ has a high specificity for phospholipid membranes exposing phosphatidylserine (for a review see Mann et al. 1988). For the localisation of membrane areas with disturbed phospholipid asymmetry we mainly used annexin V. Annexin $\mathrm{V}$ is a calcium dependent phospholipid binding protein with a very high affinity for PS (Andree et al. 1990 ,Meers and Mealy, 1993, 1994). Annexin $V$ belongs to the family of annexins which share the structural homology of a conserved core with a 4-fold internal repeat of 65-70 amino acids and a variable N-terminal domain (Geisow et al. 1986, Geisow, 1986). Besides the very strong affinity for $\mathrm{PS}$, the availability and stability of annexin $\mathrm{V}$ were important for these studies. For the interpretation of data obtained with the use of annexin $V$ under physiological conditions and at low PS concentration, it was considered essential to have more information on the binding characteristics of annexin $\mathrm{V}$ under these conditions. Therefore, we developed a system of model membranes of various lipid composition adsorbed to glass beads. Binding of annexin $V$ to these model membranes could be investigated as described in chapter three using fluorescent annexin $V$ and a flow cytometer. Annexin $V$ was used as a sensitive probe for the detection of phosphatidylserine exposure on the outside of stimulated cells, as described in chapters four to six. Cells were stimulated and, in the presence of annexin $V$ and calcium, vitrified by jetting the cell suspension into liquid ethane. After freeze-substitution and embedding, ultra-thin sections were obtained. Annexin V localized on the surface of these sections was allowed to react with a specific antibody which was subsequently visualized by a protein A coated gold particle. The activation of blood platelets followed by the localisation of PS exposure is described in chapter four. In chapter five 
the loss of membrane asymmetry was described during the apoptotic process and in chapter six the loss of membrane asymmetry after simulated ischemia of neonatal cardiomyocytes is reported. In all the cellular systems investigated, we have attempted to trace back the earliest events in PS exposition and thus in the loss of lipid asymmetry of the cell membranes. The shedding of (micro) vesicles with PS exposed on the outer bilayer leaflet appeared to be the earliest event that could be detected on the ultrastructural level. The implications of this observation will be discussed in the final chapter (chapter 7).

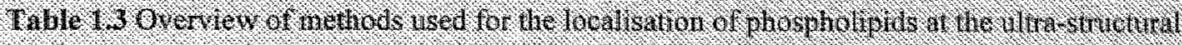
level.

\begin{tabular}{|c|c|c|}
\hline technique & use & Reference \\
\hline autoradiograplthy & various lipids & Stein and Stein 1971 \\
\hline autoradiography & phospholipid metabolism & Gould \& Armstrong 1989 \\
\hline autoradiography & $\begin{array}{l}\text { saturated phospholipids in } \\
\text { cells. }\end{array}$ & Poste et al. 1978 \\
\hline autoradiographliny & $\begin{array}{l}\text { alveolar type II pneumocyte } \\
\text { lamellar bodies }\end{array}$ & Collet 1979 \\
\hline autoradiograpliny & lung surfactant & Winter et al. 1991 \\
\hline fillipin & cholesterol & Severs 1982, D̈orge, 1985 \\
\hline fillipin and tomatine & sterols, cholesterol & $\begin{array}{l}\text { Skepper, } 1989, \text { Severs \& } \\
\text { Simons } 1986\end{array}$ \\
\hline gold-labelled phospholipase & phospholipidosis & Coulombe \& Bendayan 1989 \\
\hline gold-labelled phospholipase & lung surfactant & Coulombe et al. 1988 \\
\hline gold-labelled phospholipase & $\begin{array}{l}\text { Intranuclear localization of } \\
\text { phospholipids }\end{array}$ & Maraldi et all. 1992 \\
\hline gold-labelled phospholipase & $\begin{array}{l}\text { interphase chromatin in rat } \\
\text { hepatocytes. }\end{array}$ & Fraschini et all. 1992 \\
\hline gold-labelled phospholipase & $\begin{array}{l}\text { localization of nuclear } \\
\text { phospholipids }\end{array}$ & Maraldi et al. 1992 \\
\hline ferritin RCA 60 & glycosphingolipid asialo-GMII & Titlack et al 1982 \\
\hline PS antibody & $\begin{array}{l}\text { lipid antigen coated on } \\
\text { polystyrene }\end{array}$ & Compere et al. 1995 \\
\hline gold-labelled Va & PS on blood platelets & Stuart et al. 1992 \\
\hline annexin V & PS on blood platelets & Stuart ef al. 1995 \\
\hline $\operatorname{annexin} V$ & PS on thymocytes & Stuart et all. 1998 \\
\hline
\end{tabular}

\subsection{References}

Andree HA, Reutelingsperger CP, Hauptmann R. Hemker HC, Hermens WT, Willems GM. (1990). Binding of vascular anticoagulant alpha (VAC alpha) to planar phospholipid bilayers. J. Biol. Chem. $265,4923-4928$.

Bassé F, Gaffet P, Rendu F, Bienvenüe A. (1993). Translocation of spin-labelled phospholipids through plasma membrane during thrombin- and ionophore A23187-induced platelet activation. 
Brochemistry, $32,2337-2344$.

Basse E, Stout JG, Sims 10 , Wiedmer T. (1996). Isolation of an erythrocyte membrane protein that mediates Ca2+dependent transbilayer novement of phospholipid. J. Biol. Chem. 271, 17205-17210.

Bergmanin WL, Dressler $V$, Haest CW, Deuticke B. (1984). Reorientation rates and asymmetry of distribution of lysophospholipids between the inner and outer leaflet of the erythrocyte membrane. Biochim. Bioplys. Acta, 772, 328-336.

Bevers EM, Tilly RH, Senden JM, Comfurius P, Zwaal RF. (1989). Exposure of endogenous phosphutidylserine at the outer surface of stimulated platelets is reversed by restoration of aminophospholipid translocase activity. Biochemistry, 28, 2382-2387.

Bevers EM, Verhallen PF, Visser AJ, Comfurius P, Zwaal RF. (1990). Bidirectional transbilayer lipid movernent in human platelets as visualized by the fluorescent membrane probe 1-[4-(trimethylammonio)pheny1]-6-phenyl-1,3,5-hexatriene. Biochemistry, 29,5132-5137.

Bevers EM, Wiedmer $T$, Comfunus $P$, Zhao J, Sneets EF, Schlegel RA, Schroit AJ, Weiss HJ, Williams on $P, Z$ waal RF. (1995). The conmplex of phosphatidylinositol 4,5-bisphosphate and calcium ions is not respongible for $\mathrm{Ca}(2+)$-induced loss of phospholipid asymmetry in the human erythrocyte: a study in Scott syndrome, a disorder of calcium-induced phospholipid serambling. Blood, 86, $1983-1991$.

Bitbol M, Devaux PF. (1988). Measurement of outward translocation of phospholipids across human erythrocyte membrane. P. Natl. Acad. Sci. USA, 85, 6783-6787.

Bitbol M, Fellmann P, Zachowski A, Devaux PF, (1987). Ion regulation of phosphatidylserine and phosphatidylethanolamine outside-inside translocation in human erythrocytes. Biochim. Biophys. Acta, 904, $268-282$.

Bretscher MS. (1972). Asymmetricall lipid bilayer structure for biological membranes. Nature-New Biol. 236, 11-12.

Butikoler P, Lin ZW, Chin DT, Lubin B, Kuypers FA. (1990). Transbilayer distribution and mobility of phosphnatidylinositol in human red blood cells. J. Biol. Chem. 265, 16035-16038.

Calvez JY, Zachowski A, Hermann A, Morrot G, Devaux PF. (1988). Asymmetric distribution of phospholipids in spectrin-poor erythrocyte vesicles. Biochemistry, 27, 5666-5670.

Chap HJ, Zwaal RF, Van Deenen LL. (1977). Action of highly purified phospholipases on blood platelets. Evidence for an asymmetrical distribution of phospholipids in the surface membrane. Biocluin. Biopliys. Acta., 323, 178-193.

Colleau M, Herve P, Fellmann P, Devanx PF. (1991). Transmembrane diffusion of fluorescent phospholipids in human erythrocytes. Chem. Phys Lipids, 57, 29-37.

Collet A. (1979). Preservation of alweolar type II pneumocyte lamellar bodies for electron microscopic studies. J. Histochem. Cytochem. 27, 989-996.

Comfurius P, Senden JM, Tilly RH, Schroit AJ, Bevers EM, Zwaal RF. (1990). Loss of membrane phospholipid asymmetry in platelets and red cells may be associated with calcium-induced shedding of plasma membrane and inhibition of aminophospholipid translocase. Biochim. Biophys. Acta. 1026, $153-160$.

Comfurius P, Williamson P, Smeets EF, Schlegel RA, Bevers EM, Zwaal RF. (1996). Reconstitution of phospholipid scramblase activity from human blood platelets. Biochemistry 35, 7631-7634.

Conpère $\mathrm{P}$, Maneta-Peyret $\mathrm{L}$, Goffinet $\mathrm{G}$, Cassagne $\mathrm{C}$. (1995). Immunogold labelling of fatty acyl chains. J Immunol. Methods, 181, 201-209.

Connor d, Schroit AJ. (1987). Determination of lipid asymmetry in human red cells by resonance energy transfer. Biochemistry, 26,5099-5105. 
Connor J, Schroit AJ. (1989). Transbilayer movement of phosphatidylserine in nomhuman erythrocyles: evidence that the aminophospholipid transporter is a ubiquitous membrane protein. Biochemistry, 28 , $9680-9685$.

Connor J, Pak CH, Zwaal RF, Schroit AJ. (1992). Bidirectional transbilayer moventent of phospholipid analogs in human red blood cells. Evidence for an ATP-dependent and protein-mediated process. I Biol. Chem. 267, 19412-19417.

Coulombe PA, Kan FW, Bendayan M. (1988). Introduction of a high-resolution cytochemieal method for studying the distribution of phospholipids in biological tissues. Eur. J. Cell Biol. 46, 564-576.

Coulombe PA, Bendayan M. (1989). Cytochemical demonstration of increased phospholipid content in cell membranes in chlorphentermine-induced phospholipidosis. J. Histochem. Cytochem. 37, 139-147.

Crain RC, Zilversmit DB. (1980). Two nonspecific phospholipid exchange proteins trom beef liver. 2. Use in studying the asymmetry and transbilayer movement of phosphatidylcholine, phosphatidylethanolamine, and sphingomyelin in intact rat erythrocytes. Biochemistry, 19, 1440-1447.

Cribier S, Morrot G, Neumann JM, Devaux PF. (1990).Lateral diffusion of erythrocyte phospholipids in model membranes comparison between inner and outer leaflet components. Eur. Biophys. J. 18, $33-41$.

Dachary-Prigent $J$, Pasquet JM, Freyssinet JM, Nurden AT. (1995). Calcium involvement in aminophospholipid exposure and microparticle formation during platelet activation: a study using Ca2+-ATPase inhibitors. Biochemistry, 34, 11625-11634.

Daleke DL, Huestis WH. (1985). Incorporation and translocation of aminophospholipids in human erythrocytes. Biochemistry, 24, 5406-5416.

Devaux PF. (1992). Protein involvement in transmembrane lipid asymmetry. Annu. Rev. Bioph. Biom. $21,417-439$.

Devaux P, McConnell HM. (1972). Lateral diffusion in spin-labelled phosphatidylcholine multilayers. J Am. Chem. Soc. 94, 4475-4481.

Devaux PF, Zachowski A. (1994). Maintenance and consequences of membrane phospholipid asymmetry. Chem. Phys. Lipids, 73, 107-120.

Diaz C, Schroit AJ. (1996). Role of translocases in the generation of phosphatidylserine asymmetry. J. Membrane Biol. 151, 1-9.

Fadok VA, Voelker DR, Campbell PA, Cohen JJ, Braton DL, Henson PM. (1992a). Exposure of phosphatidyl-serine on the surface of apoptotic lymphocytes triggers specific recognition and removal by macrophages. J. Immunol. 148, 2207-2216.

Fadok VA, Savill JS, Haslett C, Bratton DL, Doherty DE, Campbell PA, Henson PM. (1992b). Different populations of macrophages use either the witronectin receptor of the phosphatidy/serine receptor to recognize and remove apoptotic cells. J. Imnunol. 149, 4029-4035.

Farge $\mathrm{E}_{*}$ Devaux PF. (1992). Shape changes of giant liposomes induced by an asymmetric transmembrane distribution of phospholipids. Biophys. J. 61, 347-357.

Fontaine RN, Harris RA, Schroeder F. (1980). Aminophospholipid asymmetry in murine synaptosomal plasma membrane. J. Neurochem. 34, $269-277$.

Forge A. (1985). Cholesterol distribution in cells of the stria vascular is of the mammalian cochlea and some effects of ototoxic diuretics. J. Cell Sci. 79, 181-197.

Fox IE, Austen CD, Reynolds CC, Steffen PK. (1991). Evidence that agonist-induced activation of calpain causes the shedding of procoagulant-containing microvesicles from the membrane of aggregating platelets. J. Biol. Chem. 266, 13289-13295. 
Franck PF, Devers EM, Lubin BH, Comfurius P, Chiu DT, Op den Kamp JA, Zwaal RF, van Deenen LL, Roelofsen B. (1985). Uncouphing of the membrane skeleton from the lipid bilayer. The cause of accelerated phospholipid flipw flop leading to an enhanced procoagulant activity of siclded cells. J. Clin. Invest. 75, 183-190.

Fraschini A, Abi E, Gahan PB, Viola-Magni MP. (1992). TEM cytoctremical study of the localization. of phospholipids in interphase chromatin in rat hepatocytes. Histochemistry, 97, 225-235.

Frederik PM, Stuart MC, Bomans PH, Busing WM. (1989). Phospholipid, nature"s own slide and cower slip for cryo-electron microscopy. J. Microse. 153, 81-92.

Gall MM. (1993). Involvement of protein cofactors in the expression of antiphospholipid antibodies. Thesis Madistricht University, Maastricht, The Nethetlands.

Gascard P, Tran D, Sauvage M, Sulpice JC, Fukami K, Takenawa T, Claret M, Giraud F. (1991). Asymmetric distribution of phosphoinositides and phosphatidic acid in the human erythrocyte membrane. Bïochim. Biophys. Acta, 1069, 27-36.

Geisow MJ. (1986). Common domain structure of $\mathrm{Ca} 2+$ and lipid-binding proteins. FEBS Leti. 203, 99.103.

Geisow MJ, Fritsche U, Hexham JM, Dash B, Johnson T. (1986). A consensus amino-acid sequence repeat in Torpedo and mammalian $\mathrm{Ca} 2+$-dependent membrane-binding proteins. Nature, $320,636-638$.

Geuze HJ, Slot JW, van der Ley PA, Scheffer RC. (1981). Use of colloidal gold particles in double-labelling immunoelectron microscopy of ultrathin frozen tissue sections. J. Cell Biol. 89, 3, 653-665.

Gould RM, Armstrong R. (1989). Use of lead aspartate block staining in quantitative EM autoradiography of phospholipids: application to myelinating peripheral nerve. J. Histochem. Cytochem. 37, 1393-1399.

Gordesky SE, Marinetti GV, Segel GB. (1972). Differences in the reactivity of phospholipids with FDNB in normal RBC, sickle cells and RBC ghosts. Biochem. Bioph. Res. Co. 47, 1004-1009.

Gordesky SE, Marinetti GV (1973). The asymmetric arrangement of phospholipids in the human erythrocyte membrane. Biochem. Bioph. Res. Co. 50, 1027-1031.

Gordesky SE, Marinetti GV, Love R. (1975). The reaction of chemical probes with the erythrocyte membratue. J. Membrane Biol. 20, 111-132.

e) Hage Chahine JM, Cribier S, Devaux PF, (1993). Phospholipid transmembrane domains and lateral diffusion in fibroblasts. P. Natl. Acad. Sci. USA 90,447-451.

Higgins JA, Evans WH. (1978). Transverse organization of phospholipids across the bilayer of plasma-membrane subtractions of rat hepatocytes. Biochem. J. 174, 563-567.

Helmstad RH, Bell RM. (1991). Molecular insights into enzynes of membrane bilayer assembly. Biochennistry, 30, 1731-1740.

Humbel BM, Weber K, MerkI R. (1991). Versatille controlling system for cryopreparation techniques in electron microscopy. I. Electron Microscopy Techn. 17, 450-455.

Kornberg RD, McConnell HM. (1971). Inside-outside transitions of phospholipids in vesicle membranes. Biochemistry, $10,1111-1120$.

Kuypers FA, Lubin BH, Yee M, Agre P, Devaux PF, Geldwerth D. (1993). The distribution of erythrocyte phospholipids in hereditary spherocytosis demonstrates a minimal role for erythrocyte spectrin on phospholipid diffusion and asymmetry. Blood, 81, 1051-1057.

Lichtenberg D, Freire E, Schmidt CF, Barenholz Y, Felgner PL, Thompson TE. (1981). Effect of surface curvature on stability, thermodynamic behaviour, and osmotic activity of 
dipamitoylphosphatidylcholine single lamellar vesicles. Biochemistry, 20,3462-3467.

Lipka $\mathrm{G}$, Op den Kamp JA, Hauser H. (1991). Lipid asymmetry in rabbit small intestinal brush border membrane as probed by an intrinsic phospholpid exchange protein. Biochemistry, 30, 11828-11836.

Mann GK, Jenny R., Krishnaswamy S. (1988). Cofactor proteins in the assembly and expression of blood clotting enzyme complexes. Annu. Rev. Biochem. 57, $915-956$.

Maraldi NM, Zini N, Squarzoni S, Del Coco R, Sabatelli P, Manzoli FA. (1992). Intranuclear localization of phospholipids by ultrastructural cytochemistry. I. Histochem. Cytochem. $40,1383-1392$.

Martin OC, Pagano RE. (1987). Transbilayer movement of fluorescent analogs of phosphatidylserine and phosphatidylethanolamine at the plasma membrane of cultured cells. Evidence for a protein-mediated and ATP-dependent process(es). J. Biol. Chem. 262, 5890-5898.

Martin SJ, Reutelingsperger CP, McGahon AJ, Rader JA, van Schie RC, LaFace DM, Green DR. (1995). Early redistribution of plasma membrane phosphatidylserine is a general feature of apoptosis regardless of the initiating stimulus: inhibition by overexpression of $\mathrm{Bcl}-2$ and $\mathrm{Abl}$. J. Exp. Med. $182,1545-556$.

van Meer G, Poorthuis BJ, Wirtz KW, Op den Kamp JA, van Deenen LL. (1980). Transbilayer distribution and mobility of phosphatidylcholine in intact erythocyte membranes. A study with phosphatidylcholine exchange protein. Eur. J. Biochem. 103, 283-288.

van Meer G, Gahmberg CG, Op den Kamp JA, van Deenen LL. (1981). Phospholipid distribution in human En(a-) red cell membranes which lack the major sialoglycoprotein, glycophorin A. FEBS Lett. $135,53-55$.

Meers P, Mealy T. (1993). Calcium-Dependent Annexin-W Binding to Phospholipids - Stoichiometry, Specificity, and the Role of Negative Charge. Biochemistry, 32, 11711-11721.

Meers P, Mealy T. (1994). Phospholipid determinants for annexin V binding sites and the role of tryptophan 187. Biochemistry, 33, 5829-5837.

Middelkoop E, Coppens A, Llanillo M, Van der Hoek EE, Slotboom AJ, Lubin BH, Op den Kamp JA, Van Deenen LL, Roelofsen B. (1989). Aminophospholipid translocase in the plasma membrane of Friend erythroleukemic cells can induce an asymmetric topology for phosphatidylserine but not for phosphatidylethanolamine. Biochim. Biophys. Acta, 978, $241-248$.

Morrot G, Herve P, Zachowski A, Fellmann P, Devaux PF. (1989). Aminophospholipid translacase of human erythrocytes: phospholipid substrate specificity and effect of cholesterol. Biochemistry, 28, 3456-3462.

Morrot G, Zachowskil A, Devaux PF. (1990). Partial purfication and characterization of the human erythrocyte Mg2(+)-ATPase. A candidate aminophospholipid translocase. FEBS Leth, 266, 29-32.

Musters RJ, Otten E, Biegelmann E, Bijvelt J, Keijzer JJ, Post JA, Op den Kamp JA, Verkleij AJ. (1993). Loss of asymmetric distribution of sarcolemmal phosphat idylethanolamine during simulated ischemia in the isolated neonatal rat cardiomyocyte. Circ. Res. 73, 514-523.

Nolan JP, Magargee SF, Posner RG, Hanmerstedt RH. (1995). Flow cytometric analysis of transmembrane phospholipid movement in bull sperm. Biochemistry, 34, 3907-3915.

Op den Kamp JA. (1979). Lipid asymmetry in membranes Annu. Rev. Biochem. 48, 47-71.

Pasquet MM, Dachary-Prigent J, Nurden AT. (1996). Calcium influx is a determining factor of calpain activation and microparticle formation in platelets. Eur. J. Biochem. 239, 647-654.

Pelletier X, Mersel M, Freysz L, Leray C. (1987). Topological distribution of aminophospholipid fatty acids in trout intestinal brush-border membrane. Biochim. Bioplays. Acta, 902, 223-228.

Perret B, Chap HJ, Douste-Blazy L. (1979). Asymmetric distribution of arachidonic acid in the plasma 
menbrane of human platelets $A$ determination using purified phospholipases and a rapid method for membrane isolation. Biochim. Bioplays. Acta, 556, 434-446.

Post JA, Langer GA, Op den Kamp JA, Verkleij AJ. (1988). Phospholipid asymmetry in cardiac sarcolemma. Analysis of intact cells and "gas-dissected" membranes. Biochim. Biophys. Acta, 943, $256-266$.

Post JA, Clague JR, Langer GA. (1993). Changes in sarcolemmal phospholipid asymmetry and Cafluxes upon metabolic inhibition. Am. J. Physiol, 265, $14461-H 468$.

Poste G, Porter CW Papahadjopoulos D. (1978). Identification of a potential artifact in the use of electron microscope autoradiography to localize saturated phospholipids in cells. Biochim. Biophys. Acta, $510,256-263$.

Rawyler A, van der Schaft PH, Roelofsen B, Op den Kamp JA. (1985). Phospholipid localization in the plasma membrane of Friend erythroleukemic cells and nouse erythrocytes. Biochemistry, 24, $1777-1783$.

Renooij W, Van Golde LM, Zwaal RF, Van Deenen LL. (1976). Topological asymmetry of phospholipid metabolism in rat erythrocyte membranes. Evidence for flip-flop of lecithin. Eur. J. Biochem. 61, 53-58.

Van der Schaft PH, Beaumelle B, Vial H, Roelofsen B, Op den Kamp JA, Van Deenen LL. (1987). Phospholipid organization in monkey erythrocytes upon Plasmodiun knowlesi infection. Biochim. Biophys. Acta, 901, 1-14.

Schroit AJ, Zwaal RF. (1991). Transbilayer movement of phospholipids in red cell and platelet menbrunes. Biochim. Biophys. Acta, 1071, 313-329.

Seigneuret $M$, Dewaux PF. (1984). ATP=dependent asymmetric distribution of spin-labelled phospholipids in the erythrocyte membrane: relation to shape changes. P. Natl. Acad. Sci. USA, 81, $3751-3755$.

Sessions A, Horwitz AF. (1983). Differentiation-related differences in the plasma membrane phospholipid asymmetry of myogenic and fibrogenic cells. Biochim. Biophys. Acta, 728, $103-111$.

Severs NJ. (1982). Cholesterol distribution and structural differentiation in the sarcoplasmic reticulum of tat cardiac muscle cells. A freeze-fracture cytochemical investigation. Cell Tissue Res. 224, 613-624.

Severs NJ, Simons HL (1986). Caveolar bands and the effects of sterol-binding agents in vascular smool muscle plasma membrane. Single and double labelling with filipin and tomatin in the aorta, pulmonary artery, and vena cava. Lab Invest. 55, 295-307.

Sims PJ, Wiedmer T, Esmon CT, Weiss HJ, Shattil SJ. (1989). Assembly of the platelet prothrombinase complex is linked to vesiculation of the platelet plasma membrane J. Biol. Chem. 264, $17049-17057$.

Singer S., Nicolson GL. (1972). The flusid mosaic model of the structure of cell membranes. Sictence, 175, 720-731.

Skepper JN. (1989). Membrane segregation in atrioventricular nodal myocytes of the golden hamster (Mesocricetus auratus). A cytochemical study using filipin and tomatine. J. Anat. 163, 143-154.

Slot JW, Geuze H. (1981). Sizing of protein A-colloidal gold probes for immunoelectron microscopy. J. Call Biol. $90,533-536$.

Sneets EF, Comfurius P, Bevers EM, Zwaal RF. (1994). Calcium-induced transbilayer scrambling of fluorescent phospholipid analogs in platelets and erythrocytes. Biochim. Biophys. Acta, 1195, 281 -286.

Squier MK, Miller AC, Malkinson AM, Cohen JJ. (1994). Calpain activation in apoptosis. J. Cell. Plysiol. 159, 229-237. 
Stein $\mathrm{O}$, Stein $\mathrm{Y}$. (1971). Light and electron microscopic radioatography of lipids: technicues tend biological applications. In: advances un lipid research. Ed. R. Paoleti and D Kritchevsky Acadenic press, New York, London.

Stuart MC, Bevers EM, Comfurius P, Zwaal RF, Frederik PM. (1992). Cryo-electron microscopic observation of blood platelet activation and the localisation of procoagulant surface. Electron microscopy 3. EUREM "92 Granadi, Spain.

Stuart MC, Bevers EM, Comfurius P, Zwwaal RF, Reutelingsperger CP, Frederik PM. (1995). Ultrastructural detection of surface exposed phosphatidy/serine on activated blood platelets. Thrombosis haemostasis. 74, 1145-1151.

Stuart MC, Damoiseaux JG, Frederik PM, Arends JW, Reutelingsperger CP. (1998). Surface expostre of phosphatidylserine during apoptosis of rat thymocytes precedes nuclear changes. Eur. J. cell biol. 76. $77-83$.

Sulpice JC, Zachowski A. Devaux PF, Giraud F. (1994). Requirement for phosphatidylinositol 4,5-bisphosphate in the $\mathrm{Ca}(2+)$-induced phospholipid redistribution in the human erythrocyte membrane. J. Biol. Chem. 269, 6347-6354.

Sune A, Bette-Bobillo P, Bienvenue A, Fellnann P, Dewaux PF. (1987). Selective outside-inside translocation of aminophospholipids in human platelets. Biochemistry, 26, 2972-2978.

Sune A, Vidal M, Morin P, Sainte-Marie J, Bienvenue A. (1988). Evidence for bidirectional transverse diffusion of spin-labelled phospholipids in the plasma membrane of guinea pig blood celis. Biochim. Biophys. Acta, 946, 315-327.

Tait JF, Gibson D. (1994). Measurement of membrane phospholipid asymmetry in normal and sickle-cell erythrocytes by means of annexin W binding. J. Lab. Clin. Med. 123, 741-748.

Tillack TW, Wong M, Allietta M, Thompson TE. (1982). Organization of the glycosphingolipid asialo-GM1 in phosphatidylcholine bilayers. Biochim. Bioplyys. Acta, 691, 261-273.

Tilley L, Cribier S, Roelofsen B, Op den Kamp JA, van Deenen LL. (1986). ATP-dependent translocation of amino phospholipids across the human erythrocyte membrane. FEBS Lett. 194, 21-27.

Tilly RH, Senden JM, Comfurius P, Bevers EM, Zwaal RF. (1990). Increased aminophospholipid translocase actiwity in human platelets during secretion. Biochim. Biophys. Acta, 1029, $188-190$.

Tokuyasu KT. (1973). A thechnique for ultracryotomy of cell suspensions and tissues. J. Cell Biology, $57,551-565$.

Venien C, Le Grimellec C. (1988). Phospholipid asymmetry in renal brushl-border membranes. Biochim. Biophys. Acta, 942, 159-168.

Verhallen PF, Bevers EM, Comfurius P, Zwaal RF. (1987). Correlation between calpain-mediated cytoskeletal degradation. Biochim. Biophys. Acta, 903, 206-217.

Verhoven B, Schlegel RA, Williamson P. (1995). Mechanisms of phosplatidylserine exposure, a phagocyte recognition signal, on apoptotic T lymphocytes. J. Exp. Med. $182,1597-1601$.

Verkleij AJ, Zwaal RF, Roelofsen B, Comfurius P, Kastelijn D, van Deenen LL (1973) The asymmetric distribution of phospholipids in the human red cell membrane. A combined study using phospholipases and freeze-etch electron microscopy. Biochim. Biophys. Acta, 323, 178-193.

Williamson P, Kulick A, Zachowski A, Schlegel RA, Devaux PF. (1992). Ca ${ }^{2 *}$ induces transbilayer redistribution of all major phospholipids in human erythrocytes. Biochemistry * 31, 6355-6360.

Williamson $\mathrm{P}$, Bewers EM, Smeets EF, Comfurius P, Schlegel RA, Zwaal RF. (1995). Continuous analysis of the mechanism of activated transbilayer lipid movement in platelets. Biochemistry, 34 , $10448-1055$. 
Winter II, Scot IE, Oulton MR, Stinson D, Allen A. (1991). Autoradiographic localization and effects of exogenous radioactively labelled surfactant in the lung of the prematurely delivered feal rabbit. Biol. Neonate. $60,292-302$.

Zachowski A, Hermann A, Paraf A, Devalux PF. (1987). Phospholipid outside-inside translocation in lymphocyte plasma membranes is a protein-mediated phenomenon. Biochim. Biophys. Acta, 897, 197-200.

Zachowski A. (1993). Whospholipids in animal eukaryotic membrames: transverse asymmetry and movement. Biochem. J. 294, 1-14.

Zachowski A, Favre E, Cribier $\$$, Hervé P, Devaux PF. (1986). Outside-inside translocation of aminophospholipids in the human erythrocyte membrane is mediated by a specific encyme.

Biochenistry, 25, 2585-2590.

Zachowski A, Gaudry-Talarmain YM. (1990). Phospholipid transverse diffusion in synaptosomes: evidence for the involvement of the aminophospholipid translocase. J. Neurochem. 55, 1352-1356 .

Zimmerman ML, Daleke DL. (1993). Regulation of a candidate aminophospholipid-transporting ATPase by lipid. Biochemistry, 32, 12257-12263.

Zhou Q, Zhao J, Stout JG, Luhm RA, Wiedmer T, Sims PJ. (1997). Molecular cloning of human plasma membrane phospholipid scramblase. J. Biol. Chem. 272, 18240-18244.

Zwaal RF, Roelofsen B, Comfurius P, van Deenen LL. (1975). Organization of phospholipids in human red cell membranes as detected by the action of various purified phospholipases. Biochim. Biophys. Acta, 406, 83-96.

Zwal RF, Comfurius P, Bevers EM. (1993). Mechanism and function of changes in membrane-phospholipid asymmetry in platelets and erythrocytes. Biochem. Soc. T. 21, 248-253. 
Chapter 2

\section{Perspective and limitations of cryo-electron microscopy.}

Based on Frederik PM, Stuart MC, Bomans PH, Busing WM, Burger KN, (1991) Perspective and fimitations of cryo-electron microscopy. J. Microsc. 16\%,253-262.

Stuart MCA, Bevers EM, Comfurius P, Zwaal RFA, Frederik PM. (1992). Cryoelectron microscopic observation of blood platelet activation and the localisation of procoagulant surface. Electron microscopy 3. EUREM ‘92 Granada, Spain. pp 139-140 


\section{Surmmary}

We investigated the possibility of vitrifying temperature sensitive lipid phases as well as small biological specimens. From a suspension of unilamellar vesicles, prepared from dipalmitoyl-phosphatidylcholine (DPPC), thin aqueous films were formed at various temperatures. With cryo-electron microscopy vesicles were found to be smooth, rippled and faceted only, depending on the temperature of thin film formation (318,312, and 296K respectively). The morphology indicates that membranes can be physically fixed by vitrification in their high temperature configuration and studied at low temperature by cryo-electron microscopy. This finding suggests that it may also be possible to preserve, in their original state, the more complex membrane systems found in living organism by initiating rapid cooling at a physiological temperature. This was explored by vitrification of thin films formed on a specimen grid with human blood platelets adhering to collagen fibres. Low temperature observation with an acceleration voltage of the electron beam at $120 \mathrm{keV}$ revealed subcellular detail. More details were observed when using higher accelerating voltages ( 200 and $300 \mathrm{keV}$ ). The question whether cryo-electron microscopic specimen grids can also be used as a test tube to follow cell biological events was more complicated. Changes in membrane structure can easily be followed upon activation of the blood platelets but when cytochemical localisations were performed concessions to the basic concept, of chemically unfixed specimens, had to be made. The results presented in this paper illlustrate the great potential of cryo-electron microscopy in the study of membrane dynamics, both in relatively simple model membrane systems and in more complex biological membrane systems. 


\section{Introduction}

Cryo-electron microscopy as introduced by Taylor \& Glaeser $(1975,1976)$ was considerably improved when it was shown (Brüggeler \& Mayer, 1980, Dubochet\& McDowall, 1981) that water can be vitrified and that suspended macromolecules observed in the (cryo)electron microscope in a frozen hydrated state (Dubochet et al. 1982). There are several advantages in using cryo-electron microscopy. First, hydrated objects can be observed at high resolution (for a review see Dubochet et al. 1987, 1988) in their 'native' state, without the interference of metal salts as 'stains". A further advantage is the reduction of beam damage at low temperatures (Lepault et al. 1983, see Chiu et al. 1986, for a consensus opinion). Hydrated and vitrified objects, thin enough to be used for cryo-(transmission) electron microscopy can be prepared in two ways: by cryo-sectioning of vitrified material and by vitrification of a thin aqueous film prepared from a suspension. Here we will confine ourselves to thin films prepared from suspended materials. The advantage offered by cryo-electron microscopy of thin films becomes obvious when considering the formation and vitrification of thin aqueous films in more detail. After dipping a bare grid into, and withdrawing it from a suspension, a thin aqueous film will form spontaneously. When surface active material is present, thinning will proceed until attractive and repulsive forces balance. At this stage a thin film has spontaneously formed, having a thickness of less than $100 \mathrm{~nm}$ near the centre of a grid-hole (for detaills see Frederik et al. 1989a, b). Owing to the dimensions of the film, heat exchange is fast and its entire contents can be vitrified by simply dipping the grid into a suitable coolant. The vitrification process is extremely fast ( $10^{-2} \mathrm{~ms}$, Bachmann \& Mayer 1987), and therefore offers excellent time resolution. In summary, a thin fill can be considered a test tube in the submicrometer size range, in which dynamic events can be trapped with the time resolution of vitrification (Frederik et al. $1989 \mathrm{c}$, Talmon et al. 1990). In addition to high time resolution, cryoelectron microscopy offers a high spatial resolution. Because of this combination of high temporal and spatial resolution we expect that cryo-electron microscopy will significantly contribute to our understanding of dynamic processes in suspension.

Before complex (biological) systems can be investigated with this approach it is important to answer the following questions: first, is vitrification from elevated temperatures (physiological temperatures and higher) possible? The second question is related to the size of the objects; can single cells be vitrified and imaged with subcellular detail by transmission electron microscopy? Third, can a specimen grid be used as a small test tube for cell biological. studies?

The first question was addressed by studying temperature-sensitive lipid phases. Phospholipids are constitutive elements of biological membranes that may undergo phase transitions under the influence of a change in temperature. Phase changes (e.g. Lamellar $\mathrm{L}_{\alpha}$ to rippled $\mathrm{P}_{\beta}$ ) take place in less than I s (for reviews see Jost et al. 1984, Knoll et al. 1987). High cooling rates were found to be essential to prevent a phase change of phospholipids during the cooling process (as was demonstrated with freezefracture replication by Ververgaert et al. 1973, Gulik-Krzywicki and Costello 1978, Melchior et al. 1982). As model systems we choose a suspension of saturated lecithins of which the thermotropic phase behaviour has been characterized by $\mathrm{X}$-ray diffraction 
(Janiak et all. 1979). Initial studies (see discussion following Frederik ef al. 1989b) showed that sonicated vesicles are not particularly well suited for this type of investigation because of anomalies in their phase behaviour (also see Lichtenberg et al. 1981). We therefore used (larger) unilamellat vesicles prepared by an extrusion method (Hope et al. 1985). Data presented in this paper show that it is possible to preserve lipid phases by vitrification, even if a lipid phase is only stable at an elevated temperature, and a thin-film formation and vitrification have to be preformed at temperatures higher than $313 \mathrm{~K}$ or higher. These findings imply that with respect to the thermotropic behaviour of phospholipids, experiments can be performed at physiological temperatures (and higher) and that subsequent vitrification will preserve the lipids in the phase in which they reside prior to vitrification.

This brings us to the second question; can (small) cells be vitrified in suspension and imaged by cryo- electron microscopy with sufficient subcellular detail? For our initial investigation we choose (human) blood platelets because their small size would allow rapid heat exchange during cooling. If these cells can be vitrified, it is of interest to study their contents of subcellular organelles also in relation to the dynamics of an extensive submembraneous cytoskeleton. Since platelets are difficult to maintain in a concentrated suspension (llactate production would challenge the buffer capacity) we have chosen for a selective adhesion to the grid. Platelets are collected from a diluted suspension by specimen grids coated with a meshwork of collagen. Platelets contain receptors for collagen and they firmly adhere to the collagen meshwork and can thus be vitrified in their hydrated state. The hydrated platelets were observed at several acceleration voltages of the (cryo)-electron microscope with the aim to investigate whether increased beam penetration at higher voltages (up to $300 \mathrm{KeV}$ ) would disclose more subcellular detail.

Addressing the third question, whether a specimen grid can be considered as a small test tube, we also used blood platelets. Platelets were activated on the grid, and the formation of mernbrane vesicles (Sims et al 1988) and the development of procoagulant surface (Bevers et al. 1982) was studied. Exposure of phosphatidylserine (procoagulant surface) to the outer membrane leaflet was monitored with coagullation factor $V$ coupled to small $(\varnothing 10 \mathrm{~nm}$ ) colloidal gold particles.

\section{Materials and methods}

Preparation of the phospholipid vesicles.

The phospholipids used were obtained from Sigma, dipalmitoyl-phosphatidylcholine (DPPC, Sigma P-0763) and dimyristoyl-phosphatidylcholine (DMPC, Sigma P-0888). A. 6.8 and $8 \mathrm{mM}$ suspension respectively were prepared in distilled water by vortexing. From this suspension unilamellar vesicles were prepared by extrusion through Nuclepore filters $(0.2 \mu \mathrm{m}$ pore size) at $323 \mathrm{~K}$ (DPPC) or $303 \mathrm{~K}$ (DMPC) using the extruder described by Hope et al. (1985). After several passages through the extruder the suspensions were used for thin-film formation and vitrification. Thermal equilibrium prior to thin-film formation lasted at least $1 \mathrm{~h}\left(\mathrm{~L}_{\alpha}\right.$ and $\mathrm{P}_{\beta}$. phases) or 1 day ( $\mathrm{L}_{\mathfrak{p}}$, phase). 


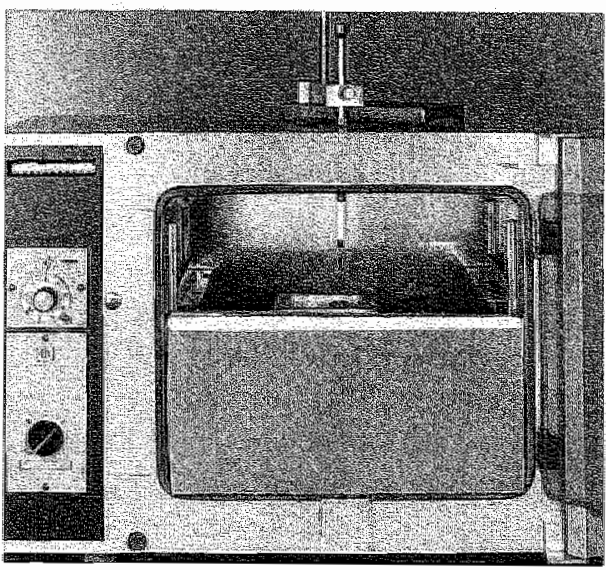

Figure. 2.1 Incubator used for thin-film formation and vitrification from elevated temperatures (303-343K). Ethane cooled by liquid nitrogen is placed on a perforated tray. The door opening of the incubator is insulated with styrofoam (bottom side) and polyethylene sleewes (top side, sleeves have been removed for better view). Thin-film formation on a specimen grid is car"ried out inside the incubator in a high humudity environment. Using forceps attached to a sliding rod the grid is plunged into the ethane (release mechanism on top of the incubator).
Thin-film preparation and vitrification of phospholipid suspensions.

A thin aqueous film was formed by dipping and withdrawing a bare specimen grid from the suspension. The grid had a fine $(700-$ mesh) honeycomb pattern of bars and were 3-4 $\mu \mathrm{m}$ thick. After withdrawal from the phospholipid suspension the grid was blotted against filter paper and in the space between the grid bars thin films formed as soap films (see also Frederik et al. 1989a, b). The thin films were vitrified within $1 \mathrm{~s}$ after their formation by plunging the grid into ethane cooled to its melting point by liquid nitrogen. A gravity-powered guillotine was used to guide the tweezers holding the grid into the ethane (Dubochet et al. 1982). Vitrification from an elevated temperature (303-333 K) was performed by placing the vitrification equipment and all solutions in an incubator at hight humidity (see Fig 2.1). A similar system has been described by Bellare et al (1988) and has been named "a controlled environment vitrification system". In our system the

coolant is placed on a perforated tray inside the incubator in order to have the steepest. possible temperature gradient near the surface of the liquid ethane.

DPPC films were prepared $5 \mathrm{~K}$ above and $5 \mathrm{~K}$ below the gel-to-liquid crystalline phase transition temperature. From DMPC thin film were prepared at $303 \mathrm{~K}$ as well as at room temperature (data not shown, see result and discussion).

\section{Isolation and vitrification of blood platelets.}

Venous blood from healthy volunteers was collected in a 1:5 volume of $130 \mathrm{mM}$ citrate, $\mathrm{pH} 7.4$, containing $180 \mathrm{mM}$ glucose. Platelet-rich plasma was prepared by centrifugation ( $10 \mathrm{~min}, 150 \mathrm{~g}$, room temperature). This was then centrifuged (10 min, $1000 \mathrm{~g}$, room temperature) to obtain a platelet rich pellet. The pellet was resuspended in Hepes buffer (10 mM Hepes, $136 \mathrm{mM} \mathrm{NaCl}, 2.7 \mathrm{mM} \mathrm{KCL}, 2 \mathrm{mM} \mathrm{MgCl}, 5 \mathrm{mM}$ glucose, $0.5 \%$ HSA, pH 7.5) to give a platelet concentration of $1 \times 10^{8} / \mathrm{ml}$.

The platelets were used for thin-film formation and vitrification $1-2 \mathrm{~h}$ after finishing the isolation procedure. Platelets were vitrified directly from the suspension or after activation and labelling with Va-gold, by using essentially the same procedure as that described for lipid suspensions. However, blotting was done more gently; excess liquid was sucked away with the pointed tip of a piece of filter paper placed at the periphery of the grid, and an additional piece of filter paper was placed between the tweezers holding the grid. Thin-film formation thus took several seconds and was followed by 
vitrification in melting ethane.

Alternatively, platelets were vitrified after they were adhered to collagen fibres. An acid collagen solution (collagen reagent, Hormon Chemie, product no. 10500) was diluted 1:1 with water. A specimen grid was dipped in this solution followed by two rinses with Hepes buffer before it was dipped in a platelet suspension. After gently blotting the grid was then vitrified.

\section{activation of blood platelets and cytochemistry.}

Platelets were activated by adhesion to collagen fibres previously attached to the grid. In addition $4 \mathrm{nM}$ thrombin (IIa) or $2 \mu \mathrm{M} \mathrm{Ca}{ }^{2+4}$ ionophore (A 23187) was added. The platelets were directly vitrified after the activation. The buffers used for activation experiments were supplemented with $3 \mathrm{mM} \mathrm{Ca}{ }^{2+}$.

To localize procoagulant surface we adsorbed blood clotting factor $\mathrm{Va}$ to $10 \mathrm{~nm}$ gold particles. Va binding sites are considered to reflect procoagulant surface. The binding properties of Va-gold were tested by ellipsometry on $20 \%$ PS, $80 \%$ PC bilayers. Blood platelets adhering to collagen fibres were activated with thrombin and after 2 minutes the activation was stopped by chemical fixation in $2 \%$ formaldehyde, $0.2 \%$ glutaraldehyde. The fixation did not dramatically change the procoagulant activity of the activated platelets while resting platelets remain non-coagulant as was determined by a prothrombinase assay. After fixation, the platelets were incubated with the Vagold probe for at least one hour. Gentle washing removed the unbound gold after which the grids were vitrified.

\section{Cryotransfer and cryo-observations.}

Immediately after vitrification the grids were stored under liquid nitrogen. Grids could be stored for several month in a storage container with special holders to accept modified LKB-grid boxes. Usually the cryotransfer was performed within 1 day after vitrification. During mounting of the grid in the cryoholder (Gatan 626) the grid as well as the tip of the cryoholder remained submerged in liquid nitrogen. This was accomplished by slight overfilling of the inclined work station. Transfer to the microscope (Philips CM12 or CM 30) was done with the protective shields of the cryoholder covering the specimen and these shields remained closed during the first 15-20 minutes in the high vacuum of the microscope column (Frederik and Busing, 1986). Both microscopes were equipped with the standard cold traps (cryo-sorption pumps) without any additional anti-contaminating devices. The micrographs from the phospholipid suspensions were made with an acceleration voltage of $100 \mathrm{keV}\left(\mathrm{LaB}_{6}\right.$ gun, spotdiameter $\leq 200 \mathrm{~nm}$, condenser aperture $=50 \mu \mathrm{m}$, objective aperture $=40 \mu \mathrm{m}$ ) defocus values of $1-1.5 \mu \mathrm{m}$ were used to optimize phase contrast and resolve the bilayer structure. Vitrified platelets were investigated at $120 \mathrm{keV}(\mathrm{CM} 12)$ or at 100 , 200 and $300 \mathrm{keV}$ (CM30). The microscope parameters of the $\mathrm{CM} 30$ were, $\mathrm{LaB}_{6}$ gun, spot sizes $42.5-110 \mathrm{~nm}$, condenser aperture $50 \mu \mathrm{m}$, objective aperture $10 \mu \mathrm{m}$. Special care was used to minimise the electron dose on the specimens. To prevent beam induced damage (platelets are especially prone to this damaging effect) the build-in low-dose unit was used to minimise the electron exposure of the specimen. 
Results

Phospholipid vesicles vitrified from various temperatures showed striking differences in their morphology when observed by cryo-electron microscopy. Unilamellar vesicles of DPPC when vitrified from $318 \mathrm{~K}$ showed circular profiles whereas vesicles vitrified from $312 \mathrm{~K}$ and $296 \mathrm{~K}$ were faceted (Fig 2.2a, b, c). Faceted contours of unilamellar vesicles have been observed before, using freeze-fracturing (Parente et al. 1985) and cryo-electron microscopy (Lepault et al. 1985). In addition to the facetted contours vesicles vitrified from $312 \mathrm{~K}$ also showed a rippled surface. This ripple can be observed in profiles but also becomes apparent as a parallel striping when observed head-on. The ripple-repeat distance observed in these micrographs is in the order of 15 $\mathrm{nm}$. This observation is probably the first report on a ripple-phase observed by cryoelectron microscopy. The observations are in accordance with data obtained by other techniques. X-ray diffraction has indicated ripple repeat distances of DPPC to be 14.0 $\mathrm{nm}$ (Janiak et al. 1976) and $14.7 \mathrm{~nm}$ (Stamatoff et al. 1982). When measured from freeze-fracture replicas, ripple repeat distances of DPPC were found to be $16.2 \pm 1.8$ $\mathrm{nm}$ (Hicks et al. 1987) and $15 \mathrm{~nm}$ (Luna and McConnell, 1.977). The various morphologies of the lipid vesicles as observed by cryo-electron microscopy can be related to the thermotropic phase behaviour of phospholipids. Figure $2.2 \mathrm{~d}$ shows the phase diagram of disaturated phosphatidylcholines (reproduced from Janiak et al. 1979 ) as derived from $X$-ray diffraction studies. Three major transitions have been observed in this class of phospholipids (sub-, pre- and main transition). For DPPC these transitions occur at 295, 309 and $315 \mathrm{~K}$ respectively. Below 295 the lipid is packed into poorly hydrated crystal-like arrangement (this phase was not investigated in this study and is also not indicated in the phase diagram). Between 95 and $309 \mathrm{~K}$ the chains become tilted $\left(\mathbb{L}_{\beta}\right.$-phase) and more disordered. At the pre-transition temperature $(309 \mathrm{~K})$ there is an increase in the population of hydrocarbon chain gauche rotamers towards the centre of the bilayer (Levin and Bush, 1981). Between 309 and $315 \mathrm{~K}$ the bilayer surface ceases to be predominantly planar and a periodic ripple appears (the $\mathrm{P}_{\beta}$-phase). Finally at the main transition temperature $(315 \mathrm{~K})$ the acylchains become more fluid $\left(\mathrm{L}_{\mathrm{a}}\right.$-phase $)$ and the periodic pattern disappears. The different shapes of the unilamellar vesicles and the presence of a ripple pattern characteristic of the $\mathbb{P}_{\beta}$, phase as observed in cryo-electron microscopy, thus seems to represent faithfully the thermotropic phase of the lipid at the moment of thin film formation.

The results on thin films of phospholipids as shown thus far demonstrate that vitrification of both water and of lipid can be achieved by rapid cooling. Vitrified thin films of phospholipids can therefore be used to study the phase behaviour of phospholipids under various conditions (temperature, $\mathrm{pH}$ ) and to study lipid polymorphism in relation to phase behaviour (Frederik et al. 1989c, Siegel et al. 1989). Lipid polymorphism probably plays a role in biological fusion events (exocytosis, endocytosis, intracellular vesicular transport). In this context we have investigated the $\mathrm{pH}$-induced fusion of influenza with liposomes (Burger et al. 1990). Vitrification is used in this investigation to have high time resolution (virus membrane fusion is a fast' process) combined with the spatial resolution of the cryo-electron microscope. 

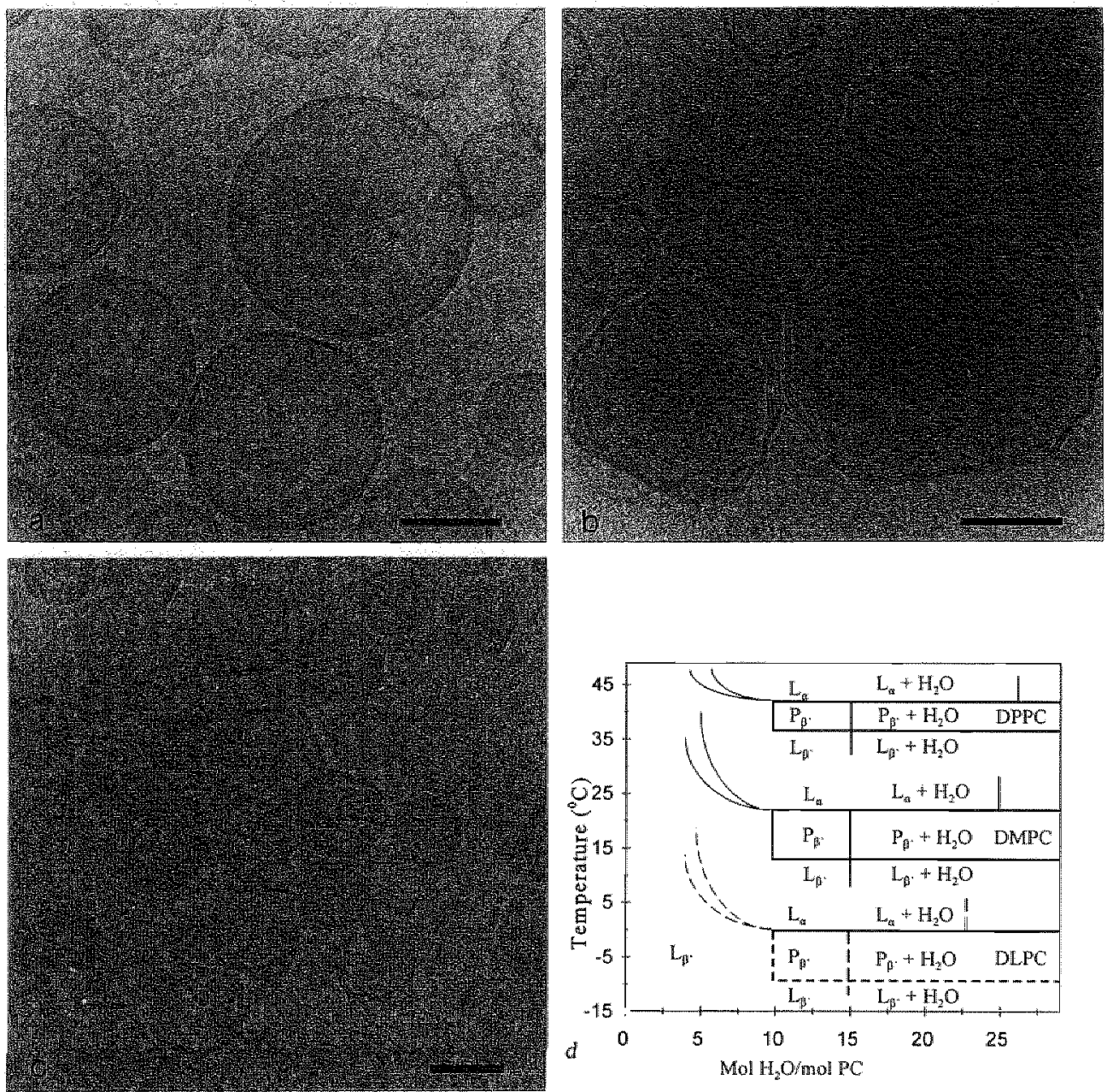

Figure 2.2 Thernotropic phase-behaviour of a phospholipid suspension. A $6.8 \mathrm{mM}$ suspension of DPPC was prepared by extrusion through a $0.4 \mu \mathrm{m}$ Nuclepore filter. Thin-film formation and vitrification were initiated from various temperatures, $318 \mathrm{~K}\left(45^{\circ} \mathrm{C}\right)(\mathrm{a}), 312 \mathrm{~K}\left(39^{\circ} \mathrm{C}\right)(\mathrm{b})$ and $295 \mathrm{~K}(22$ $\left.{ }^{\circ} \mathrm{C}\right)(\mathrm{c})_{\mathrm{i}}$ Vesicles vitrified from the liquid-crystalline $\left(\mathrm{L}_{\alpha}\right)$ phase have round contours (a). Thin-films prepared and vitrified at an internediate temperature $(312 \mathrm{~K}$; b) show rippled vesicles (ripple repeat distance of the order of $15 \mathrm{~mm}$ ) characteristic of the $P_{\beta}$-phase, with faceted contours. Thin-films prepared and vitrified from room temperature $(295 \mathrm{~K}$ ) showed vesicles with faceted contours (c) without a periodic ripple. Note the bilayer structure in al three micrographs $(a, b, c)$. (d) Temperature (C)-composition phase diagram of three disaturated phosphatidylcholines (redrawn after Janiak al al. 1979). For all three chollines the pre-transition $\left(\mathbb{L}_{j} \rightarrow \mathrm{P}_{\mathrm{B}}\right)$ and the main transition $\left(\mathrm{P}_{\mathrm{B}} \rightarrow \mathrm{L}_{\mathrm{ag}}\right)$ are indicated. Solid lines are phase boundaries based on experimental data; the dashed lines represent assumed phase boundaries. Vertical lines indicate maximum swelling of lipid in the $P_{\beta^{-}}$and $L_{\beta}$-phases (15 molecules $\mathrm{H}_{2} \mathrm{O}$ per molecule phosphatidylcholine) and of lipid in the $\mathrm{L}_{\alpha}$-phase (naximum swelling increasing with increasing chain length). DLPC $=$ dilauroy/phosphatidy/choline $(12: 0) ; \mathrm{DMPC}=$ dimyristoylphosphatidy/lcholine (14:0); DPPC = dipalmitoylphosphatidylcholine (16:0).

Bar represents $100 \mathrm{~nm}$. 
Being convinced by now that membranes are faithfully preserved by vitrification, we became curious to know if complex membrane structures in larger biological objects could also be vitrified and studied by cryo-electron microscopy. For this, we used blood platelets attached to collagen fibres. Before studying morphological and cellbiological aspects of platelet activation we want to optimize the imaging conditions for these relatively thick objects. Figure $2.3 \mathrm{a}$ is a micrograph taken from a vitrified platelet with an accelerating voltage of $100 \mathrm{keV}$. The thickness of the vitrified film increases towards the centre of the platelet. Subcellular details are most clearly resolved at the thin rim of the platelet and are less defined in the thicker central part of the platelet. When viewed at higher accelerating voltages (e. g. $300 \mathrm{keV}$, Fig $2.3 \mathrm{~b}$ ) thicker parts of the platelet show more detail. This is also evident when the cross striations of the collagen are observed. At $100 \mathrm{keV}$ these striation become obscured towards the thick central part whereas at $300 \mathrm{keV}$ cross striation is clearly visible along the entire length of the collagen fibres.

When we take a closer look at the morphological changes in the platelet that take place during activation, a massive membrane blebbing can be observed when the platelets were activated with ionophore (Fig 2.3c). The blebs which are quickly pinched of from the plasma membrane are well preserved with this technique. With platelets activated in a more gentle way with thrombin in combination with collagen to which the platelets are attached, pseudopodia are formed in which cytoskeleton can be observed (fig 2.3d). The bilayer membrane and the periodicity of the cytoskeleton can be seen. This process has been ascribed to $\mathrm{G}$-actin changing into actin filaments (Bryan et al. 1985). Platelet activation involves morphological changes as well as the development of a procoagulant surface on the membrane. Coagulation factor Va coupled to gold was used to localize this procoagulant surface on the activated platelets. Platelets treated in this way show microvesicles and some are densely labelled with gold indicating that they are procoagulant (fig 2.4). The difference in labelling density between microvesicles indicates that the formation of procoagulant surface is not equally distributed or not equally detected by factor Va-gold particles in all microvesicles.

\section{Discussion}

A comparison of the results shows that at $300 \mathrm{keV}$ more details can be observed in vitrified platelets than at accelerating voltages of $100-120 \mathrm{keV}$. With this type of thick (vitrified) specimens the resolving power of the instrument is probably not fully used. The main advantage of using higher accelerating voltages lies in a better penetrating power of the electron beam. Alternatively, this can be explained in terms of an increase in the mean free-path length of the electrons, having as an important side effect, a reduction of beam damage. The proportion of multiple scattered electrons, electrons that cause blurring of the image at conventional accelerating voltages, is thus diminished at higher accelerating voltages. At these higher accelerating voltages there is enough phase contrast to visualize subcellular organelles in weak (unstained, vitrified) phase objects. Rather extreme defocus values $(10-20 \mu \mathrm{m})$ have been used to 

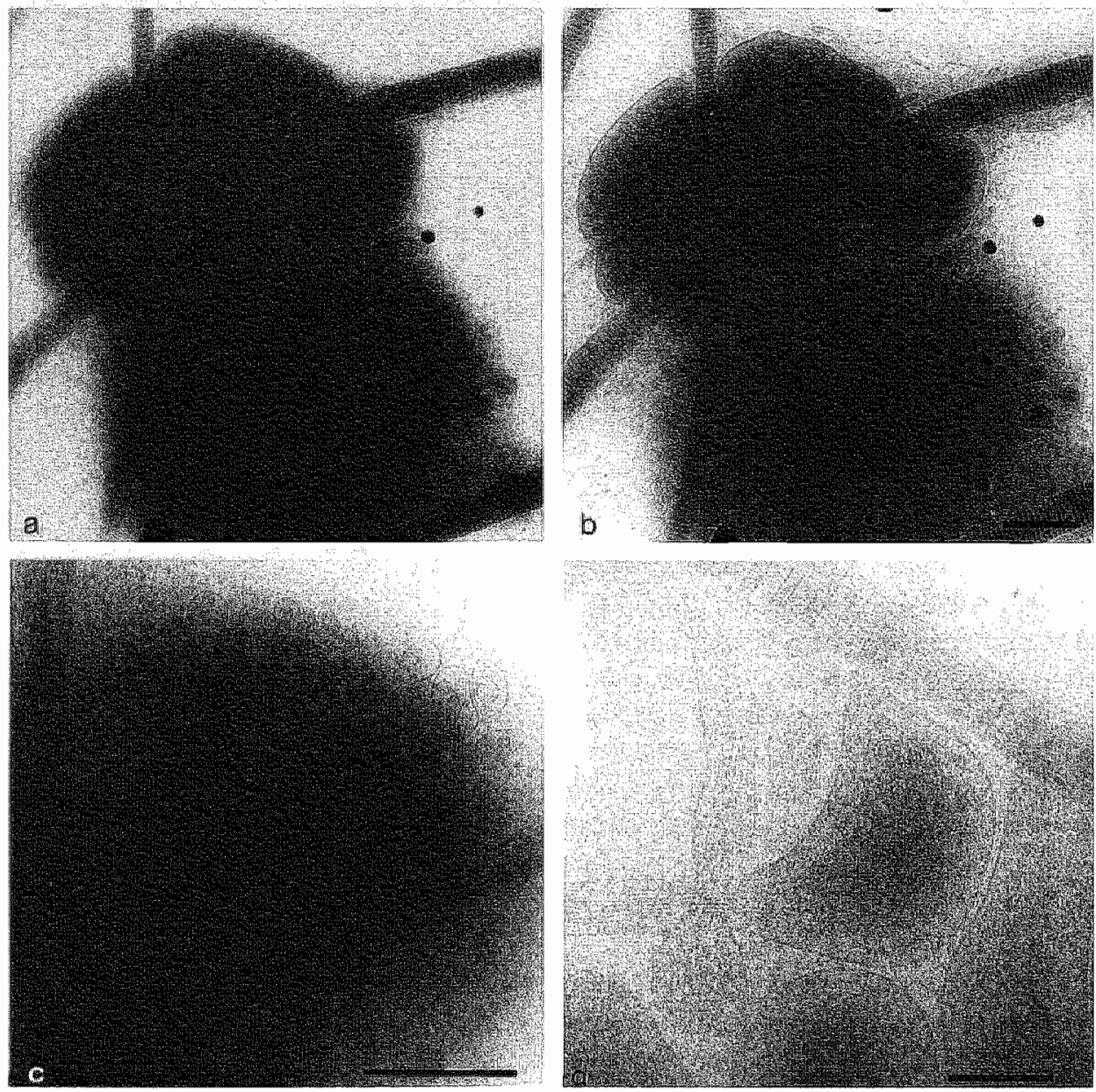

Figure 2.3 Cryo-electron microscopy of vitrified human blood platelets attached to collagen. (a), (b) micrograpli of the same specimen observed at $100 \mathrm{keV}$ (a) and $300 \mathrm{keV}$ (b)respectively. Note the improved resolution at $300 \mathrm{keV}$ as evidence by the better definition of cross striations of the collagen in fhick parts of the specimen. At $100 \mathrm{keV}$ (a) cross striation are visible in thin parts of the specimen (by proper defocus) whereas in thicker parts blurring of striations can be observed due to multiple scattering. (c) blood platelet attached to collagen fibres and activated with $1 \mu \mathrm{M}$ ionophore. Note the extensiwe vesicle formation at the outer surface of the platelet. (d) cytoskeleton formation in pseudopodia after collagen and thrombin activation of the platelets. Note the bilayer structure and the longitudinal striation of the $\mathrm{Gmactin}$ filaments. Bar represents $1 \mu \mathrm{m} \mathrm{a,b}, \mathrm{c}$ and $200 \mathrm{~nm} \mathrm{~d}$.

obtain the result here presented for blood platelets, contrary to the defocus values used for the liposomes $(1-1.5 \mu \mathrm{m})$ to resolve the billayer. By this procedure we have probably traded spatial resolution for contrast. The observation on vitrified platelets offer the prospect of a study on the rapid morphological changes occurring during platelet activation. The membrane structures formed during the activation can only be preserved when cryo-techniques are used, otherwise they will be modified during chemical treatments used in conventional electron microscopy. The application of 
cytochemical methods to specimens to be cryo-fixed can only be performed when an additional fixation step is applied. The interaction of suspended large gold particles is slow (at least 30 min incubation time is needed to generate a microscopically detectable signal) compared to the time scale of platelet activation (in the order of minutes). When chemical fixation is needed to gain time for cyto-chemistry one of the advantages of cryo-fixation (the unaltered chemical composition) is lost. In this study we also noticed there are snags attached to the probe used for the localisation of procoagulant surface. There were batch variations noticed when the adsorption of factor Va-gold was tested by ellipsometry. Furthermore we observed that coagulation factor $\mathrm{Va}$ is a rather instable protein which could only be used for a limited time after the coupling with gold particles.

Wher the time resolution of vitrification is fully exploited (in conjunction with spatial resolution) cryo-electron microscopy may significantly contribute to the ultrastructural study of membrane dynamics in model systems as well as in (intact) biological specimens. When however long incubations are needed to localize molecules on a subcellular level (such as in immunocytochemistry) additional fixation steps have to be applied to further stabilize the platelets to allow subsequent localization studies.
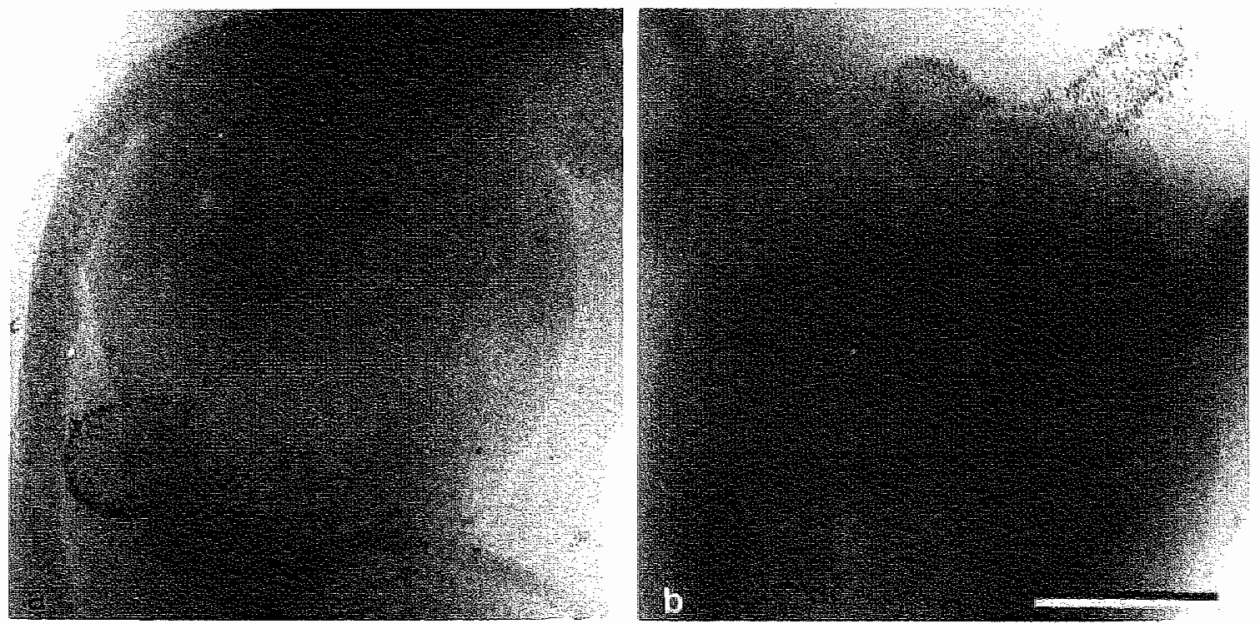

Figure 2.4 Development of procoagulant surface on collagen and thrombin activated blood platelets. The platelets are mildy fixed prior to the labelling with Va-gold particles. Procoagulant surface seem to be restricted to the shedded micro-vesicles. Bar represents $1 \mu \mathrm{m}$.

\section{References}

Bachmann I., Mayer E (1987). Physics of water and ice: implications for cryofication. Cryotechniques in biological electron microscopy (ed. By R.A. Steinbrecht and K. Zierold), pp 3-34. Springer-Verlag, Berlin.

Bellare JR, Davis HT, Scriven LE, Talmon Y. (1988). Controlled enwiromment witrification system: Arn improved sample preparation technique. J. Electronmicrosc. techn. 10, 87-111.

Bevers EM, Comfurius P, Rijn v JL, Hemker HC, Zwaal RF. (1982). Generation of 
prothrombin-converting activity and the exposure of phosphatidylserine at the outer surface of platelets. Eur. J. Biochem. $122,429-436$.

Briggeler P. Mayer $\mathbb{E}$. (1980). Complete vitification in pure liquid water and dilute solutions. Nature. $288,569-571$.

Bryan J, Colluccio LM. (1985). Kinetic analysis of $F$-actin depolymerization in the presence of platelet gelsolin and gelsolin-actin complex.. J. Cell Biol. 101, 1236-1244.

Burger KN, Knoll G, Frederk PM, Verkleij AJ. (1990). Influenza vinus mediated membrane fusion: the ddentification of fusion intemediates using modern cryotechniques. Dynamics and biogenesis of membranes. (Ed. By J.A.E. op den Kamp) pp. 185-196. Nato ASI series H40, Springer-Verlag, Berlin.

Chiu K, Downing KH, Dubochet $J$, Glaesre RM, Heide HG, Knapek E, Kopf DA, Lamvik MK, Lepault J, Roberison ID, Zeitler E, Zemlin F. (1986). Cryoprotection in electron microscopy. J. Microsc. 141, 385-391.

Dubochet J, Adrian M, Chang JJ, Homo JC, Lepault J, McDowall AW, Schulz.P. (1988).

Cryo-electron microscopy of vitrified specimens Q. Rev. Biophys. 21, 129-228.

Dubochet J, Adrian M, Chang JJ, Lepault I, McDowall AW. (1987). Cryo-electron microscopy of vitrified specimens. Cryotechniques in biological electron microscopy (ed. By R.A. Steinbrecht and K. Zierold), pp 115-131. Springer-Verlag, Berlin.

Dubochet J, Lepault J, Freeman $\mathbb{R}$, Berriman JA, Homo JC. (1982). Electron microscopy of frozen water and aqueous solutions. J. Microsc. 128, 219-237.

Dubochet J., McDowall AW. (1981). Vitrification of pure water for electron microscopy. J. Microsc. $125,3-4$.

Frederik PM., Busing WM. (1986). Cryo-transfer revised. J. Microsc. 144, $215-222$.

Frederik PM, Stuart MC, Bomans PH, Busing WM (1989a). Phospholipid, nature's own slide and cover slip for cryo-electron microscopy. J. Microsc. 153, 81-92.

Frederik PM, Stuart MC, Schrijvers AH, Bomans PH. (1989b). Thin film formation and the imaging of phospholipid by cryo-electron miicroscopy. Scanning microsc. Suppl. 3, 277-284.

Frederik PM, Stuart MC, Verkleij AJ. (1989). Intermediary structures during membrane fusion as observed by cryo-electron microscopy. Biochim. Biophys. Acta. 979, 275-278.

Gullik-Kraywicki T, Costello MJ. (1978). The use of low temperature X-ray diffraction to evaluate freezing methods used in freeze fracture electron microscopy. J. Microsc. $\mathbb{1} 2,103-113$.

Hicks A, Dinda M, Singer MA. (1987). The ripple phase of phosphatidylcholines: effect chain length and cholesterol. Biochim. Biophys. Acta. 903, 177-185.

Hope MJ, Bally MB, Wiebb G, Cullis PR. (1985). Production of large unilamellar wesicles by rapid extrusion procedure. Characterization of size distribution, trapped volume and ability to maintain a membrane potential. Biochin. Biophys. Acta. 812, 55-65.

Janiak MJ, Small DM, Shipley GG. (1976). Nature of thermal pretransition of synthetic phospholipids * dimyristoylecithin and dipalmitoylecithin. Biochemistry. 15, 4575-4580.

Janiak MJ, Small DM, Shipley GG. (1979). Temperature and compositional dependence of the structure of hydrated dimiristoyl lecithin. J. Biol Chem. 254, 6068-6078.

Jost PC, McMillan DA, Griffith OH. (1984). Effect of fixation on molecular dynamics in membranes. The science of biological specimen preparation (ed. by J. P. Revel, T. Bamard and G. Haggis) pp. 2330. SEM Inc. AMF O'Hare, $\mathrm{L}$.

Knoll G, Verkleij AJ, Plattner H. (1987). Cryofixation of dynamic processes in cells and organelles. 
Cryotechniques in biological electron microscopy (ed. By R.A. Steinbnecht and K. Zierold) pp 258271. Springer-Verlag, Berlin.

Lepault J, Booy FP, Dubochet J. (1983). Electron microscopy of frozen biological suspensions d. Microsc. 129, 89-102.

Lepault J, Patus F, Martin N. (1985). Electron microscopy of artificial biological membranes. Biochim. Biophys. Acta. 820, 315-318.

Levin IW, Bush SF. (1981). Evidence for acyl chain trans/gauche isomerisation during the thermal pretransition of dipalmitoylphosphatidylcholine bilayer dispersions. Biochim. Biophys. Acta 640,760. 766.

Lichtenberg $\mathrm{S}$, Freire E, Schmidt CF, Barenholz Y, Felgner PL, Thompsen TE, (1981). Effect of surface curvature on stability, themodynamic behaviour, and osmotic activity of dipalmitoyl phosphatidylcholine single lamellar vesicles. Biochemistry. 20, 3462-3467.

Luna EJ, McConnell HM. (1977). Intermediate monoclinic phase of phosphatidylcholines. Biochim. Biophys. Acta. 466, 381-392.

Melchior DL, Bruggeman EP, Steim IM. (1982). The physical state of quick-frozen membranes and lipids. Biochim. Biopys. Acta. 690,81-88.

Parente RA, Höchli M, Lentz BR. (1985). Morphology and phase behaviour of two types of unilamellar vesicles prepared from synthetic phosphatidylcholines studied by freeze-fracture electron microscopy and calorimetry. Biochim. Biopys. Acta. 812, 493-502.

Siegel DP, Bums JL, Chestmut MH, Talmon Y. (1989). Intermediates in membrane fusion and bilayer/nonbilayer phase transition imaged by time-resolved cryo-transmission electron microscopy. Biophys. J. 56, 16॥-169.

Sims PJ, Faioni EM, Wiedmer T, Shattil SJ. (1988). Complement proteins C5b-9 cause release of membrane vesicles from the surface that are rich in the membrane receptor for coagulation factor $\mathrm{Va}$ and express prothrombinase activity. J. Biol. Chem. 263, 18205-18212.

Stamatof J, freuer B, Guggenheim HJ, Tellez G, Yamane T. (1982). Amplitude or rippling in the P $\beta$ phase of dipalmitoylphosphatidylcholine bilayers. Biophys. J. 38, 217-226.

Talmon Y, Burns JL, Chestnut MH, Siegel DP. (1990). Time-resolved cryotransmission electron microscopy. J. Electronmicrose. Techn. 14, 6-12.

Taylor KA, Glaeser RM. (1975). Electron diffraction of frozen hydrated protein ciystals, Science. 186, $1036-1037$.

Taylor KA, Glaeser RM. (1976). Electron microscopy of frozen hydrated biological speciments. I. Ultrastruct. Res. $55,448-456$.

Ververgaert PH, Verkleij AJ, Verhoeven JJ, Elbers PF. (1973). Spray-freezing of liposomes. Biochim. Biopys. Acta. 311, 651-654. 

Chapter 3

\section{Binding of annexin $\mathrm{V}$ to bilayers with various phospholipid compositions using glass beads in a flow cytometer.}

M.C.A. Stuart, C.P.M. Reutelingsperger and P.M. Frederik. (1998). Cytometry, in press. 


\begin{abstract}
Annexin $V$ belongs to the family of calcium dependent phospholipid binding proteins and binds almost solely to phosphatidylserine (PS). When annexin $V$ is used to detect loss of membrane asymmetry in cellular systems, the binding properties under physiological conditions are of importance. Most biochemical studies use optimized binding conditions, conditions which are often far from physiological. For the interpretation of flow-cytometer studies that use fluorescent annexin $V$ to probe PS exposure, it is important to know what mixture of lipid species exposed in the outer leaflet of a membrane can evoke a positive annexin $V$ signal. The lipid species is important in this respect as well as the concentration that just evokes a positive signal (detection level). Furthermore, the influence of the composition of the lipid matrix (cholesterol content, other phospholipid species) was investigated, as well as the influence of the calcium concentration on annexin $V$ binding. In this study we report on the binding of annexin $\mathrm{V}$ to phospholipid bi-layers (adsorbed to glass beads) as measured by flow cytometry at physiological conditions. Annexin V binding was found to increase rapidly, with increasing PS concentrations up to a certain level (attained at $6 \mathrm{~mol} \%$ PS). Further increase of the PS concentration resulted only in a slight increase of annexin $\mathrm{V}$ binding. Calcium concentrations below $3 \mathrm{mM}$ were found to reduce the sensitivity of the binding assay. Phosphatidylethanolamine incorporated in the phospholipid bilayer resulted in a lower threshold for the binding assay, whereas sphingomyelin had no influence on the binding of annexin $V$ and cholesterol reduces binding of annexin $\mathrm{V}$ to lipid bilayers. These data may help in the interpretation of results obtained on binding of annexin $\mathrm{V}$ to cell membranes (e.g. involved in apoptosis).
\end{abstract}




\section{Introduction}

Cells distribute the various phospholipids species asymmetrically over the two leaflets of their plasma membrane. The most pertinent example of this organisation is the localisation of phosphatidylserine (PS), which in plasma membranes constitutes around $10 \%$ of the phospholipids (for a review see Devaux, 1991). Energy dependent and as yet unidentified transporters translocate PS from the outer to the inner leaflet thereby creating a steady state of low PS in the outer plasma membrane leaflet. Under specific conditions, such as platelet activation (for a review see Zwaal and Schroit 1997), ageing of erythrocytes (Diaz and Schroit, 1996), and cells executing the apoptotic program (Fadok et al. 1992, Martin et al. 1995), these mechanisms are counteracted by transporters moving PS from the inner to the outer leaflet giving rise to a steady state with elevated cell surface exposed PS. This PS interacts with the environment and may catalyse blood coagulation reactions (Mann et al. 1990) and may elicit phagocytosis of the PS exposing cell (Fadok et al. 1992). These reactions depend on the amount of cell surface exposed PS.

Annexin $V$ belongs to a family of phospholipid binding proteins and exhibits a high affinity for PS containing membranes in a calcium dependent manner (Raynal et al. 1994). Based on this binding property annexin $V$ is able to bind to cells which have elevated levels of PS in their outer leaflet of the plasma membrane whereas it hardly binds to cells with low levels of surface exposed PS. Hence, annexin V is a perfect tool to assess the level of surface exposed PS. So far the binding of annexin V to cells using flow cytometry could be interpreted only in a qualitative manner. In this paper we present a method to measure annexin V binding to phospholipid membranes as a function of the phospholipid composition by flow cytometry.

It is difficult to extrapolate the results from binding studies [ellipsometry (Andree et al. 1990), radio ligand binding (Thiagarajan and Tait, 1989), tryptophan 187 fluorescence (Meers and Mealy 1993a) and fluorescent-labelled annexin V (Tait et al. 1989)] to the physiological conditions used in cellular systems using fluorescent annexin $\mathrm{V}$ probes. In this paper we have tried to bridge this gap by using flow cytometry, as used in most cellular studies, to detect the binding characteristics of annexin $\mathrm{V}$ to phospholipids. Lipid vesicles of various composition (lipid species and relative concentration) were adsorbed to glass beads and assayed with respect to annexin V-FITC binding (also in relation to the calcium concentration). The aim of this approach was to gain more insight into the composition and concentration of lipids that are exposed on the outer bilayer leaflet of the cell membrane and which may give rise to a positive FITC-annexin $\mathrm{V}$ signal in the flow cytometer. The influence of phosphatidylethanolamine (PE), sphingomyelin and cholesterol on the relative binding of annexin V-FITC to phospholipid layers with physiological PS concentrations was studied. Calcium and annexin $V$ concentration were kept low in order to mimic the circumstances used in biological studies. We adsorbed phospholipid vesicles, of known composition, on small glass beads (Bayerl and Bloom, 1990, Giesen et al. 1991), using molar ratios representative of biological membranes. These coated beads were used as 
an artificial phospholipid carrier with good light scattering properties for unambiguous detection by flow cytometry.

\section{Materials and Methods}

\section{Materials}

Annexin V-FITC was obtained from Nexins Research BV(Hoeven, The Netherlands). as the APOPTEST ${ }^{\mathrm{Tm}}$-FITC kit.

Hollow glass beads with a diameter of $2-20 \mu \mathrm{m}$ (density close to one) were purchased from Poly science. Bovine brain sphingomyelin, dioleoylphosphatidylcholine (DOPC) and dioleoylphosphatidylethanolamine (DOPE) were obtained from Sigma chemical company (St. Louis, MO). Dioleoylphosphatidylserine (DOPS) was provided by Avanti polar lipids (Alabaster, AL). All other reagents used were of analytical grade.

\section{Preparing glass beads}

The glass beads were washed several times with methanol followed by rinsing several times with distilled water. The glass beads were suspended $(10 \mathrm{mg} / \mathrm{ml})$ in $5 \% \mathrm{H}_{2} \mathrm{O}_{2}, 4$ $\% \mathrm{NH}_{4} \mathrm{OH}$ and heated to at least $80^{\circ} \mathrm{C}$ for 5 minutes. The glass beads were then rinsed with distilled water and placed in a solution with $4 \% \mathrm{H}_{2} \mathrm{O}_{2}, 5 \% \mathrm{HCl}$ and heated to at least $80^{\circ} \mathrm{C}$ for at least 5 minutes. This procedure results in good hydrophilic surfaces necessary for coating the glass beads with phospholipids. Finally the glass beads were rinsed with distilled water and diluted to $1 \mathrm{mg} / \mathrm{ml}$ in TRIS / NaCl buffer (10 $\mathrm{mM}$ TRIS, $100 \mathrm{mM} \mathrm{NaCl}, \mathrm{pH} 7.4$ )

\section{Preparing liposomes}

From chloroform solutions of pure phospholipids, mixtures were made containing 0-10 mol \% DOPS, 0-30 mol \% DOPE or Sphingomyelin. The mixtures were completed to $100 \%$ with DOPC. After evaporation of the chloroform the phospholipids were dissolved in TRIS buffer ( $10 \mathrm{mM}$ TRIS, $100 \mathrm{mM} \mathrm{NaCl}, \mathrm{pH} 7.4)$ to a final concentration of $0.1 \mathrm{mM}$ total lipid. Cholesterol was added to the phospholipid mixtures in a phospholipid:cholesterol ratio of $2: 1$ and 1:1. Small unilamellar vesicles were made by ultra-sonication for 2 minutes on ice.

\section{Coating the glass beads}

$250 \mu \mathrm{g}$ glass beads were coated at room temperature with $50 \mu \mathrm{l} 0.1 \mathrm{mM}$ small unilamellat vesicles for 5-10 minutes. After spontaneous formation of a billayer on the glass beads they were washed two times with TRIS buffer to remove the unbound phospholipid. The phospholipid coated glass beads were diluted to a final concentration of $31.25 \mu \mathrm{g} / \mathrm{ml}$.

\section{Measuring annexin $V$ binding}

To phospholipid coated glass beads $(31.25 \mu \mathrm{g} / \mathrm{ml})$ annexin V-FITC was added to a final concentration of $250 \mathrm{ng} / \mathrm{ml}$. The average fluorescence of the glass beads was 

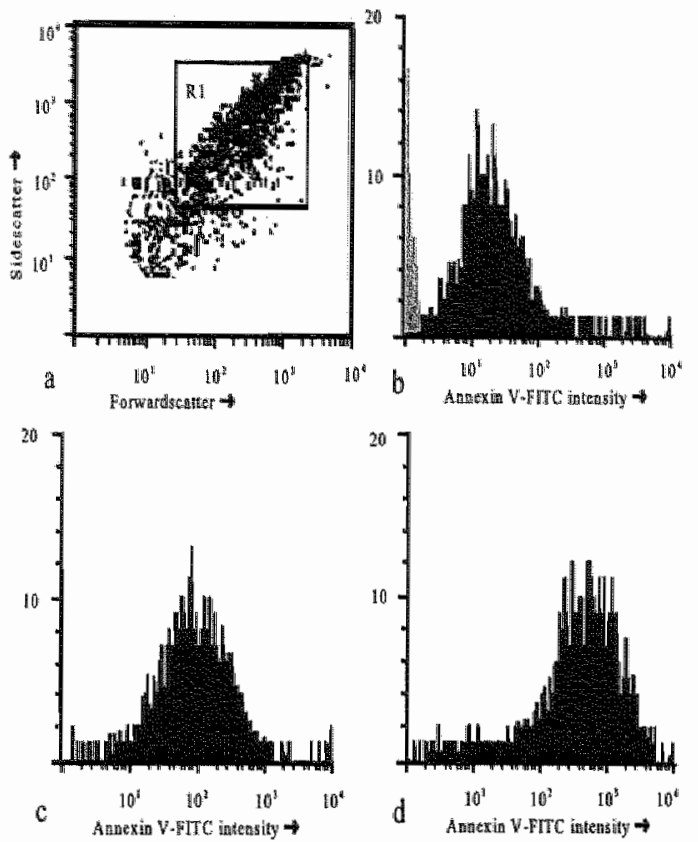

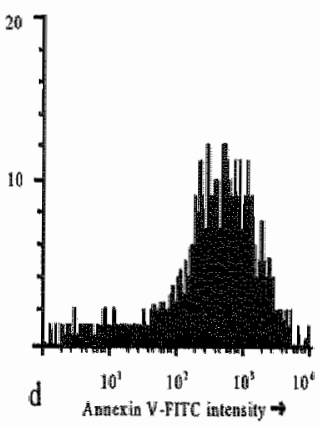

measured using a llow cytometer. Forwaid-side scatter gated flow cytometry was performed on a FACSort (Becton Dickinson) equipped with an argon laser (excitation at $488 \mathrm{~nm}$ ). The analysis was run using the Lysis II software package (Becton Dickinson). and 2,500 events were acquired in list mode.

Each data point shown in Figures $3.2-5$ is the mean of 2 individual experiments, except for DOPC/DOPS at $3 \mathrm{mM} \mathrm{Ca}$ where triple experiments were done. The error bar represents the $95 \%$ confidence interval of DOPC/DOPS at $3 \mathrm{mM} \mathrm{Ca}$ without additives. If not clearly indicated, the error bar falls within the symbol used for

Figure 3.1 a) Forward- sidescatter diagram of the glass beads indicating the average value. used. R.1 is the gate used for the analysis. b-d) flow cytometric histograms of annexin V-FTTC binding to uncoated glass beads (b, dotted bars) and phospholipid (PC/PS) coated glass beads at b) $0 \% \mathrm{PS}$, c) $3 \% \mathrm{PS}$ and d) $10 \% \mathrm{PS}$.

\section{Results}

Phospholipid vesicles collapse on the glass beads resulting in the formation of bilayers (Bayerl and Bloom, 1990, Giesen et al. 1991). This feature was utilized to prepare glass beads coated with a lipid bilayer to enable a study of annexin $\mathrm{V}$ binding by flow cytometry. The adhesion of lipids on the glass beads was checked using fluorescent labelled phospholipids (18:1/C6-NBD-PC). No desorption of fluorescent phospholipid was detected during the time span of the experiment. Proper cleaning of the glass beads was essential to get a good binding of the lipid and to avoid desorption. The optimal conditions used for adsorbing a maximal amount of phospholipid to the glass beads were assessed by using fluorescent labelled phospholipids (data not shown). Annexin $\checkmark$ binding to control glass beads (without phospholipids) was found to be negligible (figure 3.1b).

The light scatter properties of the glass beads are demonstrated in figure $3.1 \mathrm{a}$. We used a forward- sidescatter gate for the analysis of the annexin V-FITC binding to the phospholipid coated glass beads, in order to standardize the procedure. The scatter 
properties of the glass beads did not change neither on the formation of the phospholipid bilayer nor on binding of annexin V. The histograms of annexin V-FITC binding to phospholipid layers at low, intermediate and maximum levels are presented in fig $3.1 \mathrm{~b}-\mathrm{d}$. The peaks of the low and high binding of annexin V-FITC are well separated.

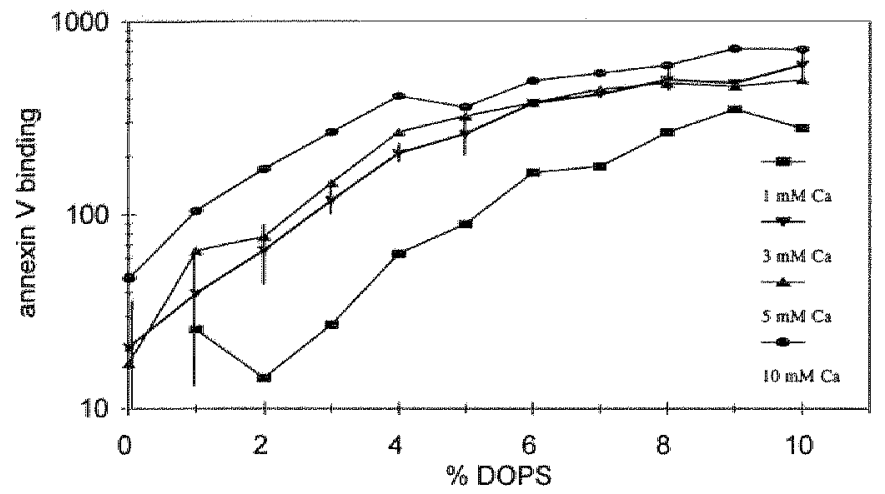

Figure 3.2 Binding of annexin V-FITC to PC/PS bilayers, coated on glass beads, at various calcinm concentrations, upon increasing PS concentration. The suspension contained $0.25 \mu \mathrm{g} / \mathrm{ml}$ annexin $\mathrm{V}-\mathrm{FITC}$ and 31.25 $\mu \mathrm{g} / \mathrm{m} /$ phospholipid coated glass beads. Annexin $\mathrm{V}$ binding was measured in arbitrary units by forward- sideward scatter gated tlow cytometry. The median values for annexin V-FITC binding are depicted from the histograms (fig $3.1 \mathrm{~b}-\mathrm{d}$ ). The error bars represent the $95 \%$ confidence interval of PC/PS at $3 \mathrm{mM} \mathrm{Ca}$.

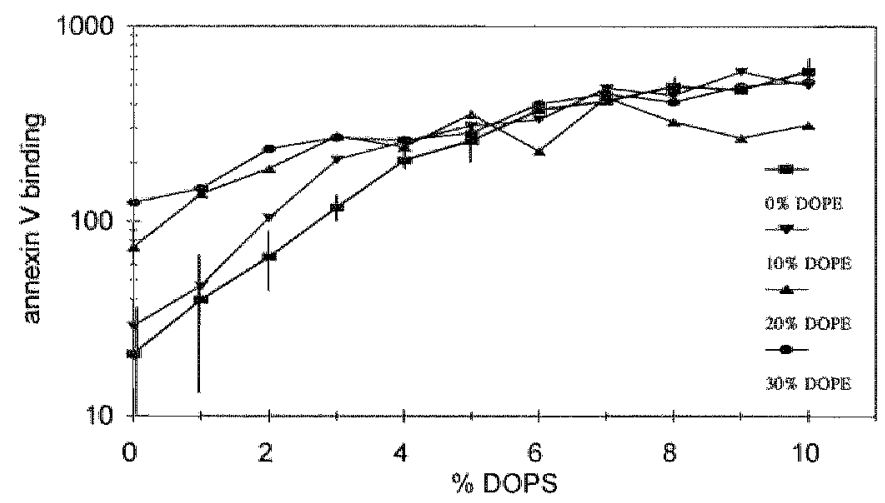

Figure 3.3 Binding of annexin $\mathrm{V}$-FTTC to PCrPS bilayers, coated on glass beads, at various PE concentrations upon increasing PS concentration. Measurments were done at $3 \mathrm{mM} \mathrm{Ca}$, for other details see figure 3.2. The error bars represent the $95 \%$ confidence interval of PC/PS. 


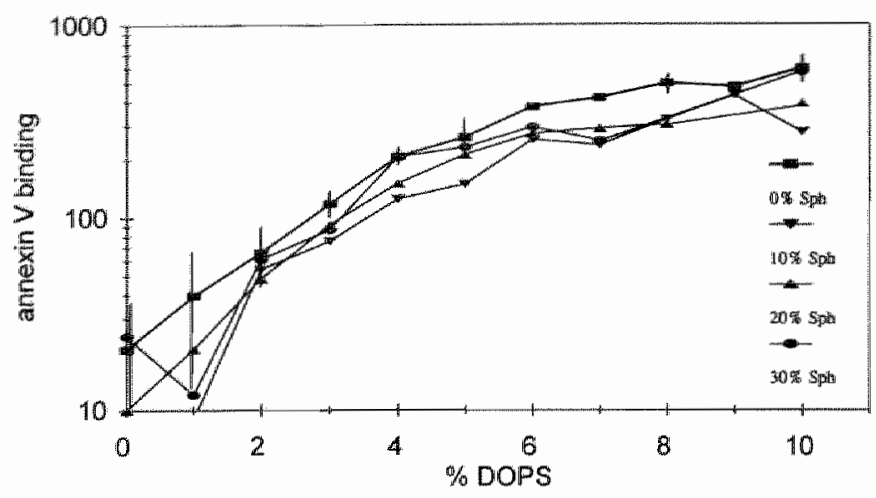

Figure 3.4 Binding of annexin V-FITC to PC/PS bilayers, coated on glass beads, at various sphingomyelin concentrations upon increasing PS concentration. Measuments wete done at $3 \mathrm{mM}$ Ca, for other details see figure 3.2. The error bars represent the $95 \%$ confidence interval of PC/PS.

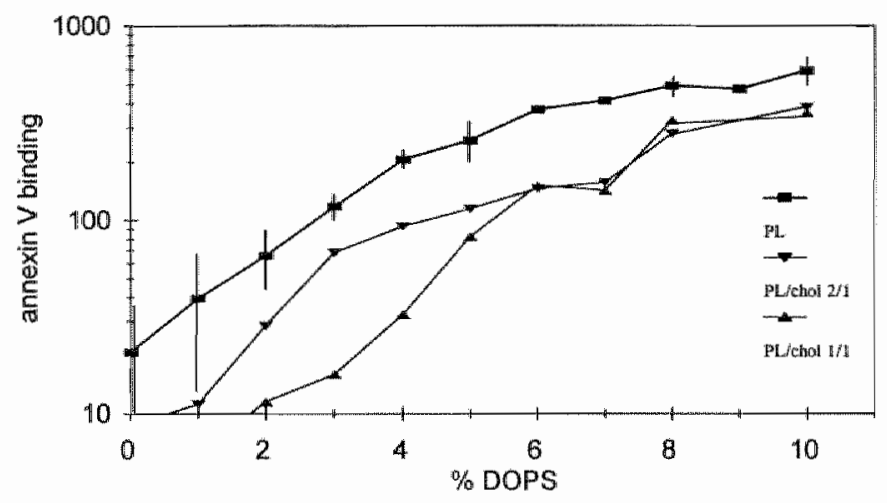

Figure 3.5 Binding of annexin V-FITC to PCPS bilayers, coated on glass beads, at various phospholipid (PL)/cholesterol (chol) ratios upon increasing PS concentration. Measurments were done at $3 \mathrm{mM}$ Ca, for other details see figure 3.2. The error bars represent the $95 \%$ confidence intervall of PC/PS.

annexinV binding. This gives the impression of an all or nothing effect (either no binding on "saturated" binding) when annexin V is used in cellular systems. This can partially explain why in cell population studies using annexin V-FITC in a flow cytometer hardly any intermediate labelling was found (Dachary-prigent et al. 1993, Vermes et al. 1995). Moreover cellular population dynamics play a role in each study as well (Dachary-prigent et al. 1993, Koopman et al. 1994, Martin et al. 1995, Vermes et al. 1995). Intermediate annexin $\mathrm{V}$ binding is only observed in a narrow range of PS mole fractions. Maximum binding of annexin $V$ is obtained when the available lipid 
surface is completely covered with annexin V. Such a saturation of binding was ascribed to the formation of a two dimensional array of annexin $V$ molecules (Andree et al. 1992, Brisson et al. 1991, Pigault et al. 1994).

The sensitivity of annexin $V$ binding is reduced when calcium concentrations below $3 \mathrm{mM}$ are used. Therefore, it is advisable to keep the calcium concentrations in the (Bayerl and Bloom, 1990) $\mathrm{mM}$ range. A slight increase in annexin $\mathrm{V}$ binding to pure PC bilayers in the presence of high $(10 \mathrm{mM})$ calcium concentrations has been reported previously by Andree et al. (1990) and Meers and Mealy (Meers and Mealy 1993a) and ascribed to non-specific binding to (possibly contaminating) negative charges (Andree ett al. 1990, Meers and Mealy 1993b).

Binding of annexin. $V$ to phospholipid layers containing phosphatidylethanolamine (PE) (in the absence of PS) has been reported by others (Andree et al. 1990, Meers and Mealy 1994). In many cell membranes $\mathrm{PE}$ is asymmetrically distributed with $\pm 20 \%$ of the membrane PE in the outer leaflet, which is approximately $6 \mathrm{~mol} \%$. This physiological $\mathrm{PE}$ content is not sufficient to elicit a positive annexin $\mathrm{V}$ signal. Our data indicate that $10 \mathrm{~mol} \% \mathrm{PE}$ in the membrane still gives a low annexin V-FITC signal. $\mathrm{PE}$ in the outer membrane leaflet will not perturb the use of annexin $\mathrm{V}$ as a probe for decreased membrane asymmetry or PS exposure. When the PE content further increases in the outer leaflet of the membrane, especially in combination with a slight increase in the PS concentration, a positive annexin V-FITC signal will be the result (at lower PS concentrations than in a pure PS/ PC system).

The addition of sphingomyelin had no effect on the annexin V-FITC binding to the phospholipid bilayer. Besides anionic PS, annexin V needs a phospholipid surface for its binding. Meers and Mealy describe the importance of the hydrophobic interactions at the $s n-2$ acyl chain and the interaction with the phosphate group for the binding of annexin V (Meers and Mealy 1993a,Meers and Mealy 1993b). In the case of sphingomyelin addition these conditions are not changed compared to PS/PC.

Incorporation of cholesterol into the phospholipid bilayer leads to a decrease of annexin V-FITC binding. This decrease can be partially explained by the reduced number of PS molecules per surface area as a result of the incorporation of cholesterol. This reduction of PS molecules per surface area is less than expected because cholesterol causes a decrease of the surface area occupied by phospholipids (Demell and Joos, 1968). The lack of an acyl chain and the absence of a phosphate group in cholesterol may cause the reduced annexin $\mathrm{V}$ binding (Meers and Mealy 1993a,Meers and Mealy 1993b).

Another way of detecting the loss of membrane asymmetry is the prothrombinase assay (Comfurius et al. 1994). The prothrombinase assay (Mann et al. 1990) is also mainly dependent on the PS concentration in the outer membrane leaflet and will increase upon increasing PE concentrations (Smeets et al. 1996). Studies on prothrombinase assays, however, are negatively influenced by sphingomyelin and not affected by cholesterol (Smeets et al. 1996) as was demonstrated by prothrombinase activity on sonicated vesicles with various phospholipid classes. Annexin V binding is known to be negatively influenced by high curvatures (Andree et al. 1992), which makes a direct comparison difficult. However, annexin V binding might thus not always be positively correlated with the prothrombinase activity. 
Annexin $\mathrm{V}$ is a sensitive probe for the study of early changes in membrane asymmetry before other changes become detectable, but we should keep in mind that binding of annexin $V$ can be elicited by a variety of lipid mixtures. Since the composition of the membranes may vary for each cell type under investigation, slight differences in the sensitivity of the probe for different cell types can be expected. In order to achieve maximum sensitivity of the annexin $\mathrm{V}$ probe, the calcium concentration should not be lower than $3 \mathrm{mM}$. When using annexin $V$ in cellular systems, one should realize that the assay conditions are often not optimal with respect to the concentrations of calcium . For the particular cell system under investigation the detection limit is not always the same as the detection limit found in a model study. The use of relevant lipid mixtures on glass beads and mimicking the further assay conditions, as described in this paper, is highly recommended for the interpretation of data obtained from such cellular binding studies.

\section{References}

Andree HA, Reutelingsperger CP, Hauptmann $\mathbb{R}$, Hemker HC, Hermens WT, Willems GM. (1990). Binding of vascular anticoagulant alpha (VAC alpha) to planar phospholipid bilayers. I. Biol. Chem. $265,4923-4928$.

Andree HA, Stuat MC, Hermens WT, Reutelingsperger CP, Hemker HC, Frederik PM, Willems GM. (1992). Chustering of lipid bound annexin V may explain its anticoagulant effect. J. Biol. Chem. 267, $17907-17912$.

Bayer TM, Bloom M. (1990). Physical properties of single phospholipid bilayers adsorbed to micro glass beads. Biophys. J. 58, 357-362.

Brisson A, Mosser G, Huber R. (1991). Structure of soluble and membrane-bound human annexin V. J. Mol. Biol. 220, 199-203.

Comfurius P, Bevers EM, Zwaal RF. (1994) Prothrombinase complex as a tool to assess changes in menbrane phospholipid asymmetry. In: Biomembrane protocols, II, architecture and function, Graham JM, Higgins JA (eds). Humania press, Totowa, New Jersey, pp, 131-142.

Dacharyprigent J, Freyssinet JM, Pasquet JM, Carron JC, Nurden AT. (1993). Arnexin-V as a Probe of Amino phospholipid Exposure and Platelet Membrane Vesiculation - A Flow Cytometry Study Showing a Role for Free Sulfhydryl Groups. Blood 81, 2554-2565.

Demel RA, Joos P. (1968). Interaction between lecithins and cholesterol at the air-water and oil-water interfaces. Chem. Phys. Lipids 2, 35-46.

Devaux PF. (1991). Static and dynamic lipid asymmetry in cell membranes. Biochemistry 30, 1163 1173.

Diaz C, Schroit AJ. (1996). Role of translocase in the generation of phosphatidylserine asymmetry. J. Membrane Biol. 151, 1-9.

Fadok VA, Voelker DR, Campbell PA, Cohen JJ, Bratton DL, Henson PM. (1992). Exposure of phosphatidy/serine on the surface of apoptotic lymphocytes triggers specific recognition and removal by macrophages. J. Lmmunol. 148, 2207-2216.

Giesen PL, Willems GM, Hermens WT. (1991). Production of thrombin by the prothrombinase complex is regulated by membrane-mediated transport of prothrombin. J. Biol. Chem. 266, 1379-1382.

Koopman G, Reutelingsperger CP, Kuijten GA, Keehnen RM, Pals ST, Vanoers MH. (1994). Annexin $V$ for flow cytometric detection of phosphatidylserine expression on $B$ cells undergoing apoptosis. 
Blood $84,1415-1420$.

Mann KG, Nesheim ME, Church WR, Haley P, Krishniaswany S. (1990). Surface-dependent reactions of the vitamin $\mathbb{K}$-dependent enzyme complexes. Blood $76,1+1.6$.

Martin SJ, Reutelingsperger CP, McGahon AJ, Rader JA, van Schie RC, LaFace DM, Green DR. (1995). Early redistribution of plasma membrane phosphatidylserine is a general feature of apoptosis regardless of the initiating stimulus: inhibition by overexpression of Bcl-2 and Abl. J. Exp. Med. 182 . $1545-1556$.

Meers P, Mealy T. (1993). Relation between annexin V tryptophan exposure, calcium, and phospholipid binding. Biochemistry 32, $5411-5418$.

Meers P, Mealy T. (1993). Calcium-Dependent Annexin-V Binding to Phospholipids - Stoichiometry, Specificity, and the Role of Negative Charge. Biochemistry 32, 11711-11721.

Meers P, Mealy T. (1994). Phospholipid deterninants for annexin V binding sites and the role of tryptophan 187. Biochemistry 33, 5829-5837.

Pigault C, Folleniuswund A, Schmutz M, Freyssinet JM, Brisson A. (1994). Formation of Two-Dimensional Arrays of Annexin V on Phosphatidylserine-Containing Liposomes. J. Mol. Biol. 236, 199-208.

Raynal P, Pollard HB. (1994). Annexins - The Problem of Assessing the Blological Role for a Gene Family of Multifunctional Calcium- and Phospholipid- Binding Proteins. Biochim. Biophys. Acta $1197,63-93$.

Smeets EF, Confuruis P, Bevers EM, Zwaal RF. (1996). Contribution of different phospholipid classes to the prothrombin converting capacity of sonicated lipid vesicles. Thromb. Res. 4, 419-426.

Stuart MC, Bevers EM, Comfurius P, Zwaal RF, Reutelingsperger CP, Frederik PM. (1995). Ultrastructural detection of surface exposed phosphatidy/serine on activated blood platelets. Thromb. Hacmostasis 74, 1145-1151.

Tait JF, Gibson D, Fujikawa K. (1989). Phospholipid binding properties of human placental anticoagulant protein-I, a member of the lipocortin family. II. Biol. Chem. 264, 7944-7949.

Thiagarajan $\mathbb{P}$, Tait JF. (1990). Binding of annexin V/placental anticoagulant protein I to platelets. Evidence for phosphatidylserine exposure in the procoagulant response of activated platelets. J. Biol. Chen. 265, 17420-17423.

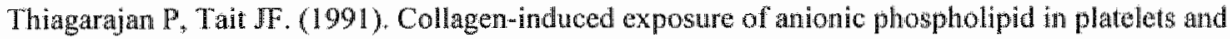
platelet-derived micro particles. J. Biol. Chem. 266, 24302-24307.

Vanheerde WL, Poort S, Vantweer C, Reutelingsperger CP, Degroot PG. (1994). Binding of recombinant annexin $V$ to endothelial cells: Effect of annexin $V$ binding on endothellat-cell-nediated thrombin formation. Biochemical J. 302, 305-312.

Vermes I, Haanen C, Steffensnakken H, Reutelingsperger CP. (1995). A novel assay for apoptosis Flow cytometric detection of phosphatidylserine expression on early apoptotic cells using fluorescein labelled Annexin V. J. Immunol. Methods 184, 39-51.

Zwaal RF, Schroit AJ. (1997). Pathophysiologic implications of membrane phospholipid asymmetry in blood cells. Blood 89, 1121-1132. 

Chapter 4

\section{Ultrastructural detection of surface exposed phosphatidylserine on activated blood platelets.}




\section{Summary}

Phosphatidylserine (PS) is normally restricted to the inner leaflet of the plasma membrane of cells (including blood platelets). Upon cell activation PS may become exposed to the outer surface of the cell. Cell membranes with surface exposed PS at the outside form a catalytic surface for coagulation reactions. When platelets are activated with ionophore or with thrombin in combination with thapsigargin, calcium induced scrambling of phospholipids takes place, resulting in PS exposure. Concomitant with PS exposition structural changes take place. On resting and activated platelets we combined the immunocytochemical detection of surface exposed PS with (ultra)structural information. Blood platelets were activated in the presence of annexin $V$, a protein which binds to PS in the presence of $\mathrm{Ca}^{2+}$. Annexin $\mathrm{V}$ was found to bind to lipid bilayers containing more than 5 mole \% PS as estimated by binding of fluorescent-labelled annexin $V$ to liposomes with varying PS concentrations. After vitrification, freeze-substitution and embedding of the platelets, annexin $V$ was located on ultra thin sections, as detected by an anti-annexin $V$ antibody and gold labelled protein A. Upon activation, the platelets show two different forms; irregular platelets with unchanged cytoplasm and round cells with apparently diluted cytoplasm. Activation with ionophore initially resulted in both forms, but after ten minutes only round platelets with diluted cytoplasm were observed. Both forms of these platelets as well as the microvesicles were found to be annexin V positive. However upon activation with thrombin in combination with thapsigargin, only the round cells with diluted cytoplasm and microvesicles were annexin $V$ positive, whereas platelets with unchanged cytoplasm, even when microvesicles are present, are negative for annexin $\mathrm{V}$. 


\section{Introduction}

Like most eukaryotic cells blood platelets have an asymmetrical distribution of phospholipids over their plasma membrane (Schroit and Zwaal, 1991, Devaux and Zachowski, 1994). The aminophospholipid phosphatidylserine (PS) is normally restricted to the inner leaflet of the plasma membrane. Cell activation, apoptosis and cell stress can induce redistribution of phospholipids and PS becomes rapidly exposed in the outer leaflet of the plasma membrane. Among the functions of surface exposed PS are macrophagal recognition (Schroit et al. 1985, Fadok et al 1992) and acceleration of the process of blood coagulation (Kalafatis et al. 1994). PS containing membranes constitute a catalytic surface for the vitamin $\mathrm{K}$-dependent coagulation factors resulting in a high rate of thrombin formation. The prothrombinase activity was found to be closely correlated with the amount of PS exposed in isolated, activated platelets (Bevers et al. 1982b, Bevers et al. 1983). Upon activation, the morphology of platelets changes from discoid to spherical with the formation of pseudopodia. This is accompanied by the shedding of highly procoagulant microvesicles from the plasma membrane, and a close relationship between microvesicle formation and loss of phospholipid asymmetry was observed (Sims et al. 1989). Several possibilities for the redistribution of phospholipids have been proposed. Sims and co-workers (Sims et al. 1989) suggested that shedding of microvesicles, accompanied by formation of an intermediate non-bilayer state of the lipid at the local fusion point, allows redistribution of phospholipids over both membrane leaflets. On the other hand Sulpice (Sulpice et al. 1994) proposed that interaction between calcium and phosphatidylinositol 4,5bisphosphate is required for transbilayer scrambling of membrane phospholipid to occur. Another possible explanation for loss of membrane lipid asymmetry is the presence of a calcium activated membrane protein (scramblase) which allows rearrangement of the lipids over the two leaflets of the membrane, resulting in PS exposure (Zwaal et al. 1993).

The aim of this study was to visualize, at an ultrastructural level, the exposure of PS and to relate this exposure to ultrastructural changes. We followed the formation of pseudopodia and microvesicles in combination with the localization of procoagulant surface upon activation with calcium ionophore A23187 or upon activation with thrombin, after pretreatment with thapsigargin, an inhibitor of intracellular $\mathrm{Ca}^{2 *}$ ATPase.

Several techniques have been described to detect the loss of membrane lipid asymmetry, in particular that of PS, e.g. chemical labelling (Schick et al 1976), prothrombinase assay (Bevers et all 1982b), phospholipase treatment followed by lipid analysis (Bevers et al. 1983), and specific PS binding proteins (Thiagarajan and Tait 1990). In this study we have employed the phospholipid binding protein annexin $V$, which inhibits prothrombinase (Reutelingsperger et al. 1985), and has a high preference for PS. The high affinity of annexin $V$ for PS at physiological extracellular $\mathrm{Ca}^{2+}$ concentrations (Andree et al. 1990) makes it a very attractive probe to monitor PS exposure. Recently, several groups have demonstrated that fluorescently labelled 
annexin $V$ can be used to detect procoagulant platelets and microvesicles by flow cytometry (Thiagarajan and Tait 1990, Dachary-Prigent et al. 1993). In this paper we describe for the first time the localisation of surface exposed PS at an ultrastructural level with annexin $V$ as a probe, using immunocytochemistry for visualisation. The detection limit of annexin $V$ for $P S$ exposed at the surface was determined with fluorescent labelled annexin $V$ on liposomes with varying PS concentrations in a flow cytometer.

Platelet activation is a dynamic process, shape and phospholipid distribution can change rapidly, and therefore an instantaneous arrest of the process is essential. By vitrification of a platelet suspension we can stop the activation process in the millisecond range, which is faster than with chemical fixation. Freeze substitution after vitrification has proved to preserve ultrastructure as well as antigenicity (Voorhout et al. 1991). Moreover extraction of lipids is reduced when uranylacetate is added to the freeze-substitution medium (Humbel and Schwarz, 1989). Especially the reduction of lipid extraction is important for the preservation of microvesicles because with conventional techniques they are largely dissolved in organic solvents. Structural analysis and localization of annexin $V$ was done on ultra thin sections after embedlding the blood platelets in lowicryl K4M. The appearance of PS and ultrastructural changes were observed at different time intervals and with high spatial resolution.

\section{Materials and Methods}

\section{Materials}

Thapsigargin, bovine brain sphingomyelin, dioleoylphosphatidylcholine (DOPC) and dioleoyl-phosphatidylethanolamine (DOPE) were obtained from Sigma chemical company (St. Louis, MO). Ionophore A23187 was from Calbiochem-Hoechst (San Diego, CA). Recombinant annexin V was prepared as described before (Maurer-Fogy et al. 1988). FITC-labelled annexin $V$ was made as described (Koopman et al. 1994, Tait et al. 1989). Anti annexin $V$ was raised against human annexin $V$ in rabbits. The polyclonal IgG fraction was affinity purified and had a final concentration of 140 $\mu \mathrm{g} / \mathrm{ml} \mathrm{IgG.} \mathrm{Thrombin} \mathrm{was} \mathrm{purified} \mathrm{from} \mathrm{bovine} \mathrm{blood} \mathrm{as} \mathrm{reported} \mathrm{before} \mathrm{(Rosing} \mathrm{et} \mathrm{al.}$ 1985). Dioleoylphosphatidylserine (DOPS) was delivered by Avanti polar lipids (Alabaster, AL). $10 \mathrm{~nm}$ Gold labelled with protein A was purchased from Aurion (Wageningen, The Netherlands). All other reagents used were of analytical grade.

\section{Blood platele isolation}

Fresh venous blood from healthy volunteers was collected into anticoagulant acid citrate dextrose $(0.18 \mathrm{M}$ glucose, $0.08 \mathrm{M}$ Trisodium citrate, $0.052 \mathrm{M}$ citric acid) $(5: 1, v / v)$, and platelets were washed by differential centrifugation (Bevers et al. 1982a). The platelets were resuspended in Hepes buffer ( $137 \mathrm{mM} \mathrm{NaCL}, 2.68 \mathrm{mM}$ $\mathrm{KCl}, 10 \mathrm{mM}$ Hepes, $1.7 \mathrm{mM} \mathrm{MgCl}, 25 \mathrm{mM}$ glucose and $0.05 \%$ human serum albumin $\mathrm{pH}$ 7.4) to a final concentration of $1.10^{8} / \mathrm{ml}$. Before the experiments $3 \mathrm{mM} \mathrm{CaCl}_{2}$ was added to all platelet suspensions. 


\section{Platelet activation}

Platelet suspensions used for thrombin activation were first incubated with $75 \mathrm{nM}$ thapsigargin (23) to enhance the effect of thrombin. Armexin $V$ was added to all platelet suspensions, to a final concentration of $10 \mu \mathrm{g} / \mathrm{ml}$ prior to activation with either $4 \mathrm{nM}$ bovine thrombin or $1 \mu \mathrm{M}$ calcium ionophore $\mathrm{A} 23187$. Platelets were activated for 1 to 10 minutes without stirring.

\section{Virrification and Freeze substitution}

After activation a $1 \mathrm{ml}$ syringe was filled with the platelet suspension and a jet nozzlo was placed at the needle end of the syringe. The jet nozzle was made of a $50 \mu \mathrm{m}$ platinum electron microscopic aperture (Bachmann and Schmit-Fumian 1973) glued to a plastic cap fitting on the needle end of the syringe. The suspension was jetted with a very fine stream into heavily stirred liquid ethane cooled to its melting point with liquid nitrogen. The outflow out of the aperture was of constant diameter over several centimetres. After vitrification of the suspension, the container with ethane and vitrified suspension was transferred to a massive copper block cooled to $-100^{\circ} \mathrm{C}$. The block and cylinder were placed in a desiccator and the ethane was evaporated under vacuum (100 Torr), while continuously stirred. The vitrified platelet suspension was then transferred in the substitution medium, methanol containing $0.5 \%$ uranyl acetate. In preliminary experiments we found that the antigenicity of annexin $V$ was lost after aldehyde fixation and thus aldehyde fixatives were omitted in the freeze substitution process (cf. Morgenstern 1991). Freeze substitution was carried out in a home built freeze substitution apparatus. This freeze substitution apparatus was based on a styrofoam box with a built in cold plate cooled with liquid nitrogen (Müller et al. 1980). The temperature was controlled by a modified LKB 14803 temperature control unit from a cryo-microtome. Freeze substitution was initiated at $-90^{\circ} \mathrm{C}$ (methanol with $0.5 \%$ uranyl acetate) and the temperature was increased to $-30^{\circ} \mathrm{C}$ in four steps, each step taking at least eight hour. At $-30^{\circ} \mathrm{C}$ the substitution medium was replaced by pure methanol (minimal eight hours) followed by infiltration in a mixture of equal parts of methanol and Lowicryl K4M. The platelets were finally infiltrated in Lowicryl K4M at $-20^{\circ} \mathrm{C}$ and polymerized under indirect UV light at $-20^{\circ} \mathrm{C}$ for at least 12 hour.

\section{Immunocytochemistry}

From the Lowicryl blocks ultra thin sections were cut on a Reichert ultra cut and collected on 75 mesh copper grids coated with a support film. The sections were rinsed on PBS containing $0.1 \%$ bovine serum albumin (BSA fraction V). The sections were incubated, for one hour, with anti annexin V diluted $1 / 20$ in PBS containing $1 \%$ BSA. After the incubation the sections were washed three times on PBS $0.1 \%$ BSA. Labelling of the anti-annexin $V$ was done with protein- $A / 10 \mathrm{~nm}$ gold diluted $1 / 20 \mathrm{in}$ PBS containing $1 \% \mathrm{BSA}$. The sections were incubated for at least one hour, followed by a three times wash on PBS $0.1 \%$ BSA. To enlnance contrast, the sections were stained with neutral uranyl acetate for five minutes. The specimens were observed in a Philips CM 10 electron microscope operating at $80 \mathrm{keV}$. 


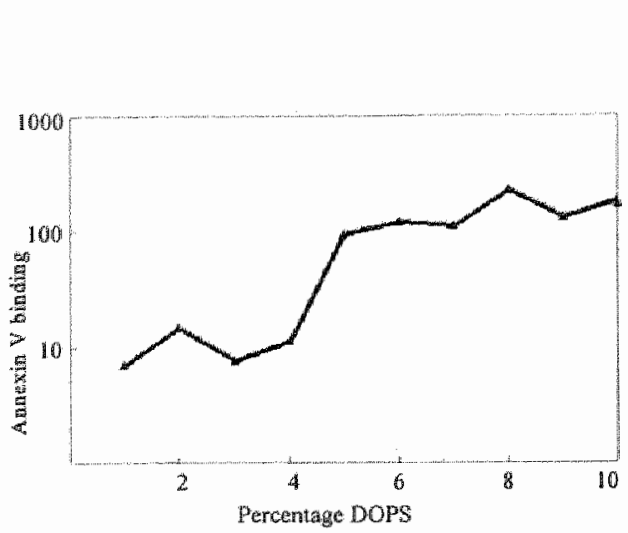

Flow cylometry

By flow cytometry the binding of FITClabelled annexin $V$ to (multi-lamellar) liposomes was measured. The lipid composition used for the liposomes represents the composition of the major phosphol classes of the platelet membrane (Bevers et al. 1982b). Annexin $\mathrm{V}$ binding was measured as a function of the PS concentration. Chloroform solutions of DOPC, DOPE, sphingomyelin were mixed to a molar ratio of DOPC:DOPE:sphingomyelin, 4:3:2 and a cholesterol to phospholipid molar ratio of $1: 2$. DOPS was added to this mixture in a range of

Figure 4.11 Annexin $V$ binding to phospholipid wesicles as a function of the phosphatidylserine concentration. The vesicles were prepared from dioleoylphosphatidylcholine, dioleoylphosphatidylone to ten mole percent of the total phospholipid. After evaporation of the chloroform under nitrogen, $\mathbb{\mathrm { ml }}$ buffer $(10$ ethanolamine, sphingomyelin in a ratio of $4: 3: 2 \mathrm{mM}$ TRIS HCl pH 7.4 containing $100 \mathrm{mM}$ and cholesterol (cholesterol phospholipid molar $\mathrm{NaCl}$ and $3 \mathrm{mM} \mathrm{CaCl}$ ) was added and ratio 1:2) and varying and dioleoyl-phosphatidyl- liposomes were made by vigourous serine (DOPS) concentrations $(0-10$ mole $\%$ ). Annexin V-FITC binding was measured in arbitrary units on a flow cytometer, gated by forward and side scatter.

vortexing for ten minutes. The liposome suspensions were diluted in the same buffer to a concentration of $50 \mu \mathrm{M}$ phospholipid. Annexin V-FITC (Koopman et al. 1994, Tait et al. 1989) was added to the suspension in a concentration of $10 \mu \mathrm{g}$ annexin $\mathrm{V}$ per $\mathrm{ml}$. The liposomes were incubated with fluorescent annexin $\mathrm{V}$ in the dark for ten minutes. Annexin $\mathrm{V}$ binding was measured on a Becton \& Dickinson FACSort flow cytometer operating with Lysys II Ver I. I software.

\section{Results}

Figure 4.1 displays the average annexin $\mathrm{V}$ binding to liposomes, gated by forward and side scatter, as a function of the DOPS concentration. To liposomes with $0-4$ mole $\%$ DOPS, no appreciable binding of annexin $V$ could be detected. At molar ratio's of 5 mole \% DOPS and higher, maximum binding of annexin $\mathrm{V}$ was observed.

The majority of the platelets show a typical morphology of unactivated cells after vitrification and freeze substitution. Resting platelets (figure 4.2) are mostly disk shaped with a smooth outline, but sometimes with a few pseudopodia. The granules are present and a band of microtubules can be observed when the section contains this part of the circumference of the platelet. The contrast in the image is usually rather poor because only uranyl acetate is involved in contrast enhancement during substitution and treatment of the section. Upon activation with ionophore two types of 
morphological different "cells" can be seen in the sections. One type are irregular blood platelets with unchanged electron opaque cytoplasm, containing granules and open canalicular system (fig $4.3 \mathrm{a}$ ). The other type of platelets are round cells with apparently diluted cytoplasm and some microvesicles. trapped inside (fig 4.3b); this type of platelets seems to be the end stage in the activating process with $\mathrm{Ca}^{2}$ ionophore. Similar structures have been observed by Gerrard and co-workers (Gerrard et al. 1974) after ionophore activation of blood platelets. The proportion of cells in this stage increases upon longer activation times and after ten minutes of activation with $\mathrm{Ca}^{2+}$ ionophore, all blood platelets have reached this stage. Apart from the two types of cells, also microvesicles are

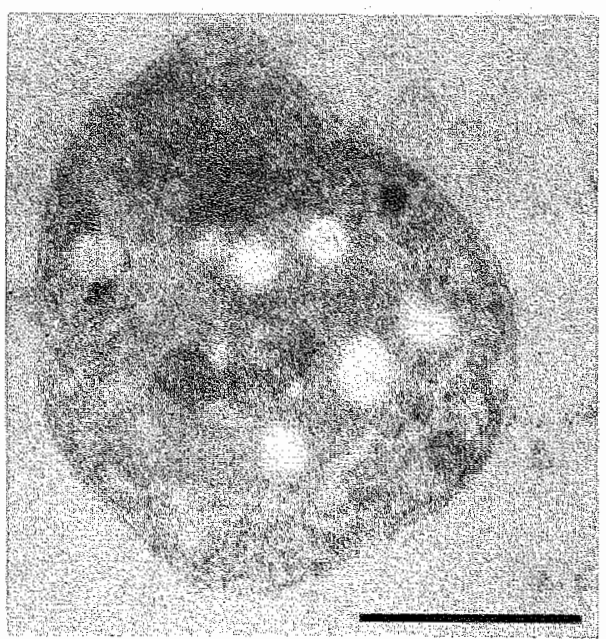

Figure 4.2 Resting blood platelet, vitrified from a suspension, in the presence of $10 \mu \mathrm{g} / \mathrm{ml}$ annexin $\mathrm{V}$, by jet freezing in ethane, freeze-substituted and embedded in lowicryl K4M. Sections stained with neutral uranylacetate. Bar represents 1 mm. observed (fig 4.3c). After one to ten mimutes of ionophore activation all membrane structures found were positively labelled for annexin $\mathrm{V}$ (involving the plasma membrane, the open canalicular system, as well as microvesicles; see fig $4.3 \mathrm{c}, \mathrm{d}, \mathrm{e})$. When platelets pretreated with thapsigargin were activated by thrombin, essentially the same types of cellular structures can be found intermingled in the sections; activated platelets with unchanged, electron opaque, cytoplasm, irregular shaped and with pseudopodia (fig 4.4a) and round swollen cells with apparently diluted cytoplasm (fig 4.4b), including microvesicles shed from the outer margins of the plasma membrane (fig 4.4c) and microvesicles shed and trapped in the open canalicular system (fig 4.4d). After ten minutes of platelet activation with thrombin, pretreated with thapsigargin, only about $50 \%$ of the cells have turned into the end stage of round swollen cells with apparently diluted cytoplasm. All microvesicles, trapped or loose, were found to be annexin $V$ positive (fig $4.4 c$, d) as well as the rounded end stage cells (fig 4.4b). The platelets with morphological signs of activation such as pseudopodia and formation of microvesicles, but with unchanged, electron opaque, cytoplasm were always annexin $\mathrm{V}$ negative on the outer plasma membrane and open canalicular system (apart from focal microvesicles) even after ten minutes of activation (fig 4.4d).

The usefulness of annexin $V$ to detect procoagulant surfaces in this system was tested by using the prothrombinase complex (factor $\mathrm{Va}, \mathrm{Xa}$ ) instead of annexin $\mathrm{V}$ as a probe. The presence of procoagulant surface was located in this system by using an antibody against Xa (images not shown). The results were analogous to those presented using annexin $\mathrm{V}$. Anmexin $\mathrm{V}$, however, was preferred as a probe because the reproducibility was better and the background labelling with anti-annexin $V$ was less than with antifactor $\mathrm{Xa}$. 

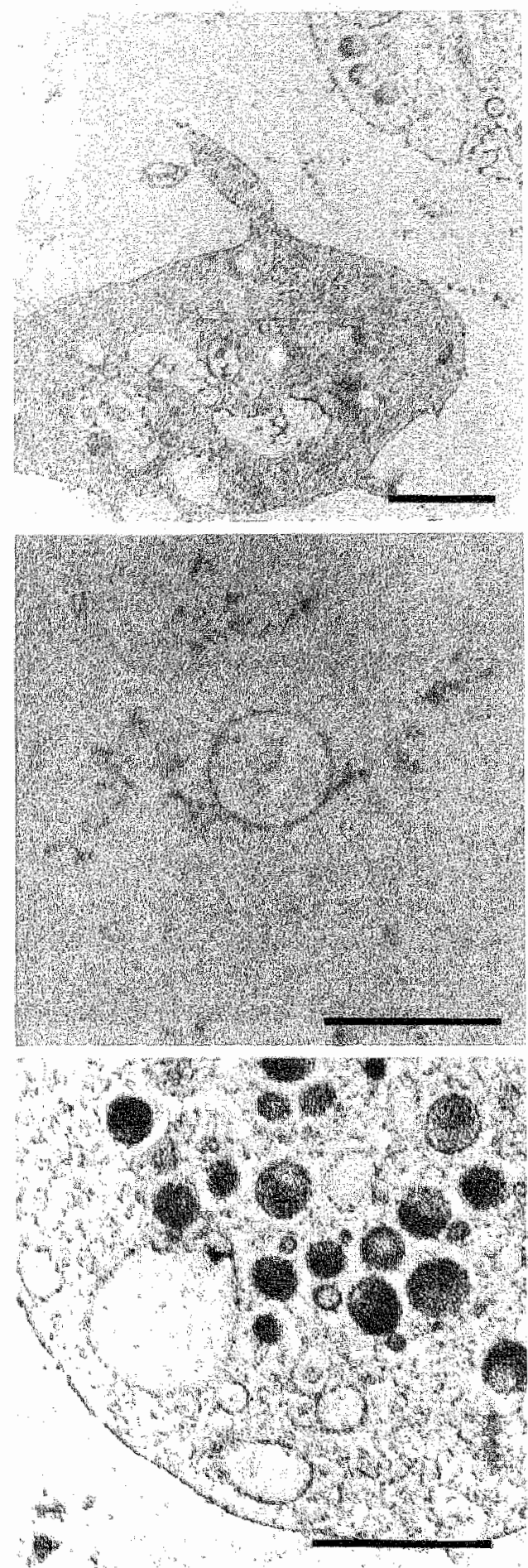
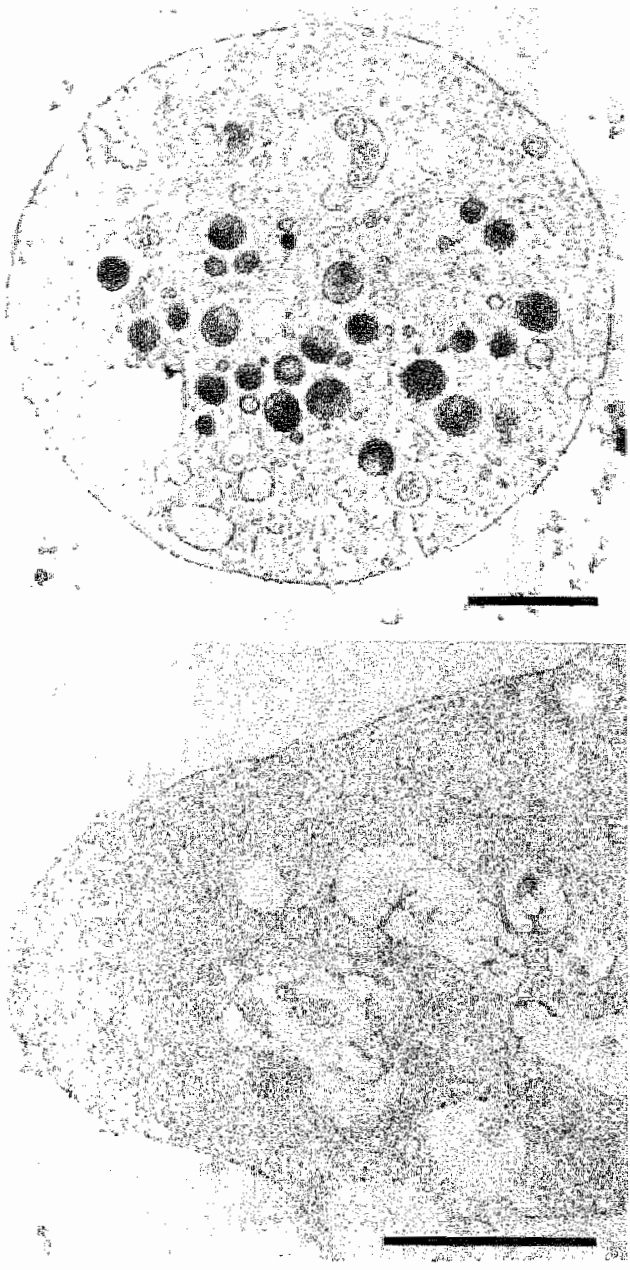

Figure 4.3 Blood platelets activated with $3 \mathrm{mM}$ $\mathrm{CaCl}_{2}$ and $1 \mu \mathrm{M}$ calcium ionophore $\mathrm{A} 23187$ in the presence of $10 \mu \mathrm{g} / \mathrm{ml}$ annexin $\mathrm{V}$ (vitrified, freeze-substituted and embedded as in fig. 4.2). Sections were labelled with antibodies raised against annexin $\mathrm{V}$. a) Activated for one minute. Platelet with unchanged cytoplasm and round swollen cell with apparently diluted cytoplasm (upper right). Both types of cells are labelled with gold. b) Activated for two minutes. Round cell with diluted cytoplasm. c) Micro vesicle pinched off liom a platelet labelled with gold. d) high magnification from $3 a$. Note the labelling on the cell membrane and open canalicular system. e) High magnification from $3 \mathrm{~b}$. Bar represents $1 . \mu \mathrm{m}$. 


\section{Discussion}

The sensitivity for the detection of surface exposed PS by annexin V on ultra thin sections was estimated on the basis of flow cytometer experiments on liposomes. The lipid composition of the liposomes resembles that of the platelet membrane. The data on liposomes can be extrapolated to platelets considering that annexin $\mathrm{V}$ and $\mathrm{Ca}^{2}$ * concentrations were the same, and assuming that interaction between annexin $\mathrm{V}$ and platelets depends on exposition of anionic PS. Liposomes containing 0 to 4 mole percent DOPS did not show any appreciable annexin $V$ binding. Once the molar ratio reaches 5 mole percent DOPS or more, maximum binding of annexin $V$ was observed. This steep change from no annexin $\mathrm{V}$ binding to maximum bindling by a slight increase of the molar ratio of PS, as observed in flow cytometer studies, may explain the observation that with platelets either positive or negative labelling on the sections is observed, apparently without an intermediate stage. This has also been observed in flow cytometer experiments, using fluorescent annexin $\mathrm{V}$ binding to platelets activated with collagen in combination with thrombin, in which the annexin $V$ positive population was well separated from the annexin $V$ negative population without an intermediate population (Dachary-Prigent et al. 1993).

The results presented in this paper demonstrate that the vitrification and freezesubstitution technique as applied in this study is suitable for the immunocytochemical localisation of annexin $\mathrm{V}$ binding on activated platelets. The ultrastructure of the majority of the platelets was well preserved during the preparative steps, only a few platelets show ice crystal damage due to slow cooling. The results confirm that the jetting of a cell suspension through a $50 \mu \mathrm{m}$ aperture results in an appropriate cryofixation as was reported before with paramecium cells (Knoll et al. 1991). $\mathrm{Ca}^{2+}$ ionophore is known to be a strong (none physiological) activator of blood platelets, which results in an increase of the prothrombinase activity to its maximum level within one minute (Comfurius et al. 1990). Both types of activated cells (fig.4.3 $a, b$ ) as well as microvesicles appear to have lost their membrane asymmetry within one minute as was shown by the presence of annexin $V(f i g ~ 4.3 \mathrm{c}, \mathrm{d}, \mathrm{e}$ ). When the platelets were activated with thrombin after pretreatment with thapsigargin, the activation is slower in time than with ionophore (Smeets et al. 1993). Upon this type of activation, prothrombinase activity reaches its maximum in about ten minutes after platelet activation. The final level of prothrombinase activity was approximately half of that found with $\mathrm{Ca}^{2+}$ ionophore activation (Smeets et al. 1993, Comfurius et al. 1990). Microvesicles trapped within the open canalicular system and microvesicles free in suspension have lost their membrane asymmetry and PS became exposed to the outside of the plasma membrane (as demonstrated by Annexin $\mathrm{V}$ binding, see fig. 4.4c, d). The extent of prothrombinase activity and microvesicle formation of platelets activated with thrombin plus thapsigargin is very similar to that of platelets activated with thrombin plus collagen (Zwaal et all 1992). However, the latter activation is less suitable for ultrastructural studies using annexin $V$ to probe the outer membrane surface. The present study shows that the cell fraction after activation contains two major classes of cells: round swollen cells with diluted cytoplasm and irregular shaped 

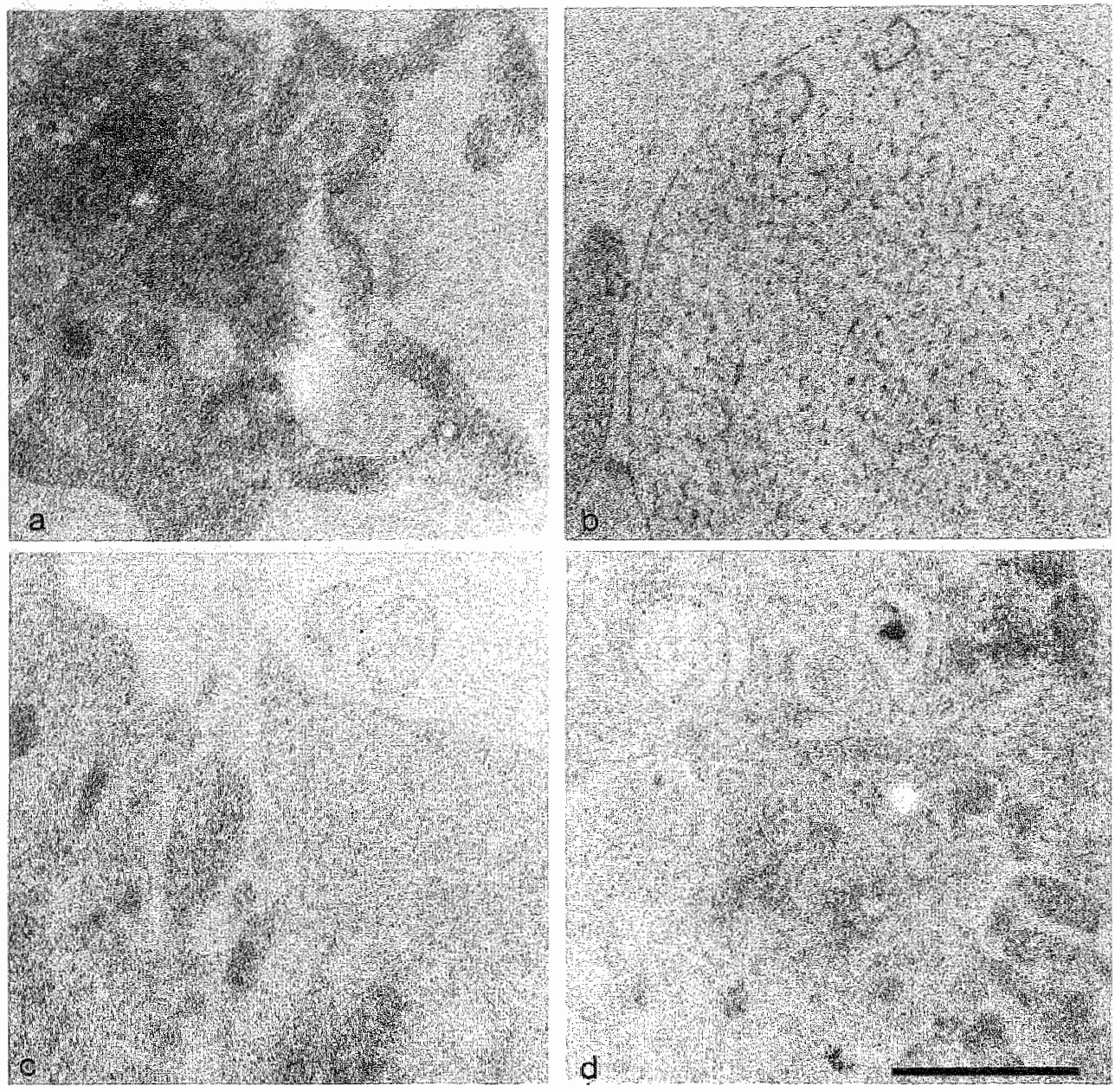

Figure 4.4 Blood platehets, preincubated with $75 \mathrm{nM}$ thapsigargin, activated with $4 \mathrm{mM}$ thrombin in the presence of $3 \mathrm{mM} \mathrm{CaCl}$ and $10 \mu \mathrm{g} / \mathrm{ml}$ annexin $\mathrm{V}$ (vitrified, freeze-substituted, embedded and labelled as in fig. 4.3), a) Platelet activated for ten minutes. Pseudopodia are formed, the open canalicular system is swollen, the central part has contracted and the cytoplasm is unchanged. No label for annexin $V$ is present. b) Platelet activated for ten minutes. Round cell with diluted cytoplasm. Cell membrane and enclosed membraness are labelled with annexin $V$. Note: part of a pseudopodium (left) has an unchanged cytoplasm and no label on its cell membrane. Cells with such a morphology and cells with morphology shown in fig 4.4a are found in the same preparation. c) Activated for two minutes. Two procoagulant microvesicles are pinched off from the membrane. The cell membrane of this platelet with unchanged (electron opaque) cytoplastn seems to have maintained phospholipid asymmetry. d) Activated for ten minutes. Microvesicle formed and trapped in the open canalicular system. Note: only the microvesicle is labelled with gold. Bar represents $1 \mu \mathrm{m}$.

platelets with virtually unchanged cytoplasm (fig $4.4 \mathrm{a}, \mathrm{b}$ ). It is remarkable that thrombin activated platelets with unchanged cytoplasm are not labelled with gold, indicating that the PS concentration in the outer membrane leaflet has not reached 5 mole $\%$, although the platelets clearly show features of stimulation. Such features 
include the formation of pseudopodia, loss of granules, a shrunken central part of the platelet, a swollen open canalicular system and microvesicles presumably in the process of being pinched off from the plasma membrane. Although microvesicles with markedly exposed PS have been pinched of (fig. $4.4 \mathrm{c}, \mathrm{d}$ ), PS in the outer leaflet of the platelet membrane remained below 5 mole \%. Since in unactivated platelets, plasma membrane PS is almost exclusively present in the inner membrane leaflet at a concentration of approx. 20 mole \%, this implies that annexin $V$ labelling can be visualized when more than $25 \%$ of the membrane PS has migrated to the outer leaflet. Therefore, it can be concluded that the round swollen cells with diluted cytoplasm exhibit a more dramatic loss of phospholipid asymmetry than the activated cells with unchanged cytoplasm. It should be mentioned that the loss of phospholipid asymmetry is not directly due to a loss of mechanisms maintaining the normal non-random phospholipid distributions (Schroit and Zwaal 1991, Devaux and Zachowski 1994) but requires a different process that strongly depends on the level of cytoplasmic $\mathrm{Ca}^{2+}$ (Zwaal et al 1993). The data presented in this paper indicate that the loss of membrane phospholipid asymmetry is a phenomenon with local differences in the extent of PS exposure when platelets are activated by thrombin plus thapsigargin, as compared to the activation with $\mathrm{Ca}^{2+}$ ionophore (see also Stuart et al. 1992). Previous reports on prothrombinase activity where microvesicles were separated from so called "remnant cells" by centrifugation (Comfurius et al. 1992) can be annotated in view of the results presented in this paper. In biochemical studies, the cell pellet might contain the two types of cells; one type assumed to be the end state after activation in which membrane phospholipid asymmetry is lost to a greater extent than in the other type consisting of platelets with a morphological unchanged cytoplasm. In addition, both types of cells may contain trapped microvesicles which can contribute to the apparent prothrombinase activity. It should be realized that in flow cytometric experiments using fluorescent Annexin V (Dachary-Prigent et al. 1993), trapped procoagulant microvesicles, in the open canalicular system (since it was accessible for exogenously added annexin V) can contribute to a positive signal for platelets with otherwise largely intact phospholipid asymmetry of their plasma mernbranes. The results presented in this paper demonstrate that the loss of membrane phospholipid asymmetry as probed with Annexin $V$ is a local phenomenon upon activation of platelets in suspension. An increase in the exposed PS (above 5 mole \% PS) is apparently accompanied by a drastic morphological change. Progressive loss of membrane asymmetry is presumably restricted to distinct ultrastructural entities, such as nicrovesicles and the plasma membrane of the platelets in an end stage of activation.

\section{References}

Andree HA, Reutelingsperger CP, Hauptmann R, Hemker HC, Hermens WT, Willems GM. (1990). Binding of vascular anticoagulant alpha (VAC alpha) to planar phospholipid bilayers. I. Bioll. Chem. $265,4923-4928$.

Bachmann L, Schmitt-Fumian WW. (1973). Spray-freezing and freeze-etching. In: Freeze-etching techniques and applications. EL Benedetti and P Favard, eds. Société Française de Microscopie Électronique Paris, pp. 73-79. 
Bewers $\mathrm{EM}$, Comfuris $\mathrm{P}, \mathrm{Z}$ waal R.F. (1982a). The nature of binding site for prothrombinase at the platelet surface as revealed by lipolytic enzymes. Eur. J. Biochem. 122, 81-85.

Pevers EM, Comfurius P, Rijn J, Hemker HC, Zwaal RF. (1982). Generation of prothrombin-converting activity and the exposure of phosphatidylserine at the outer surface of platelets. Eur, I. Biochem. 122, 429-436.

Bevers EM, Comfurius $P$, Zwaal RF. (1983). Changes in membrane phospholipid distribution during platelet activation. Biochim. Biophys. Acta, 736, 57-66.

Comfurius P, Senden JM, Tilly RH, Schroit AJ, Bevers EM. Zwaal RF. (1990). Loss of membrane phospholipid asymmetry in platelets and red cells may be associated with calcium-induced shedding of plasma membrane and inhibition of aminophospholipid transllocase. Biochim. Biophys. Acta, 1026, $153-160$.

Dachary-Prigent $\mathbb{J}$, Freyssinet JM, Pasquet JM, Carron JC, Nurden AT. (1993). Annexin-V as a Probe of Aminophospholipid Exposure and Platelet Membrane Vesiculation - A Flow Cytometry Study Showing a Role for Free Sulthydryl Groups. Blood, 81, 2554-2565.

Devaux PF, Zachowski A. (1994). Maintenance and consequences of membrane phospholipid asymmetry. Chem. Phys. Lipids, 73, 107-120.

Fadok VA, Voelker DR, Canpbell PA, Cohen JJ, Bratton DL, Henson PM. (1992). Exposure of phosphatidylserine on the surface of apoptotic lymphocytes triggers specific recognition and removal by macrophages. J. Immunol. 148, 2207-2216.

Gerrard IM, white IG, Rao GH. (1974). Effects of the lonophore A23187 on the blood platelets II. Influence on ultrastructure. Am. J. Pathol. 77, 151-66.

Humbel BM, Schwarz H. (1989). Freeze-substitution for immunochemistry. Im: Immunomgold labeling in cell biology. Verkleij AJ, Leunissen JL, eds. CRC Press Inc. pp 115-134.

Kalafatis M, Swords NA, Rand MD, Mann KG. (1994). Membrane dependent reactions in blood coagulation: role of vitamin $\mathbb{K}$-dependent enzyme complexes. Biochim. Biophys. Acta, 1227, 113-129.

Knoll G, Braun C, Plattmer H. (1991). Quenched flow analysis of exocytosis in paramecium cells: Time coarse, changes in membrane structure, and calcium requirements revealed after rapid mixing and rapid freezing of intact cells. J. Cell Biol. 113, 1295-1304.

Koopman G. Reutelingsperger CP. Kui.ten GA. Keehnen RM. Pals ST. Vanoers MH. (1994). Annexin $\checkmark$ for llow cytometric detection of phosphatidylserine expression on B cells undergoing apoptosis. Blood, 84, 1415-1420.

Matrer-Fogy I, Reutelingsperger CP, Pieters J, Bodo G, Stratowa C, Hauptmann R. (1988). Cloning and expression of cDNA for human wascular anticoagulant, a Ca2t-dependent phospholipid-binding protein. Eur. J. Biochem. 174, 585-592.

Morgenstem E. (1991). Aldehyde fixation causes membrane wesiculation during platelet exocutosis: $\mathrm{A}$ freeze-substituion study Scanning Microscopy; 5, S109-115.

Müller M, Marti TH, Kriz S. (1980). Improved structural preservation by freeze-sustitution, Proc. 7th. Eur. Reg. Conf. Electron microscopy, The Hague, 2, 720.

Reutelingsperger $\mathrm{CP}$, Honstra $\mathrm{G}$. Hemker HC. (1985). Isolation and partial purification of a novel anticoagulant from arteries of human umbilical cord. Eur. J. Biochem. 151, 625-629.

Rosing J, van Rijn JL, Bevers EM, van Dieijen $G_{3}$ Comfurius $P_{3}$ Zwaal RF. (1985). The role of activated human platelets in prothrombin and factor $X$ activation. Blood, 65, 319-332.

Schick PK. Kurica KB, Chacko GK. (1976). Location of phosphatidylethanolamine and phosphatidy/serine in the human platelet plasma membrane. J. Clin. Invest. 57, 1221-1226. 
Schroit AJ, Madsen JW, Tanaka Y. (1985). In vivo recognition and clearance of red blood cells containing phosphatidylserine in their plasma membranes. J. Biol. Chem. 260, $513 \mathrm{l}-5138$.

Schroit AJ, Zwaal RF, (1991). Transbillayer movement of phospholipids in red cell and platelet membranes. Biochim. Biophys. Acta, 1071, 313-329.

Sims $\mathbb{P J}$, Wiedmer T, Esmon CT, Weiss HJ, Shattil SJ. (1989). Assembly of the platelet prothrombinase complex is linked to vesiculation of the platelet plasma membrane J. Biol. Chent. 264. $17049-17057$.

Smeets EF, Heemskerk JW, Confurius P, Bevers EM, Zwaal RF. (1993). Thapsigargin amplifies the platelet procoagulant response caused by thrombin. Thromb. Haemostasis, 70, 1024-1029.

Stuat MC, Bevers EM, Comfurius P, Zwaal RF, Frederik PM. (1992). Cryo-electron microscopic observation of blood platelet activation and the localization of procoagulant surface. Electron Microscopy. 3, 139-140, EUREM 92 , Granada, Spain.

Sulpice JC, Zachowski A, Devaux PF, Giraud F. (1994). Requirement for phosphatidylinositol 4,5\% bisphosphate in th $\mathrm{Ca}^{2+}$-induced phospholipid redistribution in the human erythrocyte membrane. I. Biol. Chem. 269, 6347-6354.

Tait JF, Gibson D, Fujikawa K. (1989). Phospholipid binding properties of thuman placental anticoagulant protein-I, a member of the lipocortin family. J. Biol. Chem. 264, 7944-7949.

Thiagarajan P, Tait JF. (1990). Binding of annexin V/placental anticoagulant protein I to platelets. Evidence for phosphatidylserine exposure in the procoagulant response of activated platelets. J. Biol. Chern. 265, 17420-17423.

Voorhout W, van Genderen I, van Meer $G$, Geuze H. (1991). Preservation and immunogold localization of: lipids by freeze-substitution and low temperature embedding. Scanning Microscopy; 5 , S17-24.

Zwaal RF, Comfurius P, Bevers EM. (1992). Platelet procoagulant activity and microvesicle formation. Its putative role in hemostasis and thrombosis. Biochim. Biophys. Acta, 1180, 1-8.

Zwaal RG', Comfurius $P_{3}$ Bevers EM. (1993). Mechanism and function of changes in membrane-phospholipid asymmetry in platelets and erythrocytes. Biochem. Soc. T. 21, 248-53. 

Chapter 5

Surface exposure of phosphatidylserine during apoptosis of rat thymocytes precedes nuclear changes. 


\section{Abstract}

Cell surface exposure of phosphatidylserine (PS) during apoptosis serves recognition and removal of the dying cell by phagocytes. Loss of phospholipid asymmetry and PS exposure is investigated by immunocytochemistry and related to morphological changes. Loss of membrane asymmetry was determined on dexamethasone treated rat thymocytes using the PS specific probe annexin V. Thymocytes incubated in the presence of dexamethasone were studied in time series during the execution of the apoptotic program. Thymocytes first start to expose PS at their cell surface. At this initial stage the barrier function of the plasma membrane remains intact. At a later stage the plasma membrane becomes leaky for compounds like propidium iodide and subsequently the cell disintegrates into apoptotic bodies. Microscopical evaluation of dexamethasone treated thymocytes showed that the cells with an apoptotic morphology all bound annexin $\mathrm{V}$. The cells with a normal viable morphology lacked annexin $\mathrm{V}$ binding except for those cells that started to shed small vesicles. These vesicles were positive for annexin $\mathrm{V}$, indicating a local disturbance of the phospholipid asymmetry. The local exposure of PS is considered as a very early event of apoptosis, preceding the full sequence of morphological changes at the ultrastructural level. 


\section{Introduction}

Apoptosis entails gene-regulated processes of cell suicide, silent death and removal without inflammatory response. These apoptotic processes are characterized by a sequence of morphological alterations, which are clearly distinguishable from necrosis (Kerr et al. 1995). At the ultrastructural level rapid blebbing of the cell membrane (Sanderson, 1982) and chromatin condensation (Thomas and Bell, 1981) can be observed during the first stage of apoptosis. These changes are often but not always accompanied by nuclear convolution, followed by nuclear pycnosis and cell shrinkage. Also a number of biochemical changes takes place considered to be typical for apoptosis. The main biochemical feature of apoptosis is DNA cleavage at the internucleosomal sites, by calcium activated endonucleases (Arends et al. 1990, Hockenbery, 1995, Wyllie, 1980). This results in the typical DNA laddering on agarose gels, which is considered as the biochemical hallmark of apoptosis. However, this hallmark is not always present, some cell types show apoptotic morphology without demonstrable DNA laddering (Cohen et al. 1992, Oberhammer et al, 1993). Other biochemical processes underlying the morphological changes of apoptosis include the degradation of nuclear lamins and cytoskeletal proteins by activated proteases (Martin and Green, 1995). During execution of apoptosis the cell changes its phospholipid asymmetry of the plasma membrane by translocating phosphatidylserine (PS) to the outer leaflet where it functions as a tag on the dying cell for recognition and removal by phagocytes (Fadok et al. 1992a, b). Contrary to the apoptotic cell the viable cell retains PS exclusively in the inner leaflet by energy dependent processes (Diaz and Schroit, 1996, Zwaal and Schroit, 1997).

With the use of annexin $\mathrm{V}$, a phospholipid binding protein with high affinity for PS (Andree et al. 1990, Tait et al. 1989, Vanheerde et al. 1995), flow cytometric studies indicated that during apoptosis PS exposure precedes morphological changes as visualized by light scatter parameters (Koopman et al. 1994, Vermes et al. 1995). Recently it was shown in dexamethasone treated thymocytes, a prototypic model of apoptosis (Cohen and Duke 1984, Wyllie, 1980), that disruption of mitochondrial potential marks irreversible commitment to apoptosis and precedes internucleosomal DNA cleavage (Zamzami et al. 1995). Furthermore, this model system showed that PS exposure occurs downstream of the mitochondrial changes (Castedo et al. 1996). Other phenomena like cytoplasmic vacuolisation, chromatin condensation and oligonucleosomal DNA fragmentation also occur downstream of mitochondrial potential disruption (Marchetti et al. 1996).

In this study we investigated the loss of membrane phospholipid asymmetry in relation to morphological alterations of apoptotic thymocytes, using immuno-electron microscopy and flow cytometry. The aim of this approach was to correlate the (ultra)structural aspects of apoptosis to the loss of membrane phospholipid asymmetry in apoptotic cells.

With the use of annexin V it was demonstrated that PS exposure is a general feature of apoptosis regardless of the initiating stimulus and the cell type (Koopman et 
al. 1994, Homburg et al. 1995, Martin et al. 1995, Vermes et al. 1995). Annexin V has successfully been used for ultrastructural localisation of PS exposure on activated blood platelets (Stuart et al. 1995). Using this experimental approach it is possible to discriminate between local and general loss of phospholipid asymmetry of the plasma membrane. It also allows to visualise this phenomenon of apoptosis and to place it relative to morphological changes.

\section{Materials and methods}

\section{Materials}

Dexamethasone (40 $\mathrm{mg} / \mathrm{ml})$ was purchased from Pharmachemie (Haarlem, The Netherlands) Recombinant annexin $V$ was prepared as described before (Maurer-Fogy et al. 1988). Annexin V-FITC was obtained from Nexins Research BV (Hoeven, The Netherlands) as the APOPTEST ${ }^{\mathrm{Tm}}$-FITC kit. Anti annexin V antibodies were raised. against human annexin $\mathrm{V}$ in rabbits. The polyclonal $\mathrm{IgG}$ fraction was affinity purified and used at final concentration of $7 \mu \mathrm{g} / \mathrm{ml} \mathrm{IgG}$. Protein A labelled with gold $(10 \mathrm{~nm})$ was purchased from Aurion (Wageningen, The Netherlands). All other reagents used were of analytical grade.

\section{Thymocytes}

Thymocytes were isolated from female inbred Lewis rats, 8-10 weeks of age, which were obtained from the Central Animal Facillity, of the Maastricht University. The animals were maintained under specific pathogen free conditions until use and had free access to food and water. Single cell suspensions of thymus were prepared by pressing the tissue through a 100 mesh nylon gauze and rinsed with RPMI-1640 (Gibco, Paisley, Scotland, United Kingdom). The cells were washed once and resuspended in culture medium (RPMI-1640 supplemented with 10\% fetal calf serum, $2 \mathrm{mM}$ glutamine, $100 \mathrm{U} / \mathrm{ml}$ penicillin, $100 \mu \mathrm{g} / \mathrm{ml}$ streptomycin) to a final concentration of 2.5. $10^{6}$ cells per $\mathrm{ml}$. Cells were cultured in a humidified $\mathrm{CO}_{2}$ incubator at $37^{\circ} \mathrm{C}$.

\section{Induction of apoptosis}

At $T=0$ the cells were divided into 2 groups; In the experimental group $1 \mu \mathrm{M}$ Dexamethasone was added to the culture medium, whereas the control group was incubated in the culture medium only. At $\mathrm{T}=0,1,2,4,6,8,12$ and 24 hours samples were taken from both groups and placed on ice immediately for subsequent analysis by flow cytometry or immuno-electron microscopy.

\section{Flow cyrometric analysis}

The thymocytes were pelleted by centrifugation $\left(4^{\circ} \mathrm{C}\right)$ and resuspended into Hepes buffer (137 mM NaCl, $2.68 \mathrm{mM} \mathrm{KCl}, 10 \mathrm{mM}$ Hepes, $1.7 \mathrm{mM} \mathrm{MgCl}$, pH 7.4) containing $3 \mathrm{mM}$ calcium. Annexin V-FITC was added to a final concentration of 1 $\mu \mathrm{g} / \mathrm{ml}$ and propidium iodide in a final concentration of $5 \mu \mathrm{g} / \mathrm{ml}$ (incubation for at least $10 \mathrm{~min}$. in the dark). Flow cytometry was performed on a FACSort (Becton Dickinson, San Jose, CA) equipped with an argon laser (excitation at $488 \mathrm{~nm}$ ). The cells were run 
using the LYSYS II software package (Becton Dickinson), and 10,000 events were acquired in list mode. From each cell forward scatter, side scatter, fluorescence channel $l$ (annexin V-FTTC) and fluorescence channel 3 (propidium iodide) were recorded. Analysis was performed off line using the same software.

\section{Immuno-electron microscopy}

Annexin $\mathrm{V}$ and calcium were added to the thymocyte samples to give final concentrations of $10 \mu \mathrm{g} / \mathrm{ml}$ and $3 \mathrm{mM}$ respectively (incubation for at least $10 \mathrm{~min}$.). The thymocytes were prepared for ultrastructural investigation and localisation of annexin $\mathrm{V}$ by jet freezing and freeze substitution, as described previously (Stuart et al. 1995). In brief, thymocyte suspensions were vitrified by jetting them through a $50 \mu \mathrm{m}$ platinum aperture disk into liquid ethane cooled to its melting point. After evaporation of the ethane under vacuum (at $-100^{\circ} \mathrm{C}$ ), the vitrified cell suspension was freezesubstituted in methanol containing $0.5 \%$ uranyl acetate. Freeze-substitution was started at $-90^{\circ} \mathrm{C}$ and subsequently the samples were warmed to $-30^{\circ} \mathrm{C}$ in four steps, each step with a duration of minimally eight hours. At $-30^{\circ} \mathrm{C}$ the substitution medium was replaced by pure methanol followed by infiltration with Lowicryl K4M. At $-20^{\circ} \mathrm{C}$ the cells were finally embedded and polymerized under UV light.

On ultra thin sections annexin $\mathrm{V}$ was localized by immunocytochemistry. The sections were incubated with polyclonal antibody against annexin $\mathrm{V}(7 \mu \mathrm{g} / \mathrm{ml})$ followed by protein A-gold complex (diluted 1/20). The sections were stained with neutral uranyl acetate to enhance the contrast. The sections were examined in a Philips CM 10 electron microscope (Philips, Eindhoven, The Netherlands) operating at $80 \mathrm{keV}$.

\section{Results}

\section{Annexin V-FITC, propidium iodide flow cytometry}

Using annexin V-FITC and propidium iodide (PI) in 2 colour flow cytometry, 4 subpopulations can be distinguished within the dexamethasone treated thymocyte population. Double negative cells, annexin $\mathrm{V}$ single positive cells, annexin $\mathrm{V}$ propidium iodide double positive cells with normal amount of DNA (high PI signal) and annexin $V$ propidium iodide double positive cells with a reduced amount of DNA (decreased PI signal) (Fig. 5.1a).The double negative population consists of normal viable thymocytes because there is no indication of cell damage and loss of membrane asymmetry and integrity as probed by the fluorescent markers. Cells single positive for annexin $\mathrm{V}$ are considered to be the cells which have lost only (part of) their membrane asymmetry. Double positive cells have lost membrane asymmetry as well as membrane integrity as indicated by annexin $V$ staining and propidium iodide uptake respectively. The double positive cells can be divided into cells having the normal amount of DNA as indicated by high propidium iodide signal and cells with a decreased amount of DNA, as indicated by a reduced propidium iodide signal.

\section{Forward-, side scatter flow cytometry}

Since morphological alterations can also be determined globally by measuring the 

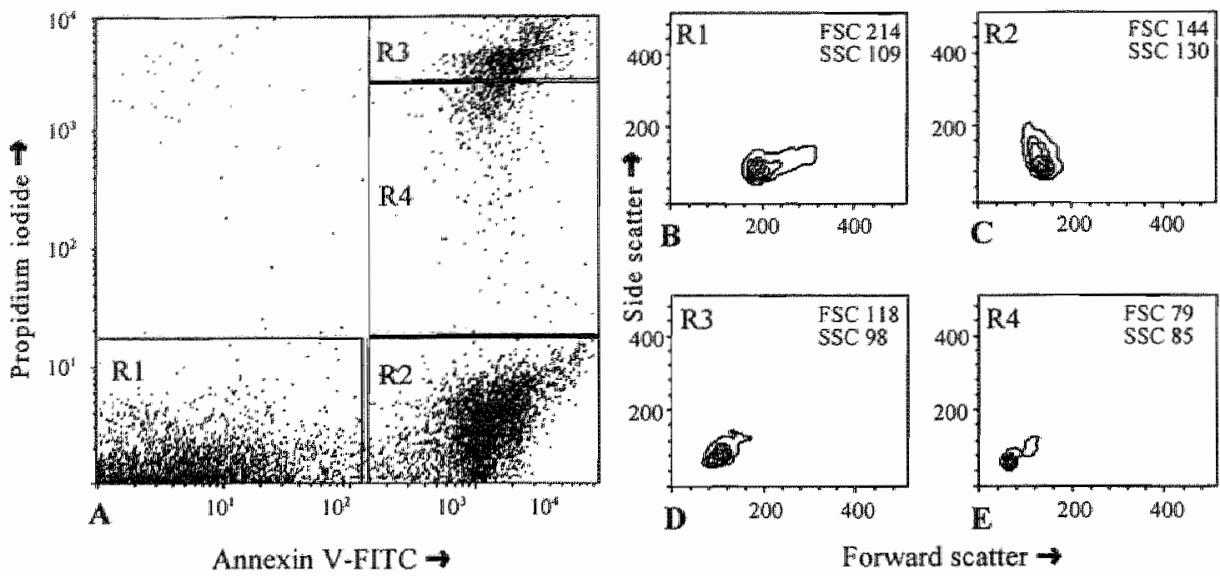

Figure 5.1 a). Dot plot of annexin V-FITC fluorescence versus propidium iodide (PI) fluorescence. Four subpopulations were made on basis of annexin V-FTTC binding and propidium iodide uptake of the thymocytes (area RI"nomal" cells, negative for both annexin V-FITC and propidium iodide, R2 apoptotic cells, positive for annexin V-FITC but negative for propidium iodide, R3 cells with an irreversibly damaged membrane positive for both fluorescent markers, with a normal amount of DNA (high PI) and R4 apoptotic bodies, with a reduced amount of DNA (decreased PI signal). The thymocytes were cultured for four hours in the presence of $1 \mu \mathrm{M}$ dexamethasone.

b-e) Each sub-population (R1-R4) presented by forward vs side scatter with their mean forward scatter (FSC) and side scatter (SSC) values.

b) R1 "nomal" cell population having the highest forward scatter.

c) R2 apoptotic cell population with the typical high side scatter.

d) R3 irreversible damaged cell population positive for both the fluorescent markers with a reduced forward and side scatter.

c) R4 the apoptotic bodies with a low forward and side scatter.

forward and side scatter by flow cytometry, this can be used to estimate the change in size of a population as defined by the fluorescent markers. The 4 different subpopulations of thymocytes as defined by annexin $\mathrm{V}$ and propidium iodide (Fig. 5.1a) are clearly different with respect to forward and side scatter profiles (Fig. 5.1b-e). The normal viable cells have the highest forward scatter, the annexin $V$ single positive cells have intermediate forward scatter and high side scatter, the double positive cells with normal amount of DNA have a lower forward and side scatter, whereas the double positive cells with reduced amount of DNA have the lowest forward and side scatter.

\section{Kinetics}

Using the 2 fluorescent markers we resolved in time the relation between loss of 
membrane asymmetry and membrane integrity upon treatment of the thymocytes with dexamethasone. Fig. 5.2a gives the kinetics of the population distribution following dexamethasone stimulation. Twenty percent of the population had lost membrane phospholipid asymmetry with intact membrane integrity after 2 hours of incubation with dexamethasone. Six hours later this reached a maximum of $52 \%$. The percentage of cells with lost membrane integrity and a normal amount of DNA starts to increase after four hours of dexamethasone treatment and peaks at 12 hours. The population of cells with lost membrane asymmetry and a reduced amount of DNA starts to increase after six hours of dexamethasone treatment and is still inclining after 24 hours. These cells have severely lost membrane integrity enabling the extrusion of DNA fragments into apoptotic bodies. After 24 hours of dexamethasone treatment nearly all cells had changed the structure of their plasma membrane as indicated by annexin $\mathrm{V}$ and propidium iodide. About $40 \%$ of thymocytes in the control group lost membrane asymmetry after culturing for 24 hours (Fig 5.2b). About 20\% of the control thymocytes subsequently lost their membrane integrity. This is the result of death by neglect representing natural occurring apoptosis in the thymus.

\section{Immuno-electron microscopy}

Using immuno-electron microscopy we determined the relation between annexin $\mathrm{V}$ labelling and morphological alterations, such as chromatin condensation and blebbing. From the kinetics of the plasma membrane changes we chose to analyse thymocytes that were
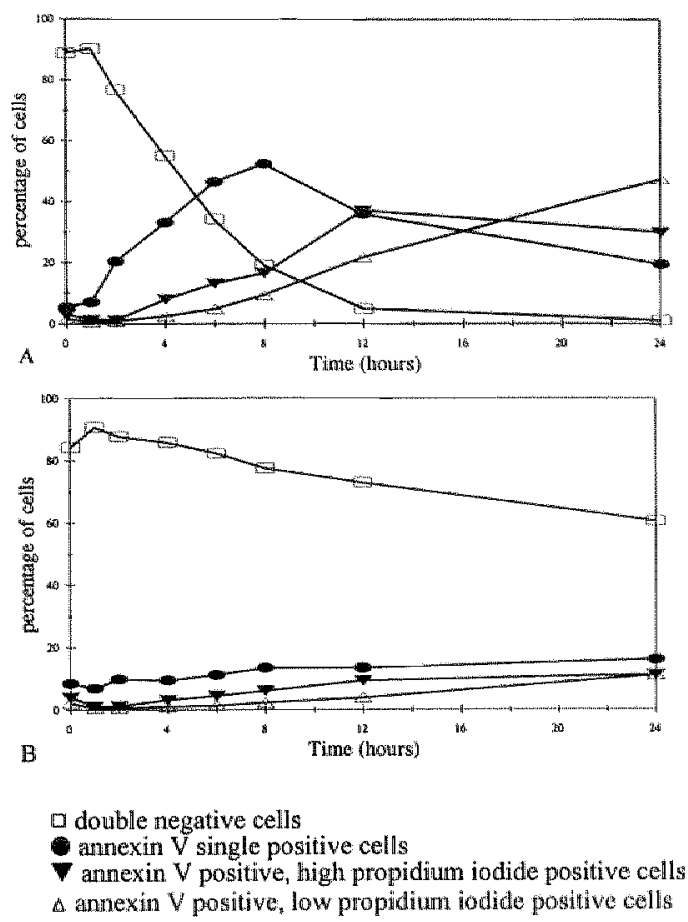

Figure 5.2 Kinetics of the apoptotic process of thymocytes after incubation with dexamethasone (A), and of control thymocytes (B). Number of thymocytes in exich subpopulation (Fig. 5.1a) as the percentage of the totall cell population, at each time point. At each time point 10,000 events were acquired, the mean values of two in. dependent experiments are presented.

incubated for one, six and eight hours with dexamethasone. The results from the ultrastructural observation and immune localisation of annexin $\mathrm{V}$ are presented in Fig. 5.3. From control incubation, the majority of thymocytes appear structurally unchanged, as judged by the chromatin and cytoplasm morphology (not shown). From the dexamethas one treated groups most "unchanged" thymocytes with normal chromatin were annexin $V$ negative (Fig. 5.3a), 
even after 8 hours of incubation with dexamethasone. After one hour of incubation with dexamethasone some cells showed blebbing; pinching off microvesicles from the cell membrane (Fig. $5.3 \mathrm{~b}$ ). On these cells with signs of blebbing no ultrastructural features of apoptosis could be detected, and no annexin $V$ label was present on the cell membrane. We never found protrusions from the cells to be positively labelled with gold particles. The blebs, however, were positive for annexin V (Fig. 5.3c). On all cells with clear morphological characteristics of apoptosis (condensation of chromatin) annexin V labelling was observed (Fig. 5.3d). Finally the cells will lose membrane integrity. Morphologically the cells appear with massive blebbing and the plasma membrane becomes separated from the cytoplasm (Fig 5.3e). This is followed by a complete degradation of the cell, where the border between nucleus and cytoplasm becomes faint (not shown). It should be mentioned that all different types of cells, as shown in Fig. 5.3, were found intermingled in each thymocyte preparation, as to be expected on basis of the flow cytometric data, because no sorting or other separation was performed. The relative amount of each cell population changed in time as demonstrated in figure 5.2. It was not possible to compere the electron microscopic and flow cytometric changes, because the criteria for diwision into the categories are not the same for the two techniques. Some background label is present on the nucleus of the thymocytes probably due to aspecific interactions with protein A gold particles. On incubations without primary antibody similar background label were found.

\section{Discussion}

Using dexamethasone treated thymocytes as a model for apoptosis we were able to distinguish several stages during the apoptotic process on basis of biochemical and morphological alterations of the cells. The flow cytometric data were used to determine the kinetics of the apoptotic process in order to relate the ultra-structural observations to the time sequence of the apoptotic process. On basis of the two fluorescent probes, annexin V-FTTC and propidium iodide, the thymocyte population could be divided into 4 distinct subpopulations, as was shown for other hemopoietic cell types (Koopman et al. 1994, Martin et al. 1995, Vermes et al. 1995). The subpopulation of cells which are annexin $V$ positive and propidium iodide negative is considered to comprise the apoptotic cells, which have changed membrane asymmetry while membrane integrity remains intact. DNA fragmentation proved the presence of apoptosis under the conditions used in the experiments (data not shown).

Immunocytochemistry at the EM level strongly suggests that before the apoptotic stage with chromatin condensation and an overall loss of membrane asymmetry PS exposure is confined to focal areas on blebs on the cell membrane. It can be postulated that these blebs are shed as microvesicles from the plasma membrane. These early (local) changes in membrane architecture take place well before nuclear changes and overall PS exposure as was reported by Martin et al. (Martin et al. 1995). Recently it was shown that CD95 ligation induces PS exposure in Jurkat cytoplasts indicating that this part of the apoptotic machinery may run in the absence of a nucleus (Kroemer et al. 1997). In the flow cytogram the small blebs attached to cells may contribute to a 
slight increase in the annexin $\mathrm{V}$ signal, but apparently not enough to identify them as a separate (intermediate) population. We showed that during the course of apoptosis loss of asymmetry of the plasma membrane can be divided into two stages. Firstly (micro)vesicles are pinched off and only the membranes of these vesicles have lost membrane asymmetry.

This phenomenon of focal PS exposure is reported here for dexamethasone treated thymocytes and may be part of apoptosis in general (Fadok et al. 1992a, Martin et al. 1995). The second stage is characterized by drastic morphological changes pertinent to apoptosis and a loss of phospholipid asymmetry over the whole plasma membrane, which still retains its barrier function. In Fig 5.4 the different morphological stages of apoptosis are schematically drawn at the background of a flow cytometer diagram.

Martin and co-workers (Martin et al. 1995) reported on basis of flow cytonetric and light microscopic studies that annexin $\mathrm{V}$ binding to celis stimulated to activate the apoptotic program emerged well before morphological changes took place. In conjunction with this study these early apoptotic cells likely commenced the process of blebbing with locally exposed PS. Ultrastructural inspection of dexamethasone treated thymocytes also revealed rarelly cells with a normal morphology and locally exposed PS. This indicates that once the Bcl-2 checkpoint is trespassed the dexamethasone treated thymocyte enters the first stage, where membrane blebbing occurs. Early reduction in mitochondrial potential (Zamzami et al. 1995) is probably also a feature of this first stage. After the first stage the thymocytes progress very quickly to the second stage of altered morphology with an overall loss of membrane asymmetry and then more slowly to the third stage of lost membrane integrity. Recently other investigators also observed, both biochemical and morphological, apoptotic events well before membrane integrity was lost (Desjardins and MacManus, 1995, Weis et al. 1995). The relative kinetics of these different stages likely depend on the type of cell and the stimulus of apoptosis. With annexin $V$ as a discriminative parameter studies will be facilitated to get further insight into the kinetics of the early apoptotic process and whether the point of no return is beyond or below the early changes of the plasma membrane structure characterized by a local exposure of PS (see also Kroemer et al. 1995, Kroemer et al. 1997).

The mechanism by which PS is exposed to the outside of the plasma membrane is not clear at the moment. Probably all eukaryotic cells carry in their membranes a translocase activity, that maintains an asymmetric phospholipid distribution over the two leaflets of their membranes, by translocating PS and phosphatidylethanolamine to the leaflet facing the cytosol (for a review see Diaz and Schroit, 1996). As was shown for erythrocytes, inhibition of this translocase is not sufficient to get PS in the outer leaflet of the plasma membrane ( $Z$ waal et al. 1993). This requires another mechanism, which is regulated by cytosolic calcium levels as was shown for agonist stimulated blood platelets (Williamson et al. 1995) and apoptotic T lymphocytes (Verhoven et al. 1995). Both studies demonstrated with fluorescent phospholipids a translocation of phospholipids over the plasma membrane. Recently Bassé et al. (Basse et al. 1996) described a $37 \mathrm{kDa}$ membrane protein with a phospholipid translocase activity. 

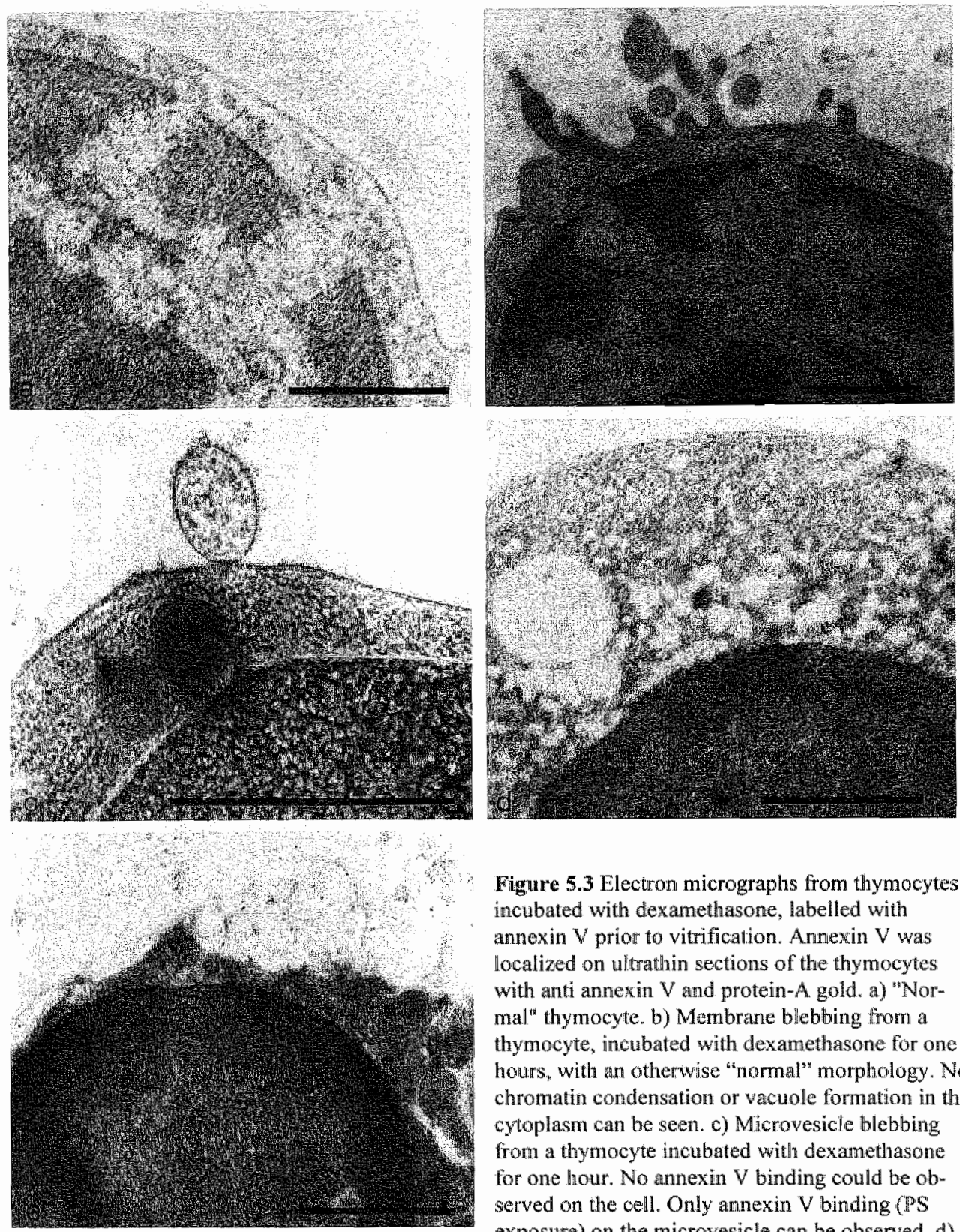

Figure 5.3 Electron micrographs from thymocytes incubated with dexamethasone, labelled with annex in V prior to vitrification. Annexin V was. localized on ultrathin sections of the thymocytes with anti annexin $\mathrm{V}$ and protein-A gold, a) "Normal" thymocyte. b) Membrane blebbing from a thymocyte, incubated with dexamethasone for one hours, with an otherwise "normal" morphology. No chromatin condensation or vacuole formation in the cytoplasm can be seen. c) Microvesicle blebbing from a thymocyte incubated with dexamethasone for one hour. No annexin $V$ binding could be observed on the cell. Only annexin $V$ binding (PS exposure) on the microvesicle can be observed. d) Thymocyte incubated with dexamethasone for six hours. Chromatin has been condensed and an overall annexin $V$ labelling is present. e) Thymocyte incubated with dexamethasone for eight hours. The membrane has become loose from the cytoplasm. Bar represents $1 \mu \mathrm{m}$ in all micrographs. 
Microvesicles, with a random distribution of phospholipids, attached to a cell, with otherwise intact membrane asymmetry, might be originating from the same cell or become secondarily attached and thus originate from an other cell which is disintegrating. If microvesicles with lost membrane asymmetry originate from a cell with more or less intact membrane asymmetry, the mechanism of loss of membrane asymmetry might be due to this local difference in PS exposition. The ultrastructural data strongly suggest that blebbing is accompanied by local exposition of PS on the blebs that are formed. A similar conclusion has been drawn in the study of platelet activation (Stuart et al. 1995). During activation, blood platelets shed membrane vesicles (Sims et al. 1988) and we observed also microvesicles with lost membrane asymmetry trapped in the open canalicular system of platelets with otherwise intact

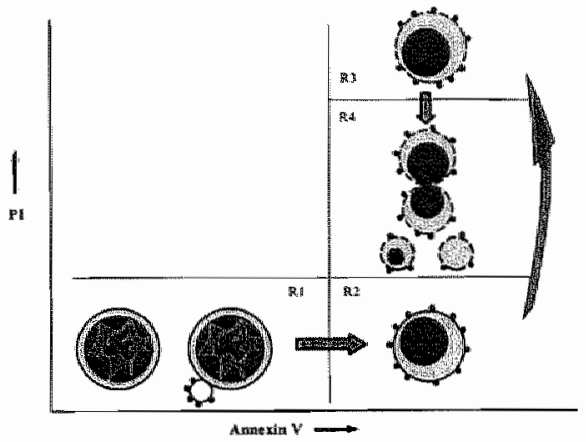
membrane asymmetry. From their location it is very unlikely that these microvesicles originate from other platelets (Stuart et al. 1995), and we postulate that the PS exposure is initially restricted to the shedded vesicles.

Further evidence of focial PS exposition can be found from the ratio of total phospholipids between the in- and outside of the plasma membrane. In most cells the amount of phospholipids in the inner

Figure 5.4 Schematic sequence of events during leaflet of the bilayer equals the amount in dexamethasone induced apoptosis in rat thymocytes the outer leaflet of the bilayer, although at the background of an annexin V, propidium iodide (PI) double fluorescence cytogram . The different stages are marked R1-R4 as in the flow cytometer diagram with in $\mathrm{R} 1$ the viable cells and the cells with early loss of membrane phospholipid asymmetry at the side of the blebs. R2 the apoptotic cells with an overall loss of membrane asymmetry and drastic morphological alterations typical for apoptosis. R3 cells with lost membrane integrity and R4 with the apoptotic bodies. The indicate the various phospholipid species are asymmetrically distributed over inner and outer leaflet. However microblebs on the plasma membrane, with a diameter of 100$200 \mathrm{~nm}$, have respectively $10-2.5 \%$ more phospholipids in the outer membrane leaflet than in the inner membrane leaflet. The formation of (micro)vesicles requires for phosphatidylserine exposure to the outside of a local increase of the lipid surface in the the cell membrane. The dashed line indicate for outer bilayer leaflet to induce the loss of membrane integrity.

curvature needed to form the microvesicle. Apparently this net lipid transfer to the outer leaflet is accompanied by PS exposure as was demonstrated on the sections. This is probably a very fast process because we never found protrusions still attached to the cell positively labelled for annexin V.

In conclusion, morphological evidence is presented that the formation of blebs, with lost membrane asymmetry, is a very early sign from cells who are predestined to undergo the full sequence of apoptosis. The formation of blebs is an early apoptotic event that is locally expressed on the plasma membrane and this event can be detected by immuno-cytochemistry at the ultrastructural level. This is a new and powerful technique to demonstrate early plasma membrane alterations with annexin $\mathrm{V}$ binding as a discriminative parameter. 


\section{References}

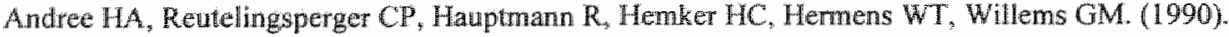
Binding of vascular anticoagulant alpha (VAC alpha) to planar phospholipid bilayers. J. Biol. Chem. $265,4923-4928$

Arends MJ, Morris RG, Wyllie AH. (1990). Apoptosis: The role of the endonuclease. Am. J. Pathol. $136,593-608$.

Basse $\mathrm{F}_{*}$ Stout $\mathrm{JG}_{\text {, sims }} \mathrm{PJ}_{*}$ Wiedrner T. (1996). Isolation of an erythrocyte membrane protein that mediattes $\mathrm{Ca}^{24}$-dependent ransbilayer movement of phospholipids. J. Biol. Chem. 271, 17205-17210.

Castedo M, Hirsch T, Susin SA, Zamzami N, Marchetii P, Macho A, Kroemer G. (1996). Sequential acquisition of mitochondrial and plasma membrane alterations during early lymphocyte apoptosis. J. Immunol. 157, 512-521.

Cohen WJ, Duke RC, Fadok VA, Sellins KS. (1992). Apoptosis and programmed cell death in immunity Annu. Rev. Immunol. 10,267-293.

Cohen JJ, Duke RC. (1984\%, Glucocorticoid activation of alcium-dependent endonuclease in thymocyte nuclei leads to cell death. J. Immunol. $132,38-42$.

Desjardins LM, MacManus JP. (1995). An adherent cell model to study different stages of apoptosis Exp. Cell. Res. 216, 380-387.

Diaz C, Schroit AJ. (1996). Role of translocase in the generation of phosphatidylserine asymmetry. I. Membrane Biol. 151, 1-9.

Fadok VA, Voelker DR, Campbell PA, Cohen JJ, Bratton DL, Henson PM. (1992). Exposure of phosphatidylserine on the surface of apoptotic lymphocytes triggers specific recognition and removal by macrophages. J. Immunol. 148, 2207-2216.

Fadok VA, Savill IS, Hasilett C, Bratton DL, Doherty DE, Campbell PA, Henson PM. (1992). Different poptulations of macrophages use either the vitronectin receptor or the phosphatidylserine receptor to recognize and remove apoptotic cells. J. Immunol. 149,4029-4035.

Hockenbery D. (1995). Defining apoptosis. Am. J. Pathol. 146, 16-19.

Homburg, CH, Dehaas M, Vondemborne AE, Verhoeven AJ, Reutelingsperger CP, Roos D. (1995). Fluman neutrophils lose their surface Fc gamma RIII and acquire annexin $V$ binding sites during apoptosis in vitro. Blood, $85,532-540$.

Kert JW, Gobé GC, Winterford CM, Harmont BV. (1995) Anatomical methods in cell death. In: Methods in cell biology. Vol. 46, Cell death. (ed. L. M. Schwart and B. A. Osborne), pp 1-27. Academic press.

Koopman G, Reutelingsperger CP, Kuijten GA, Keehnen RM, Pals ST, Vanoers MH. (1994). Annexin $\mathrm{V}$ for flow cytometric detection of phosphatidylserine expression on $\mathrm{B}$ cells undergoing apoptosis. Blood $84,1415-1420$.

Kroemer G, Petit P, Zamzami N, Vayssiere JL, Mignotte B. (1995). The biochemistry of programmed cell death. FASEB J, 9, 1277-1287.

Kroemer $\mathrm{G}_{,}$, Zamzami $\mathbb{N}$,. Susin SA. (1997). Mitochondrial control of apoptosis. Immunology today, $18,44-51$.

Marchetti P, Castedo M, Susin SA, Zamzami N, Hirsch T, Macho A, Haeffner A, Hirsch F, Geuskens M, Kroemer $\mathrm{G}$. (1996). Mitochondrial permeability transition is a central coordinating event of apoptosis. J. Exp. Med. 184, 1155-1160.

Martin SJ, Green DR. (1995). Protease activation during apoptosis: Death by thousand cuts. Cell, 82, $349-352$ 
Martin SJ, Reutelingsperger CP, McGahon AJ, Rader J, van Schie RC, Laface DM, Green DR. (1995). Early redistribution of plasma membrane phosphatidylserine is a general feature of apoptosis regardless of the initiating stimulus: Inhibition by overexpression of $\mathrm{Bcl}-2$ and $\mathrm{Abl}$. J. Exp. Med. 182 . $1,545-1556$.

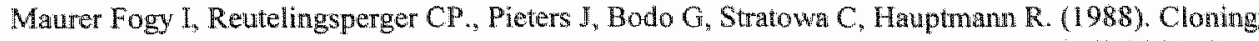
and expression of CDNA for human vascular anticongulant, a Ca2t-dependent phospholipid-binding protein. Eur. J. Biochem. 174, 585-592.

Oberhammer F, Fritsch G, Schmied M, Pawelka M, Printz D, Purchio T, Lassmann H, SchulteHermann R. (1993). Condensation of the chromatin at the membrane of an apoptotic nucleus is not associated with activation of an endonuclease. I. Cell. Sci. 104, 317-326.

Sanderson CJ.(1982). Morphological aspects of lymphocyte mediated cytotoxicity. Adw. Exp. Med. Biol. 146, 3-21.

Sims PJ, Faioni EM, Wiedmer T, Shattil S.J. (1988). Complement proteins C5b-9 cause release of membrane vesicles from the surface that are rich in the membrane receptor for coagulation factor $V$ a and express prothrombinase activity. J. Biol. Chem. 263, 18205-18212.

Stuart MC, Bevers EM, Comfurius P, Zwaal RF, Reutelingsperger CP, Frederik PM. (1995).

Ultrastructural detection of surface exposed phosphatidylserine on activated blood platelets. Thromb. Haemostasis, 74, 1145-1151.

Tait JF, Gibson D, Fujikawa K. (1989). Phospholipid binding properties of human placental anticoagulant protein-1, a member of the lipocortin family. J. Biol. Chem. 264, 7944-7949.

Thomas N, Bell PA. (1981). Glucocorticoid-induced cell-size changes and nuclear fragility in rat thymocytes. Mol. Cell. Endocrinol. 22, 71-84.

Vanheerde, W. L., P. G. de Groot, C. P. M. Reutelingsperger: The complexity of the phosphollipid binding protein annexin $\mathrm{V}$. Thromb. Haemostasis, 73, 172-179 (1995).

Verhoven B, Schlegel RA, Williamson P. (1995). Mechanisms of phosphatidylserine exposure, a phagocyte recognition signal, on apoptotic T lymphocytes. J. Exp. Med. 182, 1597-1601.

Vermes I, Haanen C, Steffens-Nakken H, Reutelingsperger CP. (1995). A novel assay for apoptosis: flow cytometric detection of phosphatidylserine expression on early apoptotic cells using fluorescein labellid annexin V. J. Immunol. Methods. 184, 39-51.

Weis M, Schlegel $J$, Kass GE, Holmstrom TH, Peters I, Eriksson J, Orrenitus S, Chow SC. (1995). Cellular events in Fas/APO-1-mediated apoptosis in JURKAT T lymphocytes. Exp. Cell, Res. 219, $699-708$.

Williamson $\mathrm{P}$, Bevers EM, Smeets EF, Confurius P, Schlegel RA, Zwaal RF. (1995). Continuous analysis of the mechanism of activated transbilayer lipid movement in platelets. Biochenistry, 34 , 10448-10455.

Wyllie AH.(1980). Glucocorticoid-induced thymocyte apoptosis is associated with endogenous endonuclease activation. Nature, 284, 555-556.

Zamzami N, Marchetti P, Castedo M, Zanin C, Vayssiere JL, Petit PX, Kroemer G. (1995). Reduction in mitochondrial potential constitutes an early irreversible step of programmed lymphocyte death in vivo. J. Exp. Med. 181, $1661 \times 1672$.

Zwaal RF, Comfurius P, Bevers EM. (1993). Mechanism and function of changes in membrane-phospholipid asymmetry in platelets and erythrocytes. Biochem. Soc. T. 21, 248-253

Zwaal RF, Schroit AJ. (1997). Pathophysiologic implications of membrane phospholipid asymmetry in blood cells. Blood. 89, 1121-1132. 

Chapter 6

\section{Sarcolemmal phosphatidylserine asymmetry in cardiomyocytes subjected to simulated ischemia.}

M.C.A. Stuart, P.M. Frederik, A.J. Verkleij, J.A. Post. (1998). Submitted to cardio vascular research. 


\section{Summary}

The phospholipid asymmetry in the sarcolemma of cardiac myocytes is partly lost during metabolic inhibition and simulated ischemia and is thought to be involved in the development of irreversible damage to the sarcolemma. The loss of the asymmetrical phosphatidylethanolamine (PE) distribution upon those conditions is biochemically detected using enzymatic or chemical labelling techniques, which did not show any changes in the distribution of phosphatidylserine (PS). However, many other conditions, such as platelet activation, apoptosis and sickling of erythrocytes, result in a change in the distribution of PE and of PS in the plasma membrane. This difference may be due to the fact that the biochemical methods (enzymatic and chemical labelling) used during the metabolic inhibition and simulated ischemia studies are not sensitive enough to detect the loss of PS asymmetry or due to the fact that one is comparing two different processes and the observed difference is real. Therefore, the present study investigated the distribution of PS during simulated ischemia of cardiomyocytes using an ultra-structural approach employing annexin V (a calcium dependent phospholipid binding protein with a high affinity for PS) and detection of this probe at both the light microscope (immuno-fluorescence) and electron microscope (immuno-gold) level. The results of the present study show that a clear distinction must be made between the sarcolemma proper and membrane vesicles. pinched of from this membrane. No labelling with annexin $V$ was observed at the cell surface (sarcolemma), not even under conditions where the biochemical approach showed loss of PE asymmetry. This implies that indeed the loss of PE asymmetry during simulated ischemia is not accompanied by an exposure of PS. A clear labelling of vesicles derived from the sarcolemma was observed, suggesting that once the vesicles are pinched off from the sarcolemma the asymmetrical distribution of PS is lost. 


\section{Introduction}

The myocardial sarcolemma has an asymmetric distribution of phospholipids over the two leaflets forming the lipid bilayer (Post et al. 1988), as is the case for most other cell types (reviewed by Devaux and Zachovski 1994). Most of the phosphatidylethanolamine (PE) and all phosphatidylserine (PS) is located in the membrane leaflet facing the cytosol. In cardiomyocytes this asymmetric distribution of aminophospholipids is postulated to play a crucial role in regulating the cellular ion balance (Peskoff et al. 1992, Hilgemann and Collins 1992, Post et al 1995). Therefore a loss of sarcolemmal phospholipid asymmetry is expected to lead to altered nembrane function. Restoration of oxygen and nutrient supply before the onset of cell lysis results in a restoration in the asymmetrical distribution of PE (Musters et al. 1996).

Metabolic compromise of myocardial cells, either by simulated ischemia or metabolic inhibition, resulted in loss of this phospholipid asymmetry in neonatal cardiomyocytes (Musters et al. 1993, Post et al. 1993). This condition is accompanied by distinct morphological changes such as blebbing of the membrane, clustering of intra-membraneous particles and detachment of the cytoskeleton from the sarcolemma (Post et al. 1985, Post et al. 1993, Musters et al 1991, Schrijvers et al. 1990), as was found for both neonatal cardiac myocytes and Langendorff perfused adult rat hearts.

In the studies on sarcolemmal phospholipid topology during metabolic compromise no change in PS distribution was observed and the loss of asymmetry involved only PE. Also in other cell systems a loss of phospholipid asymmetry has been described. Those studies, such as the activation of blood platelets and erythrocytes (Schroit and Zwaal 1991) and the induction of the apoptotic process (Fadok et al. 1992a,b; Martin et al 1995), showed the loss of membrane phospholipid asymmetry involving both PE and PS. Furthermore, it was shown that the loss of phospholipid asymmetry is a local phenomenon during the early stages of platelet activation (Stuart et al. 1995) and apoptosis (Stuart et al. 1998) and is associated with the formation of micro-vesicles on the plasma membrane. This local loss of phospholipid asymmetry was detected using the calcium dependent aminophospholipid binding protein annexin $V$, which has a high affinity for PS (Andree et al 1990). For this reason annexin $V$ has been used for the localisation of PS exposure both at light (Engeland et al. 1996, Martin et al. 1995) and electron microscopical level (Stuart et al. 1995, 1998).

The fact that during metabolic compromise of myocardial cells only a loss of $\mathrm{PE}$ asymmetry was observed, raised the question whether this process is indeed specific for PE or whether a possible loss of PS asymmetry has been missed due to possible limitations of the biochemical approaches. In the present study this question was addressed by an (ultra)structural approach, using annexin V to probe PS exposure upon various periods of simulated ischemia. This ultrastructural approach also allows to correlate morphological alterations to a loss of membrane phospholipid asymmetry. 
Materials and methods

\section{Materials}

Recombinant annexin $\mathrm{V}$ was prepared as described before ( Maurer-Fogy et al. 1988). Annexin V-biotin was obtained from Nexins Research BV (Hoeven, The Netherlands) as the APOPTEST ${ }^{\mathrm{Tm}}$-BIOTIN kit. Anti annexin $\mathrm{V}$ antibodies were raised against human annexin $\mathrm{V}$ in rabbits. The polyclonal $\operatorname{lgG}$ fraction was affinity purified and used at final concentration of $7 \mu \mathrm{g} / \mathrm{ml} \mathrm{IgG}$. Protein A labelled with gold (10 nm) was purchased from Aurion (Wageningen, The Netherlands). FITC-labelled streptavidin (DAKO, Glostrup, Denmark) was used in a 1:50 dillution. All other reagents used were of analytical grade.

\section{Culturing neonatal cardiomyocytes}

Cells were cultured as described before (Post et al. 1988). Briefly, neonatal rats were decapitated and the hearts were excised and minced. The mince was incubated with 0.1 $-0.05 \%$ trypsin (in $137 \mathrm{mM} \mathrm{NaCl}, 5 \mathrm{mM} \mathrm{KCl}, 4 \mathrm{mM} \mathrm{NaHCO} 3,5 \mathrm{mM}$ glucose, $100,000 \mathrm{U} / \mathrm{l}$ penicillin, $100 \mathrm{mg} / \mathrm{l}$ streptomycin) for 10 minutes and this medium was replenished nine to twelve times until complete digestion of the tissue. The cells were pelleted $(8 \mathrm{~min}, 430 \mathrm{~g}$ ) and resuspended in Ham's F10 growth medium (Gibco; supplemented with $10 \%$ fetal calf serum, $10 \%$ horse serum, $100,000 \mathrm{U} / 1$ penicillin, $100 \mathrm{mg} / \mathrm{l}$ streptomycin, $10 \mu \mathrm{M}$ cytosine $\beta$-D-arabinofuranoside and $1 \mathrm{mM} \mathrm{CaCl} 2$ ). The cells were platelet on Falcon 3000 dishes to remove fibroblasts by differential adherence. The myocytes were finally plated to glass cover slips and within 3 days a sub-confluent monolayer of spontaneously beating myocytes was formed.

\section{Simulating ischemia}

The cover slips were rinsed in buffer I (133 $\mathrm{mM} \mathrm{NaCl}, 5 \mathrm{mM} \mathrm{KCl}, 1 \mathrm{mM} \mathrm{MgCl} ; 1$ $\mathrm{mM} \mathrm{CaCl} 2,10 \mathrm{mM}$ Tris/ $/ \mathrm{HCl}, \mathrm{pH} 7.35$ at $37^{\circ} \mathrm{C}$ ), placed in $35 \mathrm{~mm}$ petri dishes containing $1 \mathrm{ml}$ buffer $\mathrm{L}$. The dishes were placed in special designed ischemia chamber in which air, and thus oxygen, can be replaced by $99.99 \%$ argon saturated with water (Musters et al. 1991, Musters et al. 1993) and which is kept at $37^{\circ} \mathrm{C}$. The myocytes were subjected to ischemia for $30,60,90$ and 120 minutes. After the ischemic period the cells were placed on ice and annexin $V$ (electron microscopy) or annexin V-biotin (light microscopy) was added in a final concentration of $5 \mu \mathrm{g} / \mathrm{ml}$ and [Ca] was raised to $3 \mathrm{mM}$. After the incubation with annexin $\mathrm{V}$ (electron microscopy) the cells were vitrified in propane $(83 \mathrm{~K}$ ) using a Reichert $\mathrm{KF} 80$. The cells incubated with annexin $V$-biotin were rinsed twice with buffer I, with [Ca] of $3 \mathrm{mM}$, and fixed in $4 \%$

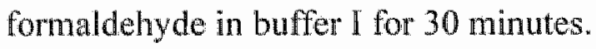



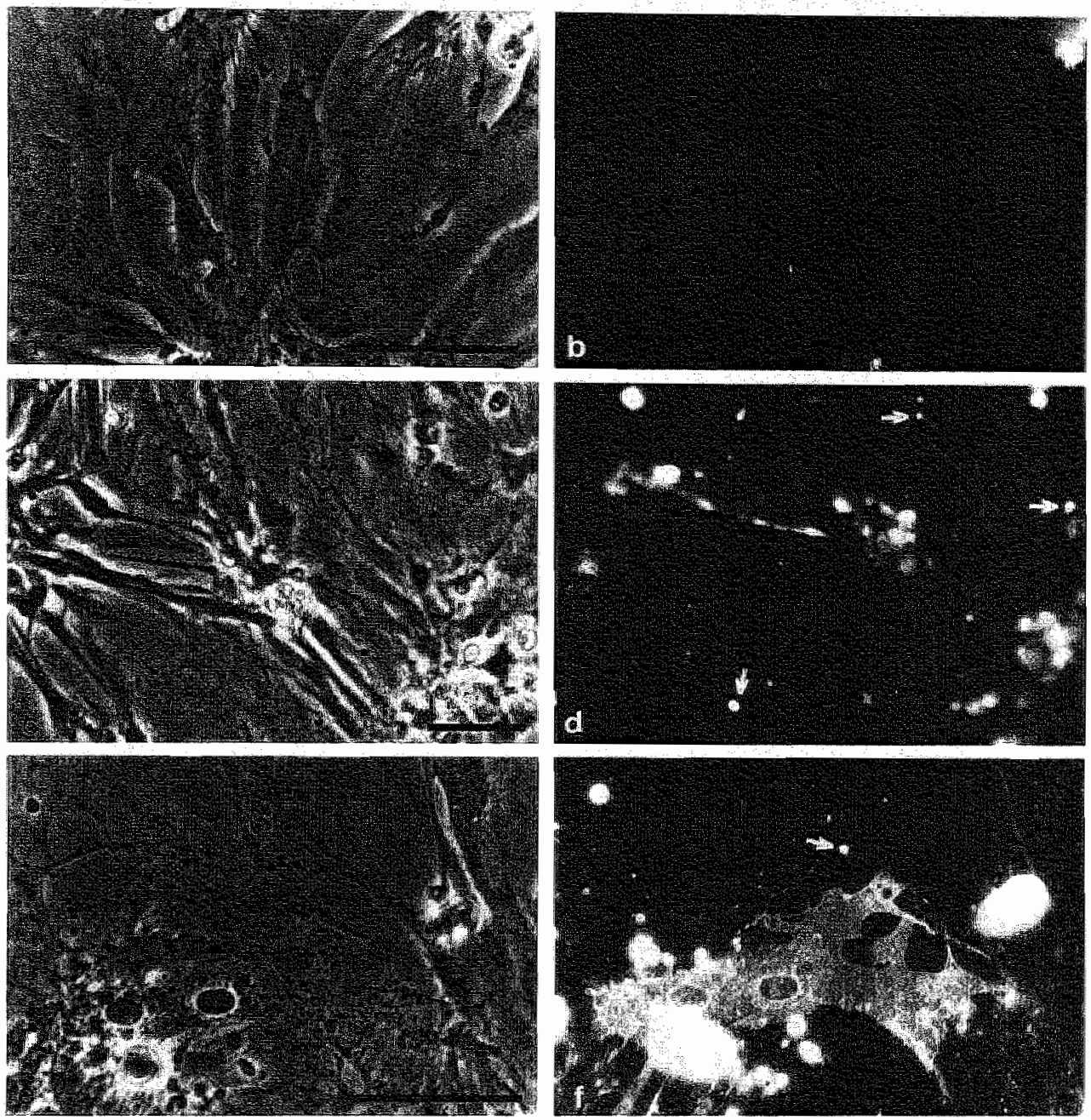

Figure 6.1 Neonatal cardiomyocytes incubated for 0 minutes $(a, b), 30$ minutes $(c, d)$ and 90 minutes (e,f) under ischemic conditions. The cells are observed with phase contrast $(a, c, e)$ and by epi fluorescence $(b, d, f)$ after labelling the cells with annexin $V$ biotin followed by streptavidin-FITC. After 30 minutes the cells show little fluorescent blebs (arrows). Upon 90 minutes of ischenta some cells became completely positive for annexin $\mathrm{V}$ whereas others only show the positive blebs (arrows) on otherwise negative cell membranes. Bar represents $50 \mu \mathrm{m}$. 
Ligh microscopy

Annexin V-biotin labelled and formaldehyde fixed cells were rinsed several time with Tris buffer ( $10 \mathrm{mM}$ Tris $/ \mathrm{HCl}, 100 \mathrm{mM} \mathrm{NaCl}, \mathrm{pH} 7.4)$. The cells were incubated with FTTC-labelled streptavidin for 15 minutes, followed by several rinses with buffer. The coverslips with the cells were finally mounted in 1,4-diazobicyclo- $[2,2,2]$-octane (DABCO) (Sigma, St. Louis, MO, USA). The cells were observed by phase contrast and epi-fluorescence microscopy.

\section{Immuno-electron microscopy}

After vitrification the cells were freeze substituted and embedded as previously described (Stuart et al 1995). In brief, the vitrified cells were freeze-substituted in methanol containing $0.5 \%$ uranyl acetate. Freeze-substitution was started at $-90^{\circ} \mathrm{C}$ and subsequently the samples were warmed to $-30^{\circ} \mathrm{C}$ in four steps, each step with a duration of minimally eight hours. At $-30^{\circ} \mathrm{C}$ the substitution medium was replaced by pure methanol followed by infiltration with Lowicryl $\mathrm{K} 4 \mathrm{M}$. At $-20^{\circ} \mathrm{C}$ the cells were finally embedded by polymerization under UV light.

Ultra thin sections were cut and were incubated. with polyclonal antibody against annexin $\mathrm{V}(7 \mu \mathrm{g} / \mathrm{ml}$ ) followed by protein A-gold complex (diluted $1 / 20$ ). The sections were stained with neutral uranyl acetate to enhance the contrast and examined in a Philips CM 10 electron microscope operating at $80 \mathrm{keV}$.

\section{Results}

From the neonatal cardiomyocyte cultures incubated under ischemic conditions samples were prepared for light and electron microscopic observations. Control cells ( $t$ $=0$ ) showed a normal morphology (Figure 6.1 a) and no annexin $\mathrm{V}$ fluorescence was observed on the cell (figure 6.1b), except for some occasional cell debris. When the cells are cultured on plastic coverslips less cell debris is found throughout the procedure, but plastic cover slips were found incompatible with the procedure used for electron microscopy. Upon 30 minutes of ischemic incubation (figure $6.1 \mathrm{c}$,d) little fluorescent dots are observed, showing labelling with Annexin $V$ and suggesting a local PS exposure. Since at the light microscopical level the nature of these dots can not be determined, further analysis by electron microscopy was performed, as described below. After 60 minutes of simulated ischemic the morphology of the cells appear the same as after 30 minutes of incubation (data not shown).

Beginning at 90 minutes of ischemia some cells start to show overall annexin $\mathrm{V}$ labelling, indicated by a massive fluorescence of the cells, whereas others remain negative except for the above described dots (figure 6.1e,f). After 120 minutes of simulated ischemia the number of cells with an overall fluorescence is increased but still the majority of the cells only show the annexin $V$ positive dots (data not shown). The overall positive cells can be explained by the fact that around 90 minutes of simulated ischemia the plasma membrane of neonatal myocytes start to loose their integrity, as determined by enzyme release (Muster et al, 1991,1993). The overall 
fluorescent signal at these stages can thus be explained by diffusion of the added Annexin $\mathrm{V}$ into the cells interior and binding to internal membranes.

On the electron microscopical level viable cells and cell debris can be easily distinguished on basis of their morphology. On control cells no gold labelling was detected, indicating the absence of any binding of annexin $V$ to the cells (figure $6.2 \mathrm{a}$ ). Occasionally some cell debris was found which was positive for annexin $\mathrm{V}$, as might be expected in any cell culture that contains some non viable cells (not shown). At the stage where fluorescent dots are observed in the fluorescence experiments (30 minutes of simulated ischemia) little membrane blebs were found, in the vicinity of viable cells. These vesicles are labelled with gold particles, showing binding of annexin $V$ to the membranes and indicating an exposure of PS (Fig. 6.2b). These vesicles are most likely derived from the plasma membrane and indeed in some preparations membrane blebs were found trapped between the neonatal cell and the glass substrate (figure $6.2 \mathrm{c})$. Because of this location it is very likely that these vesicles originate from the overlying intact cell. Control cells never showed these plasma membrane derived vesicles.

In contrast to the above described vesicles, the plasma membrane from which the vesicle originates remains negative for annexin $\mathrm{V}$, indicating that initially PS exposure is a local phenomenon confined to blebs (figure 6.2C). On the samples of cells subjected to 60 or 90 minutes of ischemia qualitatively the same observations are made as in the 30 minutes samples. Membrane derived blebs, positively labelled with gold, are found at or near the surface of the neonatal cardiomyocytes, whereas the surface of the cells remained negative. No cells with an overall labelling of gold particles were observed in the electron microscopic samples, probably due to the fact that either the sampling area is too small or that these cells are positively identified as severely damaged.

\section{Discussion}

During simulated ischemia and chemically induced metabolic inhibition of cultured neonatal rat heart ceills it was found that the asymmetrical distribution of sarcolemmal phosphatidylethanolamine (PE) is lost (Musters et al. 1993, 1996, Post et al. 1993, 1995). In these studies, using biochemical approaches to determine the phospholipid distribution over the bilayer, no phosphatidylserine (PS) exposure could be detected. Other studies on changes in plasma membrane phospholipid topology showed that, under different conditions of stimulation, both PE and PS asymmetry are lost (Williamson et al. 1995, Smeets et al. 1994, Verhoven et al. 1995). The present study was undertaken to see if this difference is real or whether a possible loss of PS asymmetry during metabolic compromise is missed due to methodological limitations. The approach used in the present study is the ultrastructural detection of PS exposure, using annexin $\mathrm{V}$, a calcium dependent amino-phospholipid binding protein (Andree et al 1990; Engeland et al. 1996, Martin et al. 1995 Stuart et al. 1995, 1998).

Both at the light and electron microscopical level no annexin $V$ labelling could be detected on the plasma membrane of the myocardial cells after 60 minutes of simulated 
ischemia, a time point at which the PE asymmetry is partly lost (Musters ef al. 1993, 1996, Post et al. 1995). This indicates that the asymmetrical distribution of PS is maintained under these conditions, despite the loss of PE distribution.

Annexin $\mathrm{V}$ binding is reported to be specific for PS, however, a slight interaction with PE might occur (Andree et al. 1990). From studies on model membranes with various phospholipid compositions we found that when the PE concentration is below $20 \mathrm{~mol}$ $\%$ no binding is observed in the absence of PS. $30 \mathrm{~mol} \%$ of PE results in a small positive signal, which however is much smaller than the increase in signal when small amounts of PS ( $1-3 \mathrm{~mol} \%$ ) are present (Stuart et al. in press). In addition to this, the affinity of annexin V for PS was found to increase when the PE concentration of the membrane is increased. This results, in a higher fluorescence signal when 1 to 3 mol\% PS is present in a PE/PC membrane, compered to a PC membrane alone. Under normal physiological conditions PE comprises about $12 \mathrm{~mol} \%$ of the phospholipids in the outer sarcolemmal leaflet (Post et al., 1988). Upon simulated ischemia this mol fraction of PE in the outer leaflet increases to around 20\% (Musters et al., 1993). Based on the model studies discussed above, this increase in PE would render the annexin system insensitive for $\mathrm{PE}$ alone but increase the sensitivity of the system for any possible PS exposure on the outer monolayer. Therefore, at the level of the intact cells it must be concluded that no exposure of PS on the sarcolemmal leaflet can be observed using the present ultrastructural approach, although the PE asymmetry was partially lost. In addition the result of the present study indicates that using the current cell model annexin $\mathrm{V}$ binding clearly discriminates between $\mathrm{PE}$ and $\mathrm{PS}$ exposition on the outer membrane leaflet of the cell, since no labelling is observed despite the increase in PE exposure.

The results presented are thus in line with our previous studies on changes in the sarcolemmal phospholipid topology during simulated ischemia (Musters et al. 1993, 1996, Post et al. 1995). However, with regard to the results on the PS distribution they are in contrast with a recent study by Maulik et al. (1998), who described that in addition to a loss of PE also PS is involved in the loss of lipid asymmetry during ischemia (Maulik et al. 1998). In that study hearts were subjected to ischemia (with or without reperfusion) and subsequently single cells were isolated from these hearts by trypsinizing pieces of tissue for 60 minutes. The cells thus isolated were used for biochemical labelling of the amino-phospholipids (PE and PS) using trinitrobenzenesulfonic acid. It was found that up to $60 \%$ of the total cellular PE and $40 \%$ of the total cellular PS could be labelled using this approach. This is a surprising high percentage of labelling considering that in cultured neonatal rat heart cells $26 \%$ of the total cellular PE and $30 \%$ of the cellular PS/phosphatidylinositol is present in the sarcolemma (Post et al. 1988) (exact numbers are not available for adult rat heart cells). It is therefore not impossible that the probe used has gained access to lipids in the cells interior resulting in a high labelling of total cellular PE and PS. Unfortunately, no data are available on the intactness of the sarcolemma of the cells isolated by trypsinization after a period of ischemia.

The change in phospholipid asymmetry during simulated ischemia is proposed to be most likely caused by the decline in cellular ATP, which results in a decrease of the aminophospholipid translocase activity (Musters et al., 1.993; Post et al, 1995). 

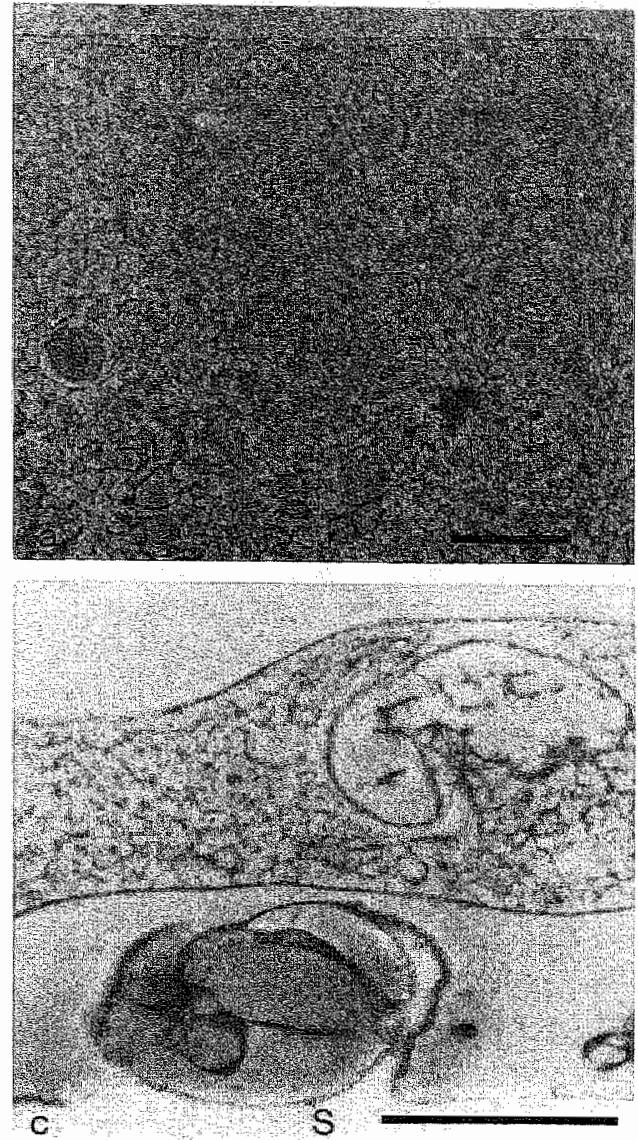

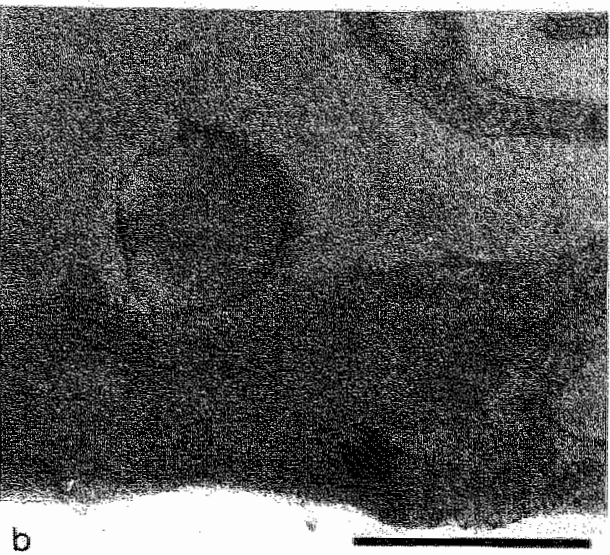

Figure 6.2 Electron micrographs of freeze-substituted control neonatal cardiomyocytes (a) and after 60 minutes of ischemia $(b, c)$. The cells were labelled with annexin $V$ prior to vitrification. Annexin $V$ was localised on sections with anti annexin antibodies and protein A-gold conplex. Only the membrane blebs are labelled with gold particles whereas the cell membrane remained negative. b), membrane bleb formed and pinched off from the membrane. c), on some cells blebs which are positive for annexin $W$ are found in between the cell and the glass substrate (S) were the cells are grown on. Bar represents $\$ \mu \mathrm{m}$.

Furthermore, an uncoupling of the cytoskeleton - bilayer complex might be involved as well, since an interaction between the aminophospholipids and the cytoskeleton has been shown. The fact that at the sarcolemmall level only $\mathrm{PE}$ asymmetry is lost might indicate that there remains an interaction between the membrane skeleton and PS. Although the plasmamembrane remained negative for PS exposure in the present study, already upon 30 minutes of simulated ischemia annexin V label was present on small membrane derived vesicles. Also in previous studies vesiculation of the sarcolemma has been observed during simulated ischemia (Muster et al., 1991). The origin of micro vesicles like these is not always easy to establish, since they can originate from the cell to which it attaches, but can also be derived from a disintegrating cell. However, at the ultrastructural level, in some occasions the micro vesicles were found in between the cell and the substrate they were grown on. From that location it must be concluded that the vesicle originates from the intact cell that is above it. The difference in PS exposure between the overall sarcolemma and the sarcolemmal derived vesicles suggests either a loss of PS topology during vesiculation or a loss of the machinery that maintains the asymmetrical distribution of PS upon or during vesiculation. With regard to the first possibility it can be mentioned that vesiculation of the sarcolemma during (simulated) 
ischemia is correlated with an aggregation of the sarcolemmal transmembrane proteins (Post et al., 1995; Musters et al., 1991), indication changes in the physico-chemistry of the sarcolemmal lipids. Furthermore, the blebbing off of vesicles from a membrane implies that part of the phospholipids temporarily adopted non-bilayer configuration, which can result in a scrambling of the membrane lipids over the two membrane halves (Verkleij et al.1979) and resulting in an exposure of PS. With regard to the second possibility an explanation might be found in the fact that the aminophospholipid-translocase, an active transporter responsible for the asymmetric distribution of PE and PS, has a lower Kd for PS as compared to PE (Zachowski et al. 1986). Thus, it might be speculated that within the vesicles ATP levels, originally still sufficient to actively transport PS to the cytoplasmic leaflet by the aminophospholipid-translocase, rapidly falls, resulting in a loss of PS asymmetry upon vesiculation. Alternatively, during the vesiculation process the underlying membrane skeleton might be lost and thereby the physical restrain for PS to move from the inner to the outer leaflet is lost.

In conclusion, morphological evidence is presented that during simulated ischemia PS asymmetry is maintained in the overall sarcolemma. Upon formation of micro-vesicles, which represent a minute amount of sarcolemmal membrane, the vesicles exhibit a lost membrane phosphatidylserine asymmetry. The results of the present study are in line with our previous work, using two independent biochemical approaches, which only showed a loss of sarcolemmal PE asymmetry during simulated ischemia of neonatal rat heart myocytes.

\section{References}

Andree HA., Reutelingsperger CP, Hauptmann R, Hemker HC, Hermens WT, Willems GM. (1990). Binding of vascular anticoagulant alpha (VAC alpha) to planar phospholipid bilayers. J. Biol. Chem. $265,4923-4928$.

Devaux PF, Zachowski A. (1994). Maintenance and consequences of membrane phospholipid asymmetry. Chem. Plyss. Lipids, 73, $107-120$.

van Engeland M, Ramackers FC, Schutte B, Reutelingsperger CP. (1996). A novel assay to measure loss of plasma membrane asymmetry during apoptosis of adherent cells in culture. Cytometry 24 , $131-139$.

Fadok VA, Voelker DR, Campbell PA, Cohen JJ, Bratton DL, Henson P M. (1992). Exposure of phosphatidy/serine on the surface of apoptotic lymphocytes triggers specific recognition and removal by macrophages. J. Jmmunol. 148, 2207-2216.

Fadok VA, Savill IS, Haslett C, Bratton DL, Doherty DE, Campbell PA, Henson PM (1992) Different populations of macrophages use either the vitronectin receptor or the phosphatidylserine receptor to. recognize and remove apoptotic cells. J. Immunol. $\rrbracket 49$, 4029-4035.

Hilgemann DW, Collins A. (1992). Mechanism of cardiac Na-Ca exchance current stimulation by MgA TP: Possible involvement of aminophospholipid translocase. J. Physiology. 454, 59-82.

Martin, SI, Reutelingsperger CP, McGahon, AI, Rader J, Schie van RC, LaFace DM, Green DR. (1995). Early redistribution of plasma membrane phosphatidylserine is a general feature of apoptosis regardless of the initiating stimullus: Inhibition by owerexpression of $\mathrm{Bcl}-2$ and $\mathrm{Abl}$.J. Exp. Med. 182, $1545-1556$. 
Maulik N, Kagan VE, Tyurin VA, Das DK. (1998). Redistribution of phosphatidylethanolanine and phosphatidylserine precedes reperfusion-indtuced apoptosis. Am. J. Physiol. 274, 11242-248.

Maurer Fogy I, Reutelingsperger, CP, Pieters J, Bodo G, Stratowa C, Hauptrnann R. (1988). Cloning and expression of cDNA for human yascular anticoagulant, a Ca2-dependent phospholipid-binding protein. Eur. J. Biochem. $174,585-592$.

Musters RJ, Post JA, Verkleij AJ. (1991). The isolated neonatal rat-cardiomyocyte used in an in witro model for 'ischemia'. L. A morphological study. Biochin . Biophys Acta, 1091, 270-277.

Musters RJ, Otten E, Biegelmann E, Bijvelt J, Keijzer JJ, Post JA, Op den Kamp JA, Verkleij A. (1993). Loss of asymmetric distribution of sancolemmal phosphatidylethanolamine during simulated ischemia in the isolated neonatal tat cardiomyocyte. Circ. Res. 73, 514-23.

Musters RJ, Probstl-Biegelmann E, van Veen TA, Hoebe KH, Op den Kanp JA, Verkleij A.J, Posi JA. (1996). Sarcolemmal phosphatidylethanolamine reorganization during simulated ischaemia and reperfision: reversibility and ATP dependency. Mol. Membr. Biol. 13, 159.164.

Peskoff A. Post JA, Langer GA. (1992). Sarcolemmal calcium binding sites in heart. II. Mathenatical model for diffusion of calcium released from sarcoplasmic reticulum into the diadic region. J. Membr. Biol. 129, 59-69.

Post $\mathbb{J A}$, Leunissen-Bijvelt J, Ruigrok TJ, Verkleij AJ. (1985). Ultrastrucural changes of sarcolemma and mitochondria in the isolated rabbit heart during ischemia and reperfusion. Biochim. Biophys. Acta, $845,119-123$.

Post JA, Langer GA, Op den Kamp JA, Verkleij AJ. (1988). Phospholipid asymmetry in cardiace sarcolemma. Analysis of intact cells and 'gas-dissected' membranes. Biochim. Biophys. Acta, 943 , 256-266.

Post JA, Clague JR, Langer GA. (1993). Changes insarcolemmal phospholipid asymmetry and Cafluxes upon metabolic inhibition. Am. J. Physiol. 265, H461-H468.

Post JA, Verkleij AJ, Langer GA. (1995). Organization and function of sarcollemmal phospholipids in control and ischemic/reperfused cardiomyocytes. J. Mol. Cell. Cardiol. 27, 749-760.

Schrijvers AH, de Groot MJ, Heijnen VV, van der Vusse GJ, Frederik PM, Reneman RS. (1990). Ischemia and reperfusion induced multilamellar vesicles in isolated rabbit hearts: time correlation between morphometric data and metabolic alterations. J. Mol. Cell. Cardiol. 22, 653-65.

Schroit AJ, Zwail RF. (1991). Transbilayer movement of phospholipids in red coll and phatelet membranes. Biochim. Biophys. Acta, 1071, 313-329.

Smeets EF, Comfurius P, Bevers EM, Zwaal RF. (1994). Calcium-induced transbilayer scranbling of fluorescent phospholipid analogs in platelets and eryhrocytes. Biochim. Biophys. Acta, 1195, $281-286$.

Stuart MC, Bevers EM, Comfurius P, Zwaal Rr, Reutelingsperger CP, Frederik PMI. (1995).

Ultrastructural detection of surface exposed phosphatidylserine on activated blood platelets. Thromb. haemostasis, 74, 1145-1151.

Stuart MC, Damoiseaux JG, Frederik PM, Arends JW, Reutelingsperger CP. (1998). Surface exposure of phosphatidylserine during apoptosis of rat thyrnocytes precedes nuclear changes. Eur. J. cell biol. 76, $77-83$.

Verhoven B, Schlegel RA, Williamson P. (1995). Mechanisms of phosphatidylserine exposure, a phagocyte recognition signal, on apoptotic T lymphocytes. J. Exp. Med. 182, 1597-1601.

Verkleij AJ, Mombers C, Gerritsen WJ, Leunissen-Bijvelt L; Cullis PR. (1979). Fusion of phospholipid vesicles in association with the appearance of lipidic particles as visualized by freeze fracturing. Biochim. Biophys. Acta, 555, 358-361.

Williamson P, Bewers EM, Smeets EF, Comfurius P, Schlegel RA, Zwaal RF. (1995), Continuous 
analysis of the mechanism of actiwated transbilayer lipid movement in platelets. Biochemistry 34 , $10448-10455$. 
Binding of annexin V to phosphatidylcholine (PC)/phosphatidylserine (PS) bilayers at various calcium concentrations is presented in figure 3.2 . Increasing phosphatidylserine mole fractions gives a rapid increase in the annexin $\mathrm{V}$ binding until approximately $6 \%$ PS (except for $1 \mathrm{mM} \mathrm{Ca}$ ). A certain amount of PS seems to be necessary before annexin $\mathrm{V}$ binding levels off. The calcium concentration is critical at low PS mole fractions. As from $2 \%$ PS each data point at $1 \mathrm{mM} \mathrm{Ca}$ is significantly (Ttest $95 \%$ ) lower than the corresponding value at $3 \mathrm{mM} \mathrm{Ca}$. At $1 \mathrm{mM} \mathrm{Ca}$ more PS is needed to achieve the point at which the binding levels off ("saturation").

The maximum calcium concentrations one can use in cellular systems is about $10 \mathrm{mM}$ calcium. At $10 \mathrm{mM}$ calcium the initial binding of annexin V to PC was significant increased and the binding at low PS concentrations (1\% $6 \%$ ) are significantly higher than the corresponding values at $3 \mathrm{mMC} \mathrm{Ca}$. As "saturation" is approached there is less difference between 3 and $10 \mathrm{mM}$ calcium.

Addition of phosphatidylethanolamine (PE) to a PC/PS lipid surface (fig. 3.3) gives an increase in the binding of annexin V at low PS concentrations. At $20 \% \mathrm{PE}$ the values of $1-3 \%$ PS and at $30 \%$ PE the values of $1-4 \%$ PS are significantly higher from the values without the addition of PE. At high PS concentrations the maximum binding is not affected.

Addition of sphingomyelin in various concentrations into the phospholipid layer has no significant effect on the binding off annexin V-FITC to phospholipid layers (Fig. 3.4). When cholesterol is incorporated in the membrane (Fig. 3.5) the binding of annexin $\mathrm{V}$ at low PS concentrations was reduced. The more cholesterol is present the stronger the reduction observed. Both at a phospholipid cholesterol ratio of $2: 1$ and at a phospholipid to cholesterol ratio of 1:1 the annexin V-FITC binding is significantly lower than to a pure phospholipid (PC/PS) bilayer.

\section{Discussion}

When annexin $V$ is used as a marker for the exposure of phosphatidylserine on cell surfaces (Comfurius et al. 1994, Koopman et al. 1994, Stuart et al. 1995, Thiagarajan and Tait, 1989, Vanheerde et al. 1994) physiological calcium concentrations (eg. 1-3 $\mathrm{mM})$ and low annexin $V$ concentrations $(0.25-5 \mu \mathrm{g} / \mathrm{ml})$ are used. In cell membranes of most cell types the total phosphatidylserine (PS) concentration is not above $10 \mathrm{~mol} \%$ and cell surface exposed PS results from an equilibrium shifting from low to maximal PS exposition (for a review see Devaux, 1991). Nevertheless, in most model studies 20 mol \% PS was used (Andree et al. 1990, Tait et al. 1989). Furthermore physicochemical binding studies used high calcium concentrations [up to $\mathbb{M}$ (Pigault et al. 1994)] and high annexin $V$ concentrations [up to $100 \mu \mathrm{g} / \mathrm{ml}$ (Thiagarajan and Tait, 1989)]. Only minor attention was paid to binding at low PS mole fractions in combination with physiological calcium concentrations, and to the influence of phospholipid classes other than phosphatidylcholine (PC).

Annexin V-FITC binding to PS/PC can be distinguished from the background beginning at about $2 \mathrm{~mol} \% \mathrm{PS}$, which makes it an efficient probe to detect PS exposure on cell membranes. A slight further increase of the PS mole fraction induces 
Chapter 7

General discussion 
Various methods were used to stimulate cells in order to induce loss of membrane phospholipid asymmetry. Using advanced cryo-electron microscopic techniques we were able to visualise plasma membrane reorganisations such as blebbing and vesicle formation. With the use of annexin $\mathrm{V}$ followed by immunocytochemical detection, loss of membrane phospholipid asymmetry could be detected simultaneously with (ultra)structural changes. In early stages of stimulation, the loss of membrane asymmetry was found to be confined to blebs formed on and derived from the plasma membrane. In these early stages of cell stimulation the remainder of the cell membrane maintained an asymmetric distribution of phospholipids over the two leaflets.

\section{Cryo-techniques}

The use of cryo-electron microscopy and freeze-substitution electron microscopy was found to be essential for the wisualisation of small membrane derived vesicles and membrane blebs. If we compare the "cryo" results with those obtained by conventional electron microscopic techniques, a large improvement is made. Cryo-techniques entail very rapid physical fixation of the specimens and avoid extraction of lipids by organic solvents.

\section{Reliability of the detection method}

The localisation of annexin V by immunocytochemistry was found a valuable tool for the determination of phosphatidylserine exposure at the outer membrane leaflet. The low Kd of annexin $V$ for PS containing membranes (Andree et al. 1990) combined with the relatively low detection limit for PS under physiological conditions (chapter 3) make annexin $V$ a suitable probe for loss of membrane phospholipid asymmetry. The binding of annexin $\mathrm{V}$ to phospholipid membranes develops more or less logarithmic, which gives the impression of an all or nothing effect. However, intermediate labelling by annexin $V$ was found (chapter 3 ). Therefore, the different cell populations observed with flow cytometry of annexin V-FITC labelled cells after activation (chapter 5, Martin et al. 1995, Vermes et al 1995, Fadok et al. 1992), do not solely result from the annexin $\mathrm{V}$ binding characteristics but also are the consequence of the mechanisms by which PS is exposed to the outer monolayer. Similar separated cell populations were observed when NBD labelled phospholipids were used instead of annex in $\mathrm{V}$ to detect loss of membrane phospholipid asymmetry (Schlegel et al. 1993, Verhoven et al. 1995). This indicates that the method used does not affect the result. Therefore, the data obtained in chapters 4-6 may be representative for where and when loss of membrane asymmetry occurs. Chapter 2 also showed a local loss of membrane phospholipid asymmetry using a different (and less reproducible) binding principle. This together with the use of coagulation factor Xa in combination with an antibody against Xa (chapter 4 , clata not shown), there is strong evidence that the local and general loss of cell membrane asymmetry as found with the use of annexin $\mathrm{V}$ represents the in vivo situation.

\section{Timescale of blebbing}

The loss of phospholipid asymmetry is probably fast (in the order of seconds to 
minutes) and a time resolution for a cytochemical method should match the rate of PS exposure. That translocation is a fast process is supported by the electron micrographs. In all three models in which loss of phospholipid asymmetry was studied, we rarely found blebs still attached to the membrane, trapped while being formed. If the formation of blebs is a relative slow process various morphological intermediates would have been observed, which was not the case.

\section{Model for the loss of membrane phospholipid asymmetry}

In all three models we found the early stages of asymmetry loss to be localised on the blebs formed on and pinched off-from the plasma membrane. However, there are several reports claiming membrane asymmetry loss in blood platelets and erythrocytes without the formation of micro-vesicles (Dachary-Prigent et al. 1993, Pasquet et al. 1996, Williamson et al. 1992) under specific conditions preventing cytoskeletal degradation by calpain. The results reported in at least one of these studies (DacharyPrigent et al. 1993) indicate that micro-vesicle formation could easily have been overlooked because the detection of microvesicles was done with a flow cytometer. Micro-vesicle size is typically in the order of $100-500 \mathrm{~nm}$, which is too small to be effectively detected using single particle light scattering techniques (standard flow cytometry conditions). Furthermore the detection revealed only two populations after activation of control platelets, whereas we clearly found three populations (e. g. intact platelets, blebbing platelets and 'scrambled' remnant platelets see chapter 4) on basis of morphological observations. Activation of blood platelets under similar conditions (using MDL, a calpain inhibitor) in our laboratory followed by observation of the platelets with cryo-electron microscopy invariably displayed the formation of micro-vesicles (unpublished data). This again stresses the importance of supplementary ultra-structural data when studying membrane dynamics.

In all the studies presented in this thesis morphological evidence was presented that the loss of membrane phospholipid asymmetry started upon stimulation as a focal phenomenon confined to blebs formed on the plasma membrane, irrespective of the type of cell or the stimulus used. The homology of the formed structures and the loss of membrane phospholipid asymmetry suggests a common mechanism.

The mechanism by which the phospholipid asymmetry is disturbed is believed to be responsible for its local character. Loss of
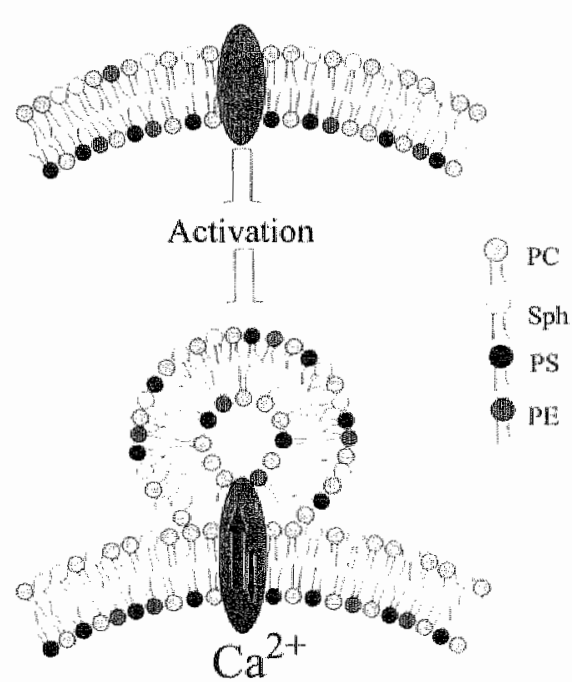

Figure 7.1 Model for the calcium activated scrambling and translocation of phospholipids over the bi-layer membrane. The large arrow indicates for a large amount of lipids transported from the inner to the outer membrane leallet, whereas the small arrow symbolises the smaller fraction of lipids transported from phospholipid asymmetry is mainly the result of the outer to the inner membrane leatet. scrambling of phospholipids over the 
membrane, as was demonstrated with different fluorescent phospholipid analogues incorporated in the plasma membrane before stimulation (Williamson et all. 1995, Smeets et al. 1994, Verhoven et al. 1995). The formation of blebs on the membrane, however, can occur when there is a net outflow of lipids during the scrambling process (in:out ratio $<1$ ). Therefore the "scramblase" is believed to shuttle phospholipids between the two bilayer halves with (slightly) different rates. At least the translocation of sphingomyelin from the outside to the inside seems to be slower than the in/out translocation (Williamson et al. 1995) which can account for a phospholipid imbalance. A mass imbalance between the outer and inner leaflet of the membrane, can be accommodated by changing the shape (Daleke and Huestis 1.985, Seigneuret and Devaux 1984). The formation of blebs is an example of such a shape change (Farge and Devaux 1992). The highly local character of the PS exposition gives the impression that lateral diffusion is hindered or that the translocation is faster than lateral diffusion. A scramblase catalysing flip-flop of phospholipids at different rates has lead to the simplified model as shown in figure 7.1 (Zwaal et al. 1993). The affinity of the "scramblase" for the glycero-phospholipids seems to be some what larger than for the ceramide based sphingomyelin. This can explain the larger outward translocation of phospholipids than the inward translocation, which may lead to bleb formation.

\section{Involvement of the cytoskeleton in the loss of} membrane asymmetry

Although the cytoskeleton is not directly involved in the loss of membrane phospholipid asymmetry (Calvez et al. 1988, Kuypers et al. 1993), the exact role of the cytoskeleton in vivo is still a matter of debate (Verhallen et al. 1987, Fox et al. 1991, Squir et al. 1994, Musters et al. 1993). Under physiologic conditions, cytoskeleton degradation by calpain activity may facilitate a fast collapse of the phospholipid asymmetry. When calpain is inhibited the number of microvesicles will be reduced (Fox et al. 1990). Most likely, loss of

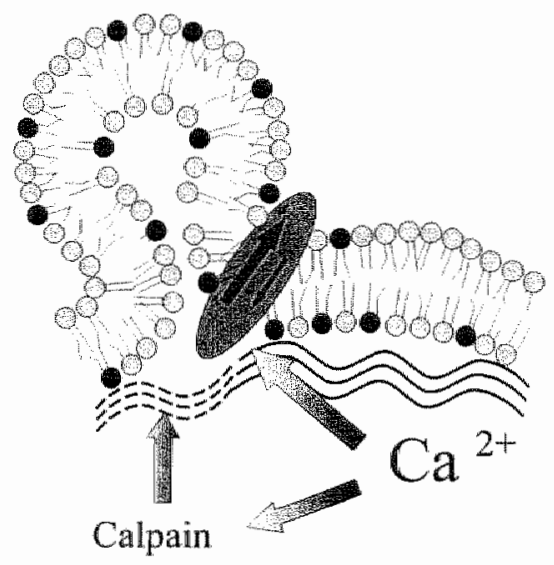

Figure 7.2 cytoskeleton degradation by calcium activated callpain will facilitate blebbing of the membrane when an imbalance between the two membrane leaflets is the result of scramblase activity. membrane asymmetry leads to a surplus of lipids in the outer membrane leaflet, which will lead to the formation of blebs on the membrane. This phenomenon will occur with or without cytoskeleton degradation, but cytoskeleton degradation will help to form a "weak spot" were the bleb can be formed more easily (figure 7.2)(adapted from Zwaal and Schroit 1997).

\section{The physiological significance of blebbing}

The physiological significance of the formation of vesicles is presently not clear.

Speculations can be made on the role of vesicle formation in the clotting process. The observation that the micro-vesicles are the first structures that expose PS at their outer 
membrane surface after the activation of blood platelets makes them the earliest formed catalytic membrane surface during activation of the coagulation cascade. Thus, tenase and prothrombinase will be first active on the micro-vesicles and consequently fibrin will be generated from the vesicle surface. Micro-vesicles derived from blood platelets contain the major glycoproteins (GPIIb/IIIa) and therefore have the ability of to bind fibrinogen (Wencel-Drake et al. 1993). The microvesicle can thus act as a basis for the formation and of fibrin anchoring. The microvesicle might thus serve as a kite on a fibrin string anchored on one end to (spread) platelets via GPIIb/IIIa (Loscalzo et al. 1986) and at the other end to the microvesicle. Another possibility is that the microvesicle acts as a spider in a fibrin web; from its surface more sticky (fibrin) strings are generated. The fibrin thus produced can promote further activation of blood platelets trapped in the network (Beguin and Kumar 1997). This leads to a stable thrombus with

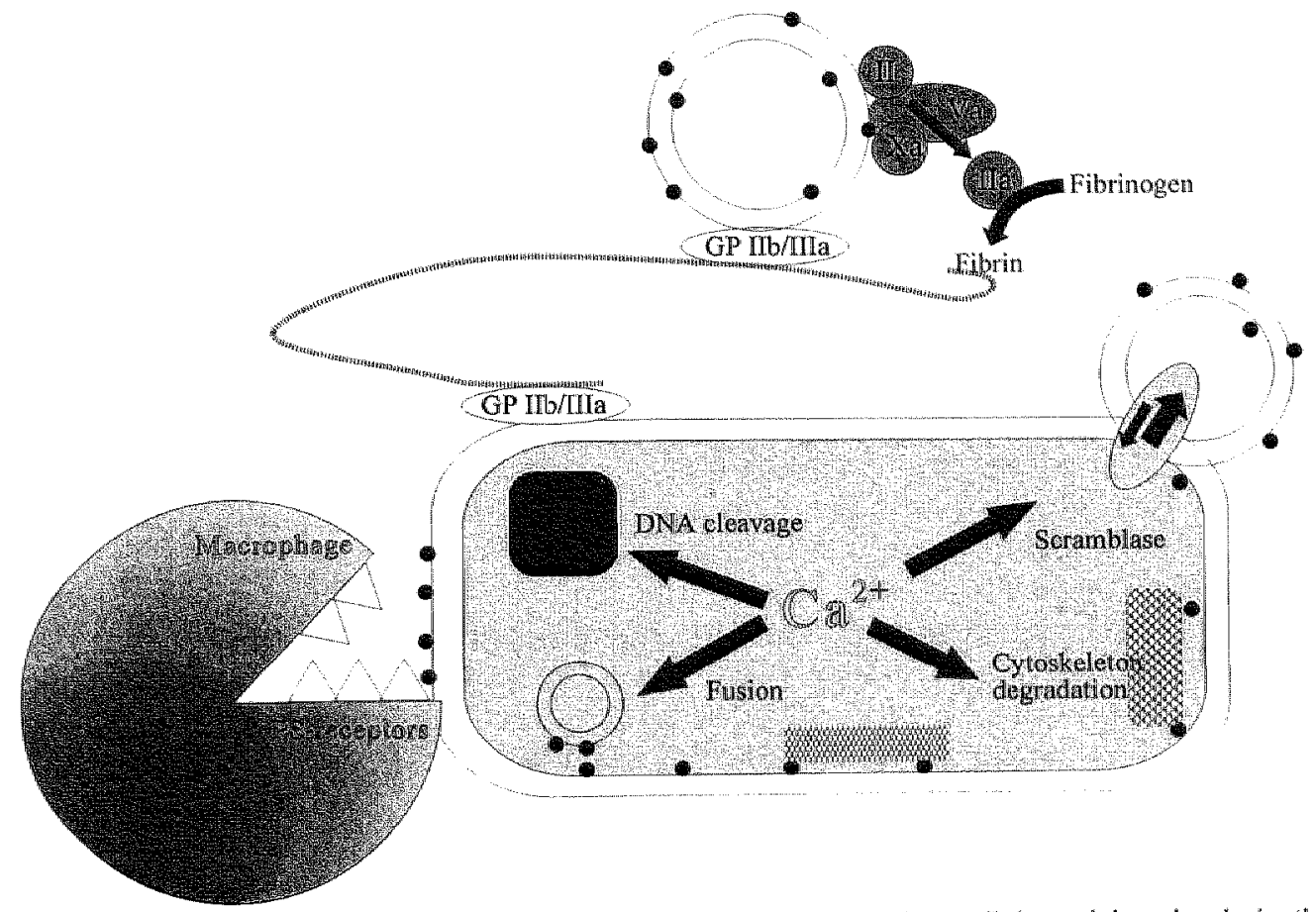

Figure 7.3 Schematic overview of the role of increased intracellular calcium levels in the loss of membrane phospholipid asymmetry and some phosphatidylserine (-) related reactions.

platelets and vesicles trapped in a fibrin clot as was observed by fluorescence microscopy and scanning electron microscopy (Silander et al. 1996).

Besides coagulation other reactions can take place on the surface of PS exposing blebs in the plasma, such as complement activation and opsonisation and interaction with the reticuloendothelial system (Fadok et al. 1992, Sambrano et al. 1995). PS exposition in tissue may lead to a different situation. In tissue, opsonisation is likely the first reaction to take place. Also activation of the complement system may occur, whereas clotting reactions may be less important. Shielding PS by endogenously produced annexin has 
been proposed as salvage principle for ischemic cardiomyocytes (Jans et al. 1997). The immediate expulsion from the cell of phosphatidylserine (as a vesicle) once it is exposed to the outside of the membrane might be a rescue mechanism without jeopardising the cell. An overall exposition of PS at the outer membrane leaflet is most likely a sign of irreversible membrane damage, whereas the early stage with PS exposure confined to the blebs and elimination of the exposed PS from the cell is still reversible (Langer et al. 1996).

\section{The role of calcium in the three models}

Although all three models (platelets, thymocytes, myocytes) seem different at first sight, shifts in calcium concentrations are involved in all three processes. The scramblase activation is one of many reactions which are activated by calcium. In both activated platelets and in apoptotic cells increased levels of, calcium activated, cytoskeletal degrading enzymes are found (e. g. calpain). In cardiomyocytes loss of membrane asymmetry has been ascribed to breaking of the PS cytoskeleton binding (Musters et al. 1993). DNA cleavage at the internucleosomal sites, by calcium activated endonucleases (Wyllie, 1980, Arends et al., 1990, Hockenbery, 1995), is also an important function of increased intracellular calcium during apoptosis. In figure 7.3 a schematic overview of relevant calcium activated processes is given (calcium signal transduction during normal haemostasis is not included but certainly also a very important parameter).

\section{Common factor between the three models}

If we consider the three models not as independent entities but try to find a common denominator on basis of the highly local exposure of phosphatidylserine on blebs derived from the plasma membrane, apoptosis could be the generic term for this. Membrane blebbing and loss of membrane asymmetry is considered as a hallmark of apoptosis, followed by DNA cleavage. The activation of blood platelets has not yet been related to apoptosis; one reason could be that there is no nuclear DNA cleavage in platelets. Alternatively we may consider platelet formation out of megakaryocytes as an apoptotic process, with a delayed offset. Platelet activation is than the trigger for executing an already started, but temporarily interrupted, sequence of events leading to the fast exposure of phosphatidylserine on membrane derived blebs. Also the formation of erythrocytes out of erythroblasts can be considered as a form of apoptosis.

Erythroblasts develop into normocytes with a pycnotic nucleus, which is then extruded from the cell. The remaining erythrocyte is then an apoptotic body with a delayed offset of membrane asymmetry loss upon ageing. It would be of great interest to know whether nucleated erythrocytes (birds, amphibians) demonstrate DNA cleavage and nuclear pycnosis upon activation.

\section{Prospects}

In future studies several aspects of the loss of membrane asymmetry can be further elucidated. With the use of cryo-electron microscopic techniques the role of the cytoskeleton membrane interactions can be monitored. Another approach could be the use of calpain inhibitors to see if their are conditions at which membrane blebbing can 
be reduced or prevented, whereas release of asymmetry continues. Another approach could be the simultaneous detection of cells and membrane derived vesicles with a flow cytometer. Because forward or side scatter properties of the vesicles can not be used for the detection, a second fluorochroom against the cell membrane can solve this problem. Such an approach could give a better insight in when and how membrane asymmetry loss occurs. Furthermore, applying the techniques developed in these studies to other models of early apoptosis, such as changes in mitochondrial potential (Zamzami et al. 1997) would be of great interest.

As stated before calcium plays an important role in the activation of processes leading to the loss of membrane phospholipid asymmetry. However no attention was paid to the extracellular calcium levels of blood platelets during their isolation (isolation was done in the absence of calcium to prevent blood coagulation). From studies on cardiomyocytes it is well known that such a calcium free period strongly activates the cells (calcium paradox). Wether such a calcium paradox affects the behaviour of the platelets used in our experiments is presently not known.

\section{Conclusion}

In conclusion, during the early stages of cell stimulation the loss of membrane phospholipid asymmetry is a local phenomenon confined to blebs, followed by an overall loss of phospholipid asymmetry. This strict local character during the early stages of activation was demonstrated by immunocytochemistry at the electron microscopic level in three different cellular model systems: the activation of blood platelets, induction of apoptosis in thymocytes and on ischemic neonatal cardiomyocytes. This may suggest a common mechanism underlying these seemingly different biological phenomena.

\section{References}

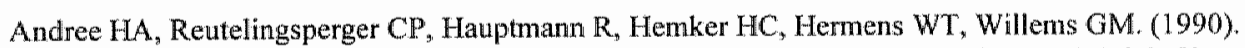
Binding of vascular anticoagulant alpha (VAC alpha) to planar phospholipid bilayers. J. Biol. Chem. $265,4923-4928$.

Arends MJ, Morris RG, Wyllie AH. (1990). Apoptosis: The role of the endonuclease. Am. J. Pathol. $136,593+6008$.

Basse F, Stout JG, Sims PI, Wiedmer T. (1996). Isolation of an erythrocyte membrane protein that mediates $\mathrm{Ca}^{2+}$-dependent transbilayer movement of phospholipids. J. Biol. Chem. 271, 17205-17210.

Beguin S, Kumar R. (1997). Thrombin, fibrin and platelets: a resonance loop in which von Willebrand factor is a necessary link. Thromb. Haemostasis, 78, 590-594.

Calvez JY, Zachowski A, Hermann A, Morrot G, Devaux PF. (1988). Asymmetric distribution of phospholipids in spectrin-poor erythrocyte vesicles. Biochemistry, 27, $5666-5670$.

Connor J, Pak CH, Zwaal RF, Schroit AJ. (1992). Bidirectional transbilayer movement of phospholipid analogs in human red blood cells. Evidence for an ATP-dependent and protein-mediated process. J.

Biol. Chem. 267, 19412-19417.

Dacharyprigent J, Freyssinet JM, Pasquet JM, Carron JC, Nurden AT. (1993). Annexin-V as a Probe of Aminophospholipid Exposure and Platelet Membrane Vesiculation - A Flow Cytometry Study

Showing a Role for Free Sulfhydryl Groups. Blood, 81, 2554-2565. 
Daleke DL, Huestis WH. (1985). Incorporation and translocation of aminophospholipids in human erythrocytes. Biochemistry, 24, 5406-5416.

Fadok VA, Savill JS, Hasleti C, Bratton DL, Doherty DE, Campbell PA, Henson PM. (1992). Different populations of macrophages use either the vitronectin receptor or the phosphatidylserine receptor to recognize and remove apoptotic cells. J. Immunol. 149, 4029-4035.

Farge E, Devaux PF. (1992). Shape changes of giant liposomes induced by an asymmetric transmembrane distribution of phospholipids. Biophys. I. 61, 347-357.

Fox JE, Austin CD, Boyles. IK, Steffen PK. (1990), membrane. Role of the membrane skeleton in preventing the shedding of procoagulant-rich microvesicles from the platelet plasma. J. Cell. Biol. 111, $483-493$.

Eox J1, Austen CD, Reynolds CC, Steffer PK. (1.991). Evidence that agonist-induced activation of calpain causes the shedding of procoagulant-containing microvesicles from the membrane of aggregating platelets. J. Biol. Chem. 266, 13289-13295.

Hockenbery, D. (1995). Defining apoptosis. Am. J. Pathol. 146, 16-19.

Jans SW, Willems J, van Bilsen M, Reutelingsperger CP, van der Vusse GJ. (1997). Phospholipid degradation in energy-deprived cardiac nyocytes: does annexin V play a role? J. Mol. Cell. Cardiol. $29,1401-1410$.

Kuypers FA, Lubin BH, Yee M, Agre P, Devaux PF, Geldwerth D. (1993). The distribution of erythrocyte phospholipids in hereditary spherocytosis demonstrates a minimal role for erythrocyte spectrin on phospholipid diffusion and asymmetry. Blood, 81, 1051-1057.

Loscalzo I, Inbal A, Handin RI. (1986). von Willebrand protein facilitates platelet incorporation in polymerizing fibrin.J. Clin. Invest.. 78, 1112-1119.

Martin SJ, Reutelingsperger CP, McGahon AJ, Rader JA, van Schie RC, LaFace DM, Green DR. (1995). Early redistribution of plasma membrane phosphatidylserine is a general feature of apoptosis regardless of the initiating stimulus: inhibition by overexpression of $\mathrm{Bcl}-2$ and $\mathrm{Abl}$. J. Exp. Med. $182,1545-1556$.

Musters RJ, Otten E, Biegelmann E, Bijwelt J, Keijzer JJ, Post JA, Op den Kamp JA, Verkleij AJ. (1993). Loss of asymmetric distribution of sarcolemmal phosphatidylethanolamine during simulated ischemia in the isolated neonatal rat cardiomyocyte. Circ. Res. 73, 514-23.

Pasquet JM, Dachary-Prigent $J$, Nurden AT. (1996). Calcium influx is a determining factor of calpain activation and microparticle formation in platelets. Eur. J. Biochem. 239, 647-654.

Sambrano GR Steinberg D. (1995). Recognition of oxidatively damaged and apoptotic cells by an oxidized low density lipoprotein receptor on mouse peritoneal macrophages: role of membrane phosphatidylserine. P. Natl. Acad. Sci. USA, 92, 1396-1400.

Schlegel RA, Stevens M, Lumley-Sapanski K, Williamson P. (1993). Altered lipid packing identifies apoptotic thymocytes. Immunol. Lett. 36, 283-288.

Schlegel RA, Callahan M, Krahling S, Pradhan D, Williamson P. (1996). Mechanisms for recognition and phagocytosis of apoptotic lymphocytes by macrophages. Adv. Exp. Med. Biol. 406, 21-28.

Seigneuret M, Dewaux PF. (1984). ATP-dependent asymmetric distribution of spin-labeled phospholipids in the erythrocyte nembrume: relation to shape changes. P. Natl. Acad. Sci. USA, 81, $3751-3755$.

Siljander $P$, Carpen O, Lassila R. (1996). Platelet-derived microparticles associate with fibrin during thrombosis. Blood, 87, 4651:4663.

Sneets EF, Comfurius P, Bevers EM, Zwaal RF. (1994). Calcium-induced transbilayer scrambling of 
luorescent phospholipid analogs in platelets and erythrocytes. Biochim. Biophys. Acta, 1195, 281-286,

Speijer H, Jans SW, Reutelingsperger CP, Hack CE, van der Vusse GJ, Hermens WT, (1997). Partial coverage of phospholipid model membranes with annexin $V$ may completely inhibit their degradation by phospholipase A2. FEBS Lett. 402, 193-197.

Squier MK, Miller AC, Malkinson AM, Cohen JJ. (1994). Calpain activation in apoptosis. I. Cell. Physiol. 1.59, 229-237.

Verhallen PF, Bevers EM, Comfurius P, Zwaal RF. (1987). Cortelation between calpain-mediated cytoskeletal degradation. Biochin. Biophys. Acta 903, $206-217$.

Verhoven, B, Schlegel RA. Williamson P. (1995). Mechanisms of phosphatidylserine exposure, a phagocyte recognition signal, on apoptotic T lymphocytes. J. Exp. Med. 182, 1597-1601.

Vermes I, Haanen C, Steffens-Nakken H, Reutelingsperger CP. (1995). A novel assay for apoptosis: flow cytometric detection of phosphatidylserine expression on early apoptotic cells using fuorescein labellld annexin V. J. Immunol. Methods. 184, $39-51$.

Wencel-Drake JD, Dieter MG, Lam SC. (1993). Immunolocalization of beta I integrins in platelets and platelet-derived microvesicles. Blood, 82, 1197-1203.

Williamson P, Kulick A, Zachowski A, Schlegel RA, Dewaux PF: (1992). Ca ${ }^{2+}$ indnces transbilayer redistribution of all major phospholipids in thuman erythrocytes. Biochemistry, 31, 6355-6360.

Williamson P, Bevers EM, Smeets EF, Comfurius P, Schlegel RA, Zwal RF. (1995). Continuous analysis of the mechanism of activated transbilayer lipid movennent in platelets. Biochemistry, 34. $10448-10455$.

Wyllie AH. (1980), Glucocorticoid-induced thymocyte apoptosis is associated with endogenous endonuclease activation. Nature, 284, 555-556.

Zamzami N, Marchetti P, Castedo M., Zanin C, Vayssiere IL, Petit PX., Kroemer G. (1995). Reduction in mitochondrial potential constitutes an early irreversible step of programmed lymphocyte death in vivo. J. Exp. Med. 181, 1661-1672.

Zhou Q, Zhao J, Stout 『G, Luhm RA, Wiedmer T, Sims PJ. (1997). Molecular cloning of human plasma membrane phospholipid scramblase. A protein mediating transbilayer movement of plasma membrane phospholipids. J. Biol. Chem. 272, $18240-18244$.

Zwaal RF, Bevers EM, Comfurius P, Rosing J, Tilly RH, Verhallen PF. (1989). Loss of membrane phospholipid asymmetry during activation of blood platelets and sickled red cells; mechanisms and physiological significance. Mol. Cell. Biochem. 91, 23-31.

Zwall RF, Schroil AJ. (1997). Pathophysiologic implications of membrane phospholipid asymmetry in blood cells. Blood, 89, $1121-1132$. 



\section{Summary}

The cell membrane separates the interior from the exterior of the cell. Communication of the cell with the outside world goes via the cell membrane, uptake of nutrients as well as the receiving signals. The cell membrane of all cells have a common architecture. Phospholipids, the building blocks, form a bilayer in which proteins are embedded. Their are different classes of phospholipids which are not symmetrical distributed over the two halves of the membrane. The choline phospholipids (phosphatidylcholine, $\mathrm{PC}$ and sphingomyelin, Sph) are predominantly located in the outer halve of the lipid bilayer. From the amino-phospholipids is

phosphatidylethanolamine (PE) predominantly and phosphatidylserine (PS) exclusively located in the inner halve of the lipid bilayer. This asymmetric distribution is maintained by the aminophospholipid translocase. However, the asymmetric distribution of phospholipids over the plasma membrane can be partially or completely abolished when cell are stimulated (loss of phospholipid asymmetry). Loss of membrane phospholipid asymmetry is accompanied by a number of biochemical and morphological alterations in the stimulated cell. The most important morphological alteration is the formation of membrane blebs, which are pinched off from the membrane. An overview of the loss of membrane asymmetry is given in chapter 1 . In this thesis three models are investigated with respect to their morphological alterations and to the loss of membrane asymmetry. The aim of these studies was to investigate the relation between morphological changes and previously described biochemical alterations.

The perspectives and limitations of cryo-electron microscopy are outlined in chapter 2 and illustrated on liposomes and whole cells (blood platelets). Furthermore loss of membrane asymmetry is visualised with a combination of cryo-electron microscopy and cytochemical labelling of PS with coated gold particles. Cryo-electron microscopy was found to be very suitable for the observation of aqueous suspensions of phospholipids and to trap fast changes such as phase changes. For the observation of complete cells the specimen penetration by the electron beam was a limiting factor, not the resolution. The use of higher acceleration voltages (e.g. $300 \mathrm{kV}$ instead of 120 $\mathrm{kV}$ )could overcome this problem. Dynamic changes of the structure of cells could be (physically) fixed as was demonstrated by the activation of blood platelets. Activated platelets form many membrane blebs which are pinched off from the membrane. Localisation of the loss of membrane asymmetry by coagulation factor Va coupled to gold particles could only be performed when concessions were made to the speed of the method. Furthermore the localisation of PS in this way was difficult to reproduce due to instability of the Va-gold complex. The results however, clearly show a local difference in PS exposition. Membrane vesicles are densely labelled whereas the platelet it self was not labelled.

Annexin V, a phospholipid binding protein with a high affinity for PS, is a suitable probe for the detection of loss of membrane asymmetry at the electron microscopic 
level. However all binding studies used optimal conditions whereas we wanted to use annexin $V$ at more physiological conditions. We therefore had to look for a method to characterise the binding properties at physiological conditions. In chapter 3 annexin V binding to membranes with various composition was studied. Hollow glass beads (2-20 $\mu \mathrm{m})$ were coated with phospholipid bilayers. With the use of fluorescent annexin $V$ binding could be measured in a flow cytometer. Annexin V binding to PC bilayers was found to increase rapidly with increasing amounts of PS (2-5\%). As from about $6 \%$ PS the binding reaches a plateau. The addition of PE to the bilayer renders the system to be more sensitive for PS. Sphingomyelin has no effect on the binding of annexin $V$ to the phospholipid bilayer. Cholesterol on the other hand has a negative influence on the binding of annexin $V$.

In chapter 4 is a method described for vitrification (rapid cooling without the formation of ice crystals) of activated blood platelets in the presence of annexin V. After freeze substitution and embedding in a plastic sections were made on which annexin $V$ can be localized with immuno cytochemistry. Platelets activated with calcium ionophore, a strong activator, loose their membrane asymmetry almost instantly, as seen by labelling of al the membranes. Platelets activated with thrombin (coagulation factor IIa) in combination with thapsigargin, a calcium ATPase inhibitor, only loose their membrane asymmetry on vesicles derived from and pinched of from the plasma membrane. The cellular material could be divided into three sub-populations; intact platelets, "empty" remnants from activated platelets and micro-vesicles. The micro-vesicles and the empty remnants were always found positively labelled, whereas in the intact platelets the asymmetric distribution of phospholipids remained intact. Blood platelets have an extended internal network of cell membrane invaginations (open canalicular system). Upon activation micro-vesicles were found trapped in the open canalicular system. The microvesicles had lost their membrane asymmetry whereas the membrane from which these micro-vesicles are derived maintained the asymmetric distribution of phospholipids.

The second model of cell activation is the programmed suicide (apoptosis) of thymocytes. Apoptosis was induced by treating the thymocytes with dexamethasone. The course of the apoptosis was followed by flow cytometry with fluorescent annexin $V$ as a marker for the loss of membrane asymmetry. Simultaneously the accessibility of the nucleus for propidium iodide was measured. Morphological changes were again studied in combination with the ultrastructural localisation of the loss of membrane asymmetry (chapter 5). As a result of the apoptotic process micro-vesicles are pinched of from the membrane with lost membrane asymmetry. The thymocytes remain there asymmetric distribution of phospholipids until the nucleus changes dramatically. At that moment the cell membrane becomes positively labelled for annexin $V$. Later in the apoptotic process the thymocytes disintegrate into apoptotic bodies.

The third model describes the loss of phospholipid asymmetry of myocytes as the result of an ischemic period (chapter 6). Both at light an electron microscopic level loss of membrane asymmetry of the myocytes was observed. Although it is known that myocytes partially loose their PE asymmetry during early stages of ischemia, no annexin $\mathrm{V}$ binding could be detected on the cells. Only membrane derived vesicles showed annexin $V$ binding during early stages of ischemia. After prolonged ischemia 
the myocytes loss their membrane integrity and an overall annexin $\mathrm{V}$ binding was observed.

In conclusion, loss of membrane phospholipid asymmetry is a local phenomenon, restricted to micro-vesicles, during the early stages of cell activation. 



\section{Samenvatting}

De celmembraan vormt de afscheiding tussen binnen en buiten de cel. leder contact van de cel met de buiten wereld verloopt via de celmembraan, of het nu gaat om opname van voedingsstoffen of het ontvangen van signalen. De membranen van alle cellen zijn opgebouwd volgens hetzelfde basis principe. Fosfolipiden, de basis bouwstenen, vormen een dubbel-laag (bilaag) waarin eiwitten zijn ingebed. Er bestaan verschillende klassen van fosfolipiden en deze zijn niet symmetrisch over de twee helften van de membraan verdeeld. Zo komen de choline fosfolipiden (phosphatidylcholine, $\mathrm{PC}$ en sphingomyelline) komen voornamelijk voor in de buitenste helft van de lipiden bilaag. Van de amino-fosfolipiden (phosphatidylserine, PS en phosphatidylethanolamine, PE) komt PE voornamelijk en PS uitsluitend voor in de binnenste helft van de lipiden bilaag. Deze asymmetrische verdeling wordt in stand gehouden door amino-fosfolipiden translocase. Echter, door cel-activatie kan de asymmetrische verdeling van de verschillende fosfolipiden klassen verstoord raken, we spreken dan van verlies van membraanasymmetrie. Verlies van membraanasymmetrie gaat gepaard met een groot aantal biochemische en morfologische veranderingen in de geactiveerde cel. De belangrijkste morfologische verandering is de vorming van membraanvesikels, die afgesnoerd worden. Een overzicht van membraanasymmetrie en verlies van membraanasymmetrie wordt in hoofdstuk 1 gegeven. In dit proefschrift wordt bij een aantal modellen van cel-activatie gekeken naar de morfologische veranderingen en naar het verlies van membraanasymmetrie. Het doel is een verband te leggen tussen de morfologische veranderingen en eerder beschreven biochemische veranderingen.

In hoofdstuk 2 worden de mogelijkheden en de grenzen van cryo-elektronenmicroscopie beschreven aan de hand van een liposoom en een hele cel (bloedplaatjes) model. Tevens wordt een eerste poging ondernomen om verlies van membraanasymmetrie zichtbaar te maken in een combinatie van cryo-elektronenmicroscopie en cytochemische labeling van PS met behulp van gecoate goud bolletjes. Cryoelectronenmicroscopie blijkt uitermate geschikt voor de observatie van waterige oplossingen van fosfolipiden en voor het vast leggen van snelle veranderingen zoals fase veranderingen. Voor het bekijken van hele cellen is niet zozeer het oplossend vermogen een beperkende factor als wel de doordringbaarheid van het (dikke) preparaat voor elektronen. Het gebruik van hogere versnel spanningen ( $300 \mathrm{kV}$ in plaats van $120 \mathrm{kV}$ ) kan hiervoor uitkomst bieden. Ook dynamische structuur veranderingen kunnen goed worden vast gelegd zoals gedemonstreerd wordt aan de hand van de activatie van bloed plaatjes. Geactiveerde bloed plaatjes vormen grote hoeveelheden membraan vesikels die afgesnoerd worden. Lokalisatie van verlies van membraan asymmetrie met behulp van stol factor $\mathrm{Va}$, dat sterk bind aan membraan oppervlakken met PS, gekoppeld aan goudbolletjes bleek alleen mogelijk indien concessies gedaan werden aan de snelheid van de methoden. Bovendien was deze methoden moeilijk reproduceerbaar door instabiliteit van het Va-goud complex. De 
resultaten die verkregen zijn laten duidelijk lokale verschillen zien in PS expositie. Met name de membraan vesikels zijn sterk gelabeld terwijl het plaatje zelf niet gelabeld is.

Annexine $V$, een fosfolipiden bindend eiwit met een hoge affiniteit voor PS, bleek een geschikte probe voor het opsporen van verlies van membraanasymmetrie op electronemmicroscopisch niveau. Aangezien alle bekende bindings studies uitgaan van optimale bindings condities en niet van fysiologische condities, moest gezocht worden naar een mogelijkheid om onder fysiologische omstandigheden de bindingseigenschappen te meten. In hoofdstuk 3 wordt de binding van annexine $\mathrm{V}$ aan membraan opperwlakken van verschillende samenstelling gemeten. Dit gebeurd door kleine holle glasbolletjes van 2-20 $\mathrm{m}$ te coaten met een (fosfo)lipiden dubbel-laag. Met behulp van fluorescerende annexine $\mathrm{V}$ kan vervolgens in een flow cytometer de binding worden gemeten aan deze glasbolletjes. Annexine $\mathrm{V}$ binding aan PC bilagen blijkt snell toe te nemen bij toenemende hoeveelheden PS (2-5\%). Vanaf ongeveer $6 \%$ PS wordt een plateau in de binding bereikt. Toevoeging van PE aan de bilaag heeft tot gevolg dat het systeem nog gevoeliger op PS reageert. Sphingomyeline heeft geen effect op de binding van annexine $V$. Cholesterol daaren tegen heeft een nadelige invloed op de binding van annexine $\mathrm{V}$ aan bi-lagen.

In hoofdstuk 4 wordt beschreven hoe geactiveerde bloedplaatjes in aanwezigheid van annexine $\mathrm{V}$ worden gevitrificeerd (heel snel afgekoeld, zonder vorming van ijskristallen). Na vries-substitutie en inbedding in een plastic kunnen van de cellen ultradunnen coupes worden gemaakt waarop via immuno-cytochemie annexine $V$ kan worden gelokaliseerd. Waneer de plaatjes geactiveerd zijn met ionofoor, een zeer krachtige activator, blijken de cellen zeer snel hun membraanasymmetrie te verliezen, wat in de electronenmicroscoop gezien wordt als labeling op de membranen. Indien de plaatjes worden geactiveerd met thrombine (stol-factor IIa) in combinatie met de calcium ATPase remmer thapsigargine blijken tijdens de begin fasen van de activatie uitsluitend de afgesnoerde membraanvesikels gelabeld. Verder kan het celpreparaat duidelijk in drie sub-populaties worden onderverdeeld; te weten, min of meer intacte plaatjes, lege achterblijfsels van (uit-)geactiveerde plaatjes en afgesnoerde microvesikels. De microvesikels en de lege achterblijfsels werden ten alle tijden positief bevonden, terwijl de min of meer intacte plaatjes hun membraanasymmetrie behouden hadden (niet gelabeld). Bloedplaatjes bezitten een uitgebreid en vertakt inwendig netwerk van insnoeringen van de celmembraan (; het open canaliculaire systeem). $\mathrm{Na}$ activatie werden ook in dit deel van de celmembraan afgesnoerde vesikels gevonden en deze microvesikels bleken hun membraanasymmetrie verloren te hebben. De membraan van het plaatje waarvan de vesikels kennelijk afkomstig zijn had de asymmetrische verdeling van fosfolipiden behouden.

Het tweede model van cel activatie is de "milde" geprogrammeerde zelfdood (apoptose) van thymocyten (lymfocyten afkomstig uit de zwezerik). Apoptose werd geinduceerd bij thymocyten door deze te behandelen met dexamethasone. Het verloop van de apoptose (kinetiek) kon met behulp van een flow cytometer gevolgd worden aan de hand van verlies van membraan asymmetrie door middel van fluorescerend. annexine V. Simultaan werd gemeten of de celkernen van buitenaf gelabeld konden worden met propidium iodide, een kleuring die aangeeft of de celmembraan functioneel is. Morfologische veranderingen werden bestudeerd in combinatie met de 
eerder genoemde immunocytochemie voor de (ultrastructurele-)lokalisatie van verlies van membraanasymmetrie (hoofdstuk 5). Als gevolg van de apoptose snoeren de thymocyten membraanvesikels af die hun membraanasymmetrie verloren hebben. De thymocyt zelf behoud de asymmetrische verdeling van fosfolipiden tot dat ook de kern sterk verandert. Op dat moment wordt ook de celmembraan van de thymocyt positief gelabeld. In een later stadium begint de cel te desintegreren tot apoptotische bodies.

Het derde en laatst gehanteerde model beschrijft het verlies van membraan asymmetrie in hartspiercellen (hoofdstuk 6) als gevolg van een zuurstof loze periode (na gebootste ischemie). Zowel op licht- als elektronenmicroscopische niveau werd gekeken naar het verlies van membraanasymmetrie met behulp van annexine $V$. Hoewel bekent is dat myocyten in de wroege fasen van nagebootste ischemie hun phosphatidylethanolamine asymmetrie gedeeltelijk verliezen vindt er aan de cel geen annexine binding plaats. Tijdens deze vroege fasen vindt uitsluitend annexine binding plaats aan door de membraan afgesnoerde vesikels die ook hun phosphatidy/serine asymmetrie verloren hebben. $\mathrm{Na}$ langdurige ischemie verliezen de cellen hun integriteit en vind er aan de hele celmembraan binding van annexine $V$ plaats.

Concluderend kunnen we stellen dat het verlies van membraanasymmetrie tijdens de vroege fasen van de stimulatie van de onderzochten cellulaire systemen strikt lokaal is en beperkt blijft tot kleine (elektronenmicroseopisch waarneembare) afgesnoerde membraanvesikels. 



\section{Curriculum Vitae}

Marc Stuart werd geboren op 3 februari 1961 te Nijmegen. In 1979 behaalde hij het eindexamen HAVO aan de scholengemeenschap Canisiuscollege-Mater Dei in Nijmegen. Na twee jaar HTS chemie in Eindhoven werd in 1981 begonnen met de hogere laboratorium opleiding (HLO) aan de rijks hogere agrarische school (STOVA) te Wageningen. In 1985 werd het diploma HLO behaald met als afstudeerrichting biologie botanisch. In hetzelfde jaar trad hij in dienst van de Rijksuniversiteit Limburg bij de vakgroep fysiologie als analist ten behoeve van het door ZWO gefinancieerde onderzoek naar morfologische veranderingen van de hartspier tijdens ischemie. Van 1986 tot 1995 was hij werkzaam bij de vakgroep pathologie als onderzoeksassistent electronenmicroscopie onder leiding van Dr. P. M. Frederik. Het wetenschappelijk onderzoek dat in deze periode werd uitgevoerd, vormt de basis voor dit proefschrift. Vanaf 1997 is hij als post-doc onderzoeker aangesteld bij de vakgroep biofysische chemie van de Rijks Universiteit Groningen.

Marc Stuart is getrouwd met Maike Persoons en heeft twee zonen. 



\section{List of Publications.}

Schrijwers AH, Frederik PM, Stuart MC, van der Vusse GJ, (1989). Dual effect of tannic acid on the preservation and ultrastructure of phosphatidyl choline vesicles. Mol. Cell. Biochem. 88, 91-96.

Frederik PM, Stuart MC, Bomans PH, Busing WM (1989) Phospholipid, nature's own slide and cover slip for cryo-electron microscopy. J. Microsc. 153,81-92.

Frederik PM, Stuart MC, Verkleij AJ (1989) Intermediary structures during membrane fusion as observed by cryo-electron microscopy. Biochim. Biophys. Acta. 979, 275-278

Schrijvers AH, Frederik PM, Stuart MC, Burger KN, Heijnen VV, (1989). Formation of multilamellar vesicles by addition of tannic acid to phosphatidylcholine-containing small unilanullar vesicles. J. Histochem. Cytochem. 37, 1635-1643.

Frederik PM, Bomans PH, Stuart MC. (1991) The ultrastructure of cryo-sections and intact vitrified cells. The effect of cryoprotectants and acceleration voltage on beam induced bubbling Scanning. microscopy suppl. 5, 43-52.

Frederik PM, Stuart MC, Bomans PH, Busing WM, Burger KN, (1991) Perspective and limitations of cryo-electron microscopy. From model systems to biological specinens. J. Microsc. 161, 253-262.

Frederik PM, Burger 'KN, Stuart MC, Verkleij AJ (1991) Lipid polymorphism as observed by" cryo-electron microscopy. Biochim. Biophys. Acta. 1062, 133-141

Andree HAM, Stuart MC, Hermens WT, Reutelingsperger CPM, Hemker HC, Frederik PM and Willems GM. (1992). Clustering of lipid bound annexin $\mathrm{V}$ may explain its anticoagulant effect. J. Biol. Chem. 267, 17907-17912.

Lasic DD, Frederik PM, Stuart MC, Barenholz Y, McIntosh TJ. (1992). Gellation of liposome interior. A novel method for drug encapsulation. FEBS Lett. 312, 255-258.

Stuart MC, Bevers EM, Comfurius P, Zwaal RF, Frederik PM. (1992). Cryo-electron microscopic observation of blood platelet activation and the localisation of procoagulant surface. Electron microscopy. EUREM' 92 Granada, Spain.

Andree HA, Willems GM, Hauptmann R, Maurerfogy I, Stuart MC, Hermens WT, Frederik PM, Reutelingsperger CP. (1993) Aggregation of Phospholipid Vesicles by a Chimeric Protein with the $\mathrm{N}$-Terminus of Annexin-I and the Core of Annexin-V. Biochem. 32, 4634-4640.

Frederik PM, Bomans PH, Stuart MC (1993) Matrix Effects and the Induction of Mass Loss or Bubbling by the Electron Beam in Vitrified Hydrated Specimens. Ultramicroscopy 48, 107-119.

Giesen PL, Willems GM, Hemker HC, Stuart MC, Hermens WT (1993) Monitoring of Unbound Protein in Vesicle Suspensions with Off-Null Ellipsometry. Biochim. Biophys. Acta 1147, 125-131.

Lasic DD, Ceh B, Stuart MC, Guo L, Frederik PM, Barenholz Y. (1995). Transmembrane gradicnt driven phase trasition within vesicles: lessons for drug delivery. Biochim. Biophys. Acti. 1239, 145 156.

Stuart, MC, Bevers, EM, Comfurius, P, Zwaal, RF, Reutelingsperger, CP, Frederik, PM. (1995).

Ultrastructural detection of surface exposed phosphatidylserine on activated blood platelets.

Thrombosis haemostasis. 74, 1145-115il.

Frederik PM, Stuart MC, Bomans PH, Lasic DD. (1996). Cryo-electron microscopy of liposomes. In: Nonmedical aplications of lipposomes. Eds, DD Lasic, Y Barenholz. CRC Press, Boca Raton, New York. 
Wild P, Gabrieli A, Schraner EM, Pellegrini A, Thomas U, Frederik PM, Stuart MC, Vonfellenberg R. (1997). Reevaluation of the Effect of Lysozyme on Escherichia-Coli Employing Uttrarapid Freezing Followed by Cryo-electron microscopy or Freeze-Substitution. Microscopy research and technique 39 , 297.304 .

Lasic DD, Strey H, Stuart MC, Podgornik R, Frederik PM. (1997). The Structure of DNA-Liposome Complexes. Journal of the american chemical society. 119,832-833.

Pestman JM, Terpstra KR, Stuart MC, van Dorem HA, Brission A, Kellogg RM, Engberts JB. (1997). Nonionic Bolaamphiphiles and Gemini Surfactants Based on Carbohydrates. Langmuir, 13,6857-6860.

Skalko N, Bouwstra J, Spies F, Stuart MC, Frederik PM, Gregoriadis G. (1.998). Morphological observations on liposomes bearing covalently bound protein: Studies with freeze-fracture and cryo electron microscopy and small angle X-ray scattering techniques. Biochim. Biophys, Acta, 1370, 151 160.

Stuart MC, Damoiseaux JG, Frederik PM, Arends JW, Reutelingsperger CP. (1998). Surface exposure of phosphatidylserine during apoptosis of rat thymocytes precedes nuclear changes. Eur. J. Cell Biol. $76,77-83$.

Stuart MC, Reutelingsperger CP, Frederik P.M. (1998). Binding of annexin V to bilayers with various phospholipid compositions using glass beads in a flow cytometer Cytometry, in press.

Boekema EJ, Stuart MC, Koning RI, Keegstra W, Verheij HM, Dekker N, Brisson A. (1998) A 7.4-A projection structure of outer membrane phosphollipase A from Escherichia coli by electron crystallography. J. Struct. Bïol. (in press) 


\section{Nawoord}

Vele mensen hebben op enige, of meerdere wijze(n) aan het tot stand komen van dit proefschrift bijgedragen en natuurlijk ben ik hen daar dankbaar voor. Eén iemand is in deze heel bijzonder voor mij geweest. Dr. P. M. Frederik, Peter jij bent degene die de aanzet tot dit alles is geweest, die mij op het juiste spoor heeft geplaatst en gehouden en mij voortdurend stimuleerde ook werkelijk tot een proefschrift te komen. Ik dank je dat je het hebt aangedurfd mij dit promotiepad op te sturen, zonder clat er op dat moment garanties waren voor een goede afloop. Naast jouw wetenschappelijke inbreng, heb ik het altijd als zeer plezierig ervaren om met en vóor jou te werken. Ook buiten de universiteit heb ik je leren kennen als een goede vriend.

Ook zonder mijn steun en toeverlaat Paul Bomans was ik nooit tot promotieonderzoek in staat geweest. Beste Paul, jij was gewoon altijd Paul. Gedurende meer dan 10 jaar Maastricht ben jij voor mij de meest stabiele factor geweest. Jij hebt altijd mee gedacht en hebt vele praktische oplossingen aangedragen voor ogenschijnlijk onmogelijke problemen. Bovendien heb jij heel veel "klote klusjes" opgeknapt, waardoor ik tijd aan mijn onderzoek kon besteden.

Naast de mensen die direct bij het onderzoek betrokken zijn geweest, zijn er natuurlijk nog vele anderen onmisbaar geweest. Allereerst mijn promotoren prof.dr. R. Zwaal en prof.dr. J. W. Arends. Best Rob, ik heb altijd genoten van de discussies die wij op het lab gevoerd hebben over bloedplaatjes en het verlies van membraanasymmetrie, ik heb daar zeer veel van geleerd. Jou enorme kennis op de gebied is voor mij, met name in de laatste fase van dit proefschrift, van ontschatbare waarde gebleken. Beste Jan-Willem, als vakgroepvoorzitter heb jij mij altijd alle ruimte gegeven om dit onderzoek te laten plaatsvinden. Ik denk dat wij in de loop der jaren meer gediscussieerd hebben over de universitaire en facultaire politiek dan dat wij inhoudelijk op dit proefschrift zijn ingegaan. Desalniettemin heb ik ook hiervan zeer veel geleerd en hebben deze discussies bijgedragen aan mijn bredere kijk op het universitair bedrijf.

Annexin $V$ is onmisbaar geweest voor het welslagen van dit onderzoek en zonder de hulp van Dr. C. Reuterlingsperger was het dan ook zeker geen succes geworden. Beste Chris, naast een grote hoeveellheid annexin $V$ die ik van jouw heb gekregen heb jij mij geïntroduceerd in de wereld van annexine en de mogelijkheden voor het aantonen van verlies van membraanasymmetrie. Ook heb jij mij de grondbeginselen van apoptose bijgebracht. Natuurlijk moet ik ook hier Rein en Cecile bedanken voor het mij praktisch op weg helpen met annexine $V$.

De meeste tijd is wel gaan zitten in het werk met bloedplaatjes dat niet mogelijk was geweest zonder de biochemische kennis van Edouard, Paul en Edgar. Bovendien kon ik altijd rekenen op voldoende gezuiverde bloedplaatjes die belangeloos ter beschikking werden gesteld door de vele vrijwilligers.

Voor de verschillende modellen zoals beschreven in dit proefschrift heb ik gebruik moeten maken van de kennis van anderen. Voor het stollingsmodel ben ik de al eerder genoemde Maastrichtse biochemici veel dank verschuldigd. Jan Damoiseaux jouw inbreng bij het isoleren en kweken van de thymocyten waren onontbeerlijk voor het 
apoptose model.

Voor het gebrukte myocyten model is gebruik gemaakt van de kennis van de Utrechtse groep van prof.dr. A. Verkleij en dr. Post. Beste Arie en Jan-Andries zonder jullie steun en brede kennis had ik nooit met myocyten kunnen werken. Ook Bruno wil ik bedanken voor de hulp met het opzetten van de vries-substitutie in Maastricht.

De dames van het lab, Jos en Viviane dank ik voor de gezellige tijd en Ralph met name voor het afdrukken van alle foto's in veelvoud.

Verder heb ik met veel plezier zitting gehad in Universiteits- en Faculteitsraad. Ik wil de collega OBP raadsleden hartelijk danken voor hum prettige samenwerking en soms heftige, maar vruchtbare diskussies.

De volleyballers van Phoenix en IVO, jongens bedankt voor jullie begrip wanneer ik weer eens niet kwam opdagen.

Onze oppassen Hennie en Yvonne, die altijd voor ons klaar stonden om de kinderen op te vangen in Emmen en tijdens onze werkbezoekjes aan Maastricht zijn van groot belang geweest in het traject naar onze boekjes.

Mijn ouders ben ik zeer dankbaar voor alle kansen die ze mij gegeven hebben en hun stimulatie deze te benutten.

Lieve Tijmen en Merijn door jullie ben ik met beide benen op de grond blijven staat en jullie hebben mij laten realiseren dat er meer is dan de wetenschap. Zonder jullie afleiding was het wast niet sneller gegaan.

Lieve Maike, wat had ik zonder jou moeten beginnen? Twee promoties en nog op dezelfde dag ook, wie had dat acht jaar geleden gedacht. Zonder jouw steun had ik het in ieder geval niet gered. Op naar de volgende grote gebeurtenis in december. 